\title{
TEACHERS' BELIEFS AND PRACTICES REGARDING YOUNG CHILDREN'S LEADERSHIP: \\ A COMPARISON BETWEEN NEW ZEALAND AND HONDURAS
}

\author{
BY: \\ MARÍA AUXILIADORA CERRATO CORRALES
}

A thesis submitted to the Victoria University of Wellington in partial fulfilment of the requirements for the degree of Master of Education

Victoria University of Wellington

March 2012 


\begin{abstract}
The main purpose of this comparative study was to explore how teachers of four to five year old children in New Zealand and Honduras translate their beliefs regarding children's leadership into practice. This study has the potential to increase our understanding of beliefs and practices that will assist teachers in supporting children's leadership. The study used a comparative case-study design in order to look at similarities and differences between the two cases, focusing on two early childhood centres from low socio-economic areas in the capital cities of each country. Two teachers from each centre were asked to be participants in the study. Data was gathered through semi-structured interviews, participant observations, and documentation. The findings suggest that both New Zealand and Honduran teachers translate their beliefs regarding children's leadership into practice. However, the findings showed significant differences between New Zealand teachers' child-directed and Honduran teachers' teacherdirected beliefs and practices. The teachers in the New Zealand settings encourage leadership by empowering the children to deliberately take a leadership role, while the teachers in the Honduran settings encourage leadership by allocating opportunities for the children to take a leadership role. In addition, the teachers in New Zealand highlighted their belief and practice concerning children sharing leadership, while the concept of sharing leadership was not emphasized by the Honduran teachers. This study suggests the importance of teachers reflecting on their beliefs regarding children's leadership and how these guide their teaching practice in order to support children's leadership.
\end{abstract}




\section{Acknowledgements}

I wish to sincerely thank all the people who in one way or another have contributed to enable me to complete this thesis.

I would like to extend my appreciation to my supervisors, Dr. Kate Thornton and Maggie Haggerty, for their helpful feedback throughout this research. Thank you for your suggestions and helping to clarify ideas.

My deepest gratitude to the New Zealand Association of International Aid (NZAID) for sponsoring my Master of Education in New Zealand and unconditionally supporting me through conducting this research. I also thank the Victoria University of Wellington Faculty of Education for sponsoring my data collection in New Zealand.

I want to express my sincere gratitude to the New Zealand and Honduran head teachers/supervisors for welcoming me at their early childhood centres. Special thanks to the teacher participants for their willingness to participate in this study. Thank you for your time and sharing your knowledge and experiences with me. This study would have not been possible without your contribution. My thanks also to the teachers from the early childhood centre where I conducted the pilot study for their assistance. I also acknowledge the aid of the Wellington Kindergarten Association in helping to find the kindergartens for this study. Thanks to the parents who allowed their children to be observed and thanks to the children for being an inspiration in my work.

My special thanks to my brother, José Manuel, and my colleague and friend, Shue Yen, for their patience, guidance, support and encouragement during the hardest stages of this thesis report. I also thank Maria Luisa Ulloa for her guidance on important stages of this research. Thanks to Mabel, for her guidance and editing, and my sister-in-law, for providing feedback, over the completion of this report. To all my colleagues and friends, specially, Lacey, Shue, Mohamed, Loreto, Shaila, and Pheng, thank you for your encouragement and sharing of this experience. 
Lastly, I want to thank my parents, brother and sisters for their eternal love, prayer, emotional support, and encouragement, which strengthen me to complete this journey. 


\section{Table of Contents}

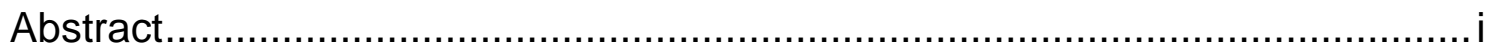

Acknowledgements ....................................................................................

Table of Contents ..................................................................................... iv

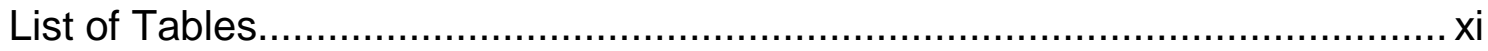

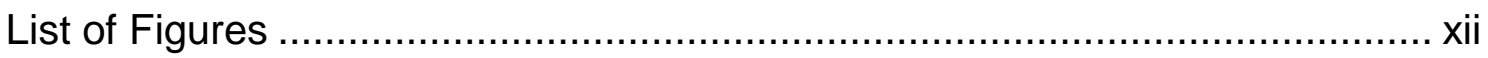

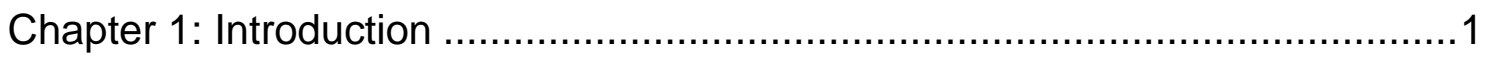

1.1 Chapter Overview .........................................................................

1.2 New Zealand and Honduran Early Childhood Education .......................1

1.3 Children's Leadership in the New Zealand and Honduran Early Childhood

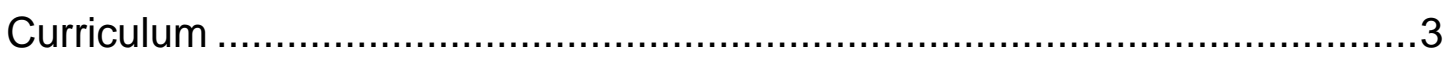

1.4 The Researcher Background ...........................................................

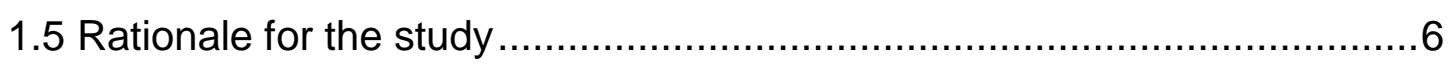

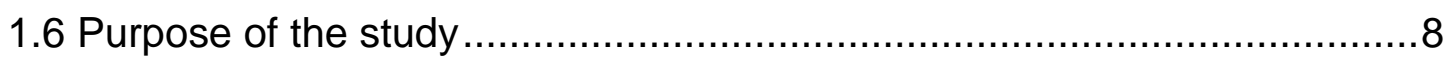

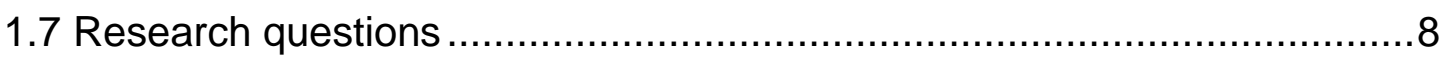

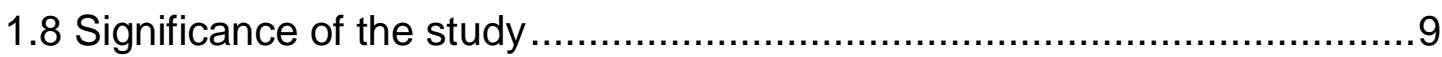

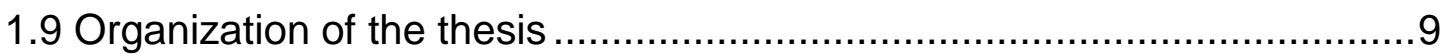

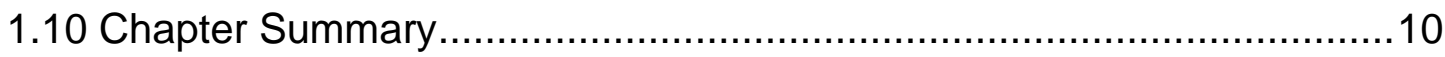

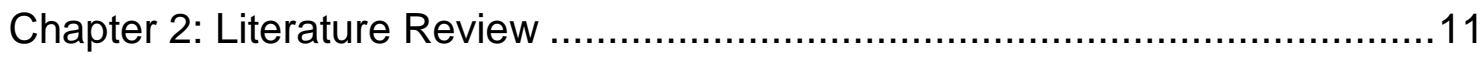

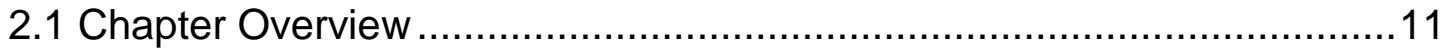

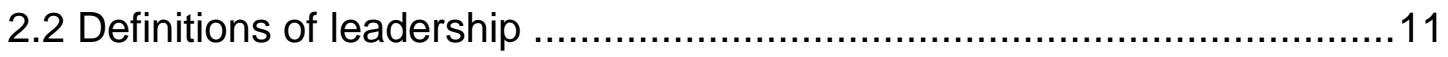

2.3 Previous studies on children's leadership ...........................................12

2.4 Nurturing leadership skills in children ..............................................15

2.4.1 Teacher- directed/Child - initiated curriculum .................................16

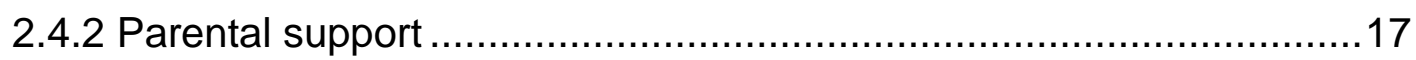

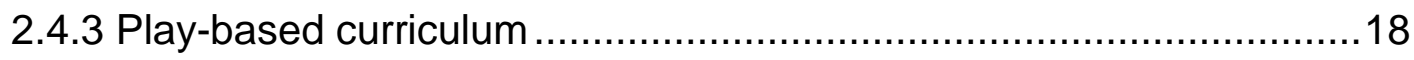


2.4.4 How does the New Zealand and Honduran Early Childhood Curriculum support children's leadership?

2.5 Previous studies on children's leadership in New Zealand and Honduras .20

2.6 Teachers' beliefs 24

2.7 Teachers' beliefs in early childhood education 25

2.7.1 Influential factors on early childhood teachers' beliefs 26

2.8 Relationship between teachers' beliefs and practices in early childhood education .28

2.8.1 Teachers' beliefs and practices regarding children's leadership .......29

2.9 Chapter Summary 31

Chapter 3: Methodology .32

3.1 Chapter Overview .32

3.2 Research Paradigm .32

3.3 Strategies of inquiry 33

3.3.1 Qualitative approach. .33

3.3.2 Case Study 35

Comparative case study. 36

3.4 Research Methods. 37

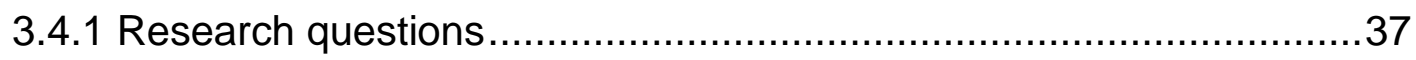

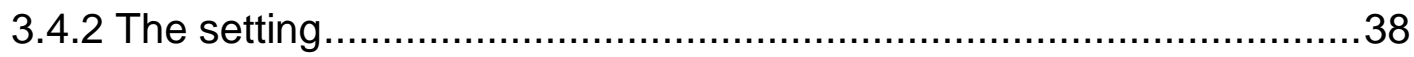

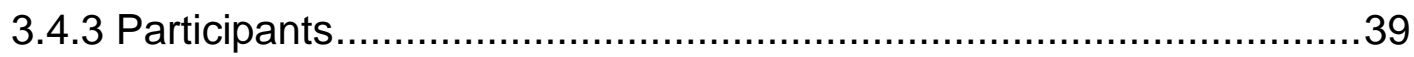

3.4.4 Data Collection ...................................................................... 40

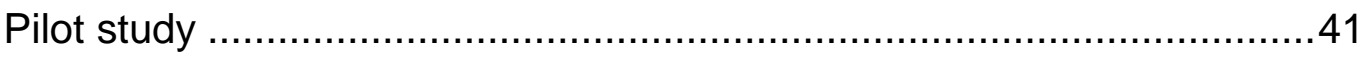

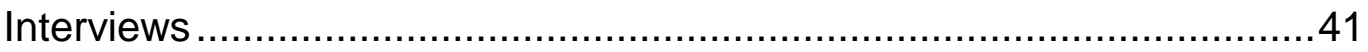

Naturalistic Observations ......................................................... 42

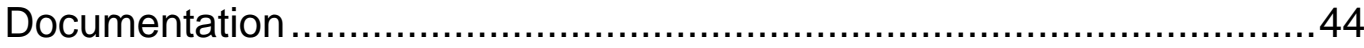

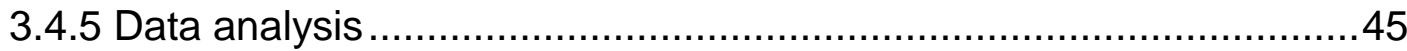


3.5 Trustworthiness of the findings

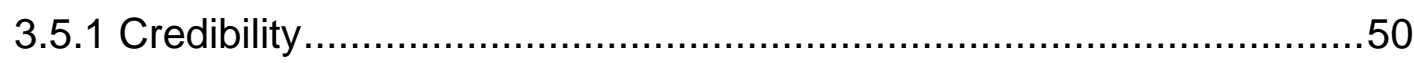

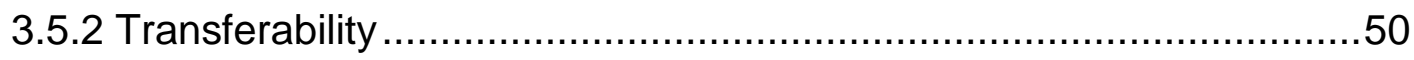

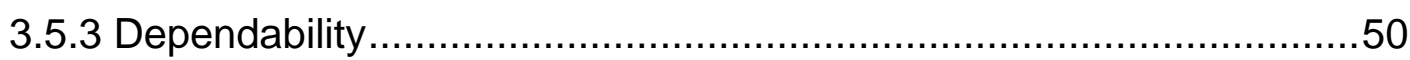

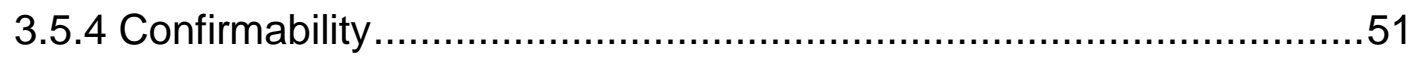

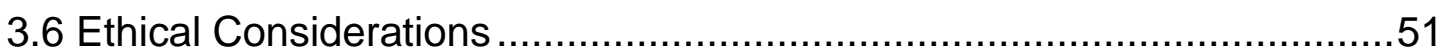

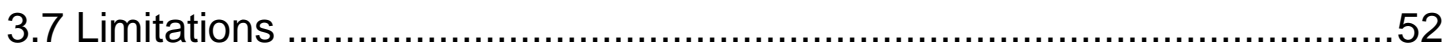

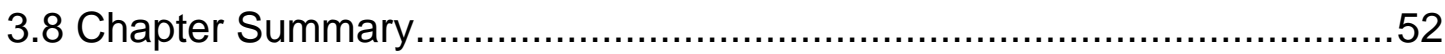

Chapter 4: Centre 1 - New Zealand …….......................................................

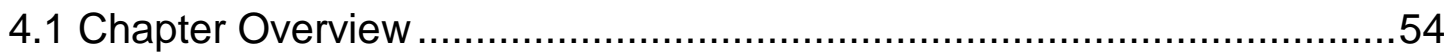

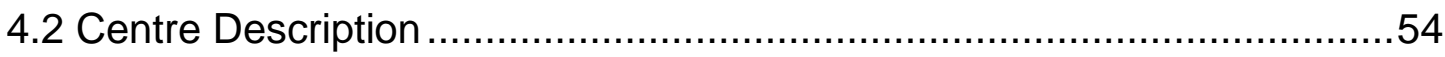

4.2.1 Erica; "All children have some form of leadership...in their own skills,

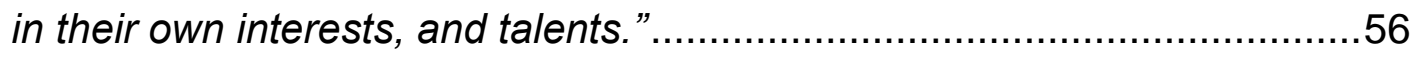

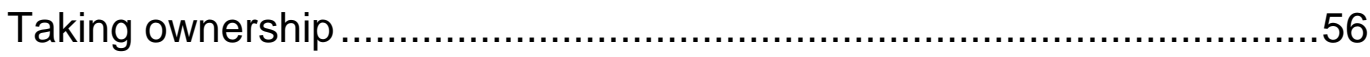

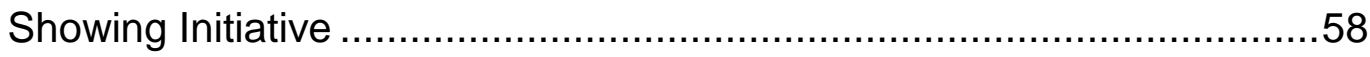

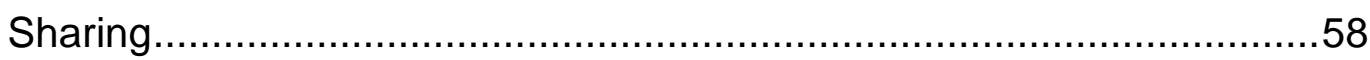

Te Whāriki and Te Manawa as a support for encouraging children's

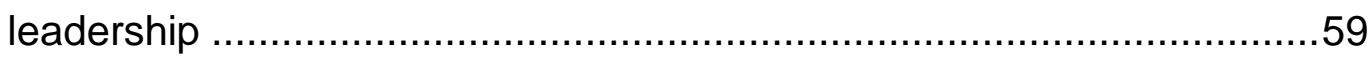

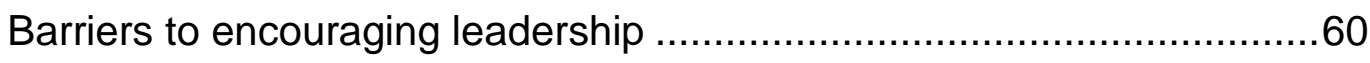

Summary of Erica's beliefs and practices and relationship to leadership framework 60

4.2.2 Frances; "Letting them make their own decisions." 61

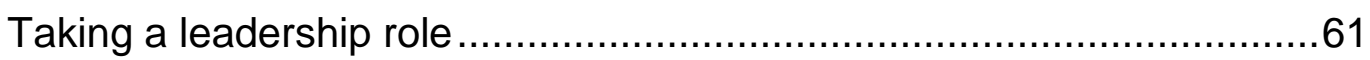

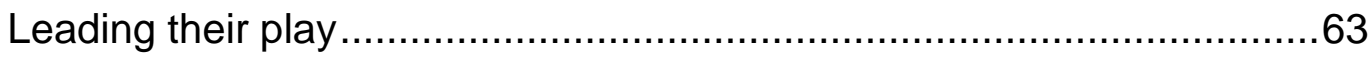

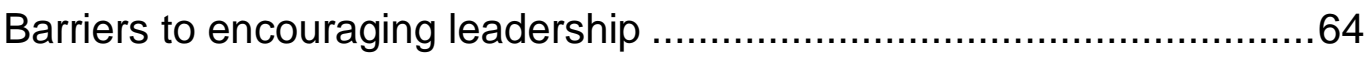

Summary of Frances' beliefs and practices and relationship to leadership

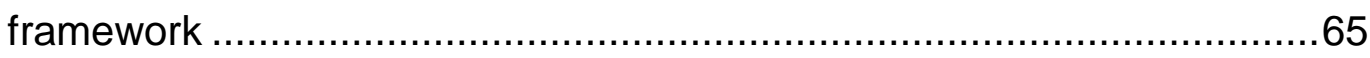

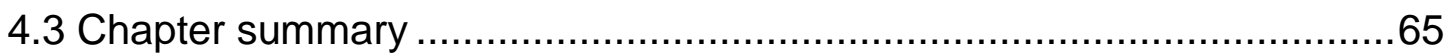


Chapter 5: Centre 2 - New Zealand

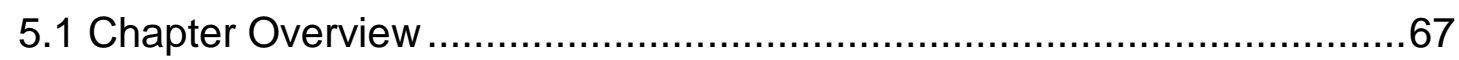

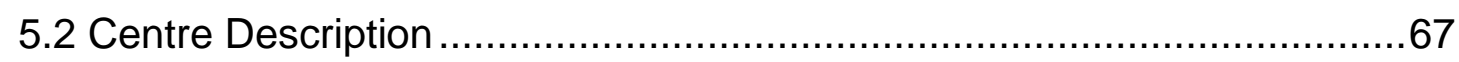

5.2.1 Grace; "Being aware of consequences and other people."...............68

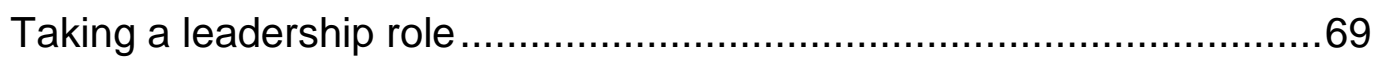

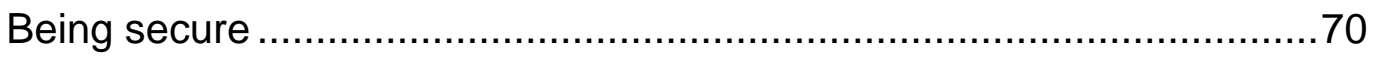

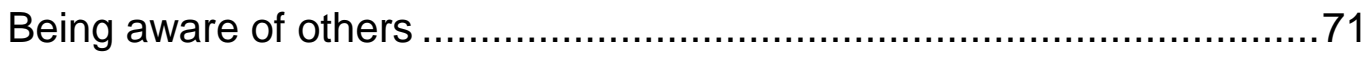

Barriers to encouraging leadership ................................................72

Summary of Grace's beliefs and practices and relationship to leadership

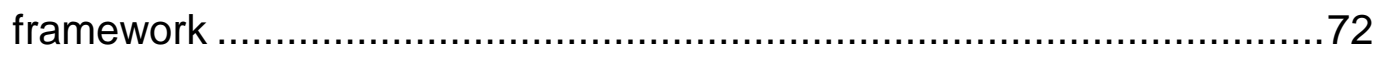

5.2.2 Jill; "The children that inspire others to join an activity." .....................73

Taking a leadership role ....................................................................

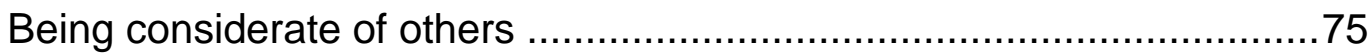

Play-based curriculum as a catalyst for children's leadership .................76

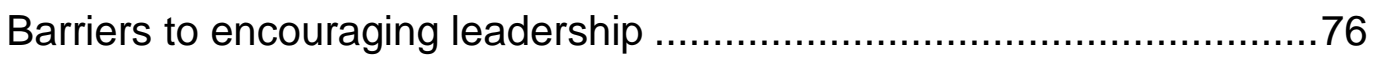

Summary of Jill's beliefs and practices and relationship to leadership

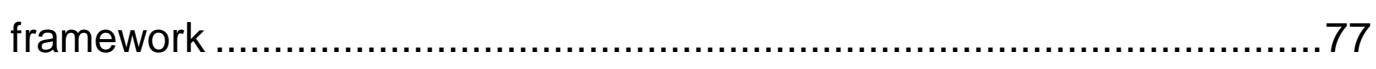

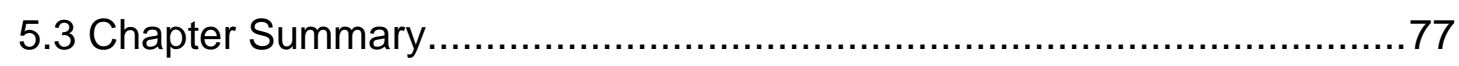

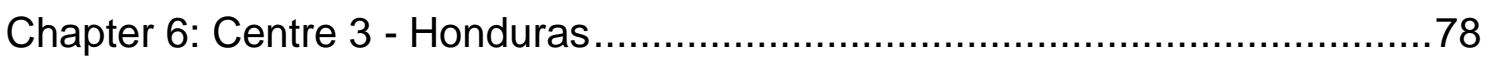

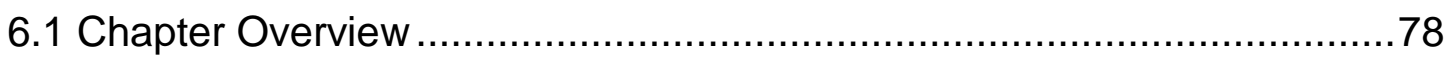

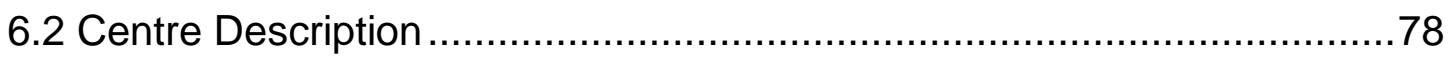

6.2.1 Ana; "The children capable of controlling the group." .........................80

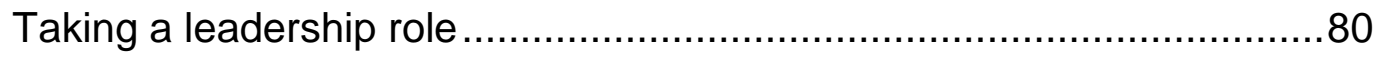

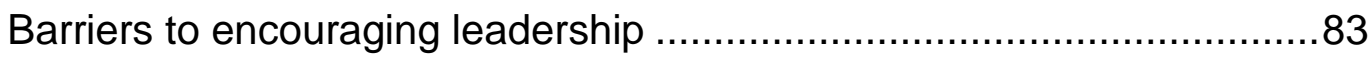

Summary of Ana's beliefs and practices and relationship to leadership

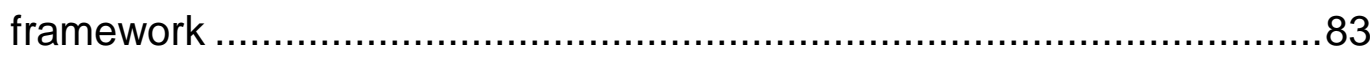

6.2.2 Blanca; "The way they cope when being among others." ..................83

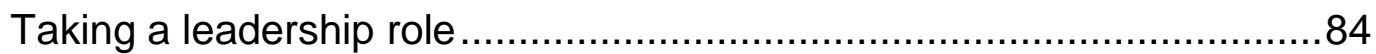


Integration

Barriers to encouraging leadership

Summary of Blanca's beliefs and practices and relationship to leadership framework .86

6.3 Chapter Summary .87

Chapter 7: Centre 4 - Honduras .88

7.1 Chapter Overview 88

7.2 Centre Description .88

7.2.1 Carol; "They want to command others." .89

Taking a leadership role .90

Barriers to encouraging leadership .92

Summary of Carol's beliefs and practices and relationship to leadership framework .93

7.2.2 Diana; "The one who stands out in a group.". .93

Taking a leadership role .94

Barriers to encouraging leadership .95

Summary of Diana's beliefs and practices and relationship to leadership framework

7.3. Chapter Summary

Chapter 8: Cross-case analysis and discussion 98

8.1 Chapter Overview .98

8.2 Sub-question 1: How do teachers conceptualize children's leadership? .98

8.2.1 New Zealand .99

8.2.2 Honduras 101

8.2.3 Cross-case analysis 102

8.3 Sub-question 2: How do teachers encourage children's leadership? ....104

8.3.1 New Zealand 104

8.3.2 Honduras 105 
8.3.3 Cross-case analysis 106

8.4 Sub-question 3: What are some of the barriers/enablers for teachers to encourage leadership in their students? ..................................................108

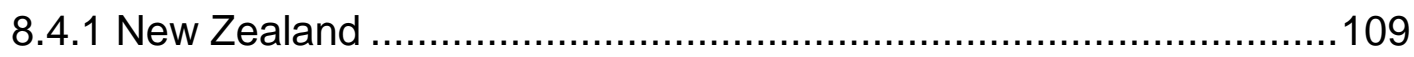

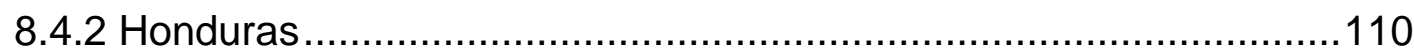

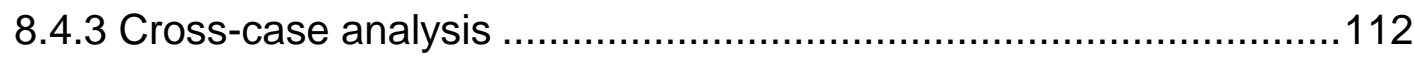

8.5 Main research question: How do teachers in New Zealand and Honduras translate their beliefs about children's leadership into practice?

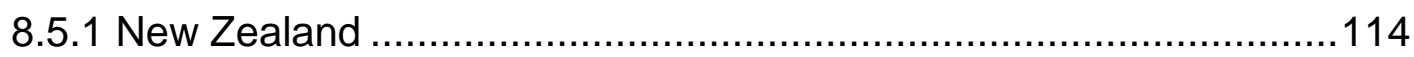

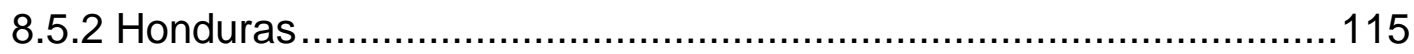

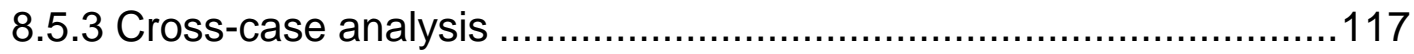

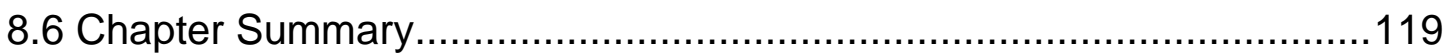

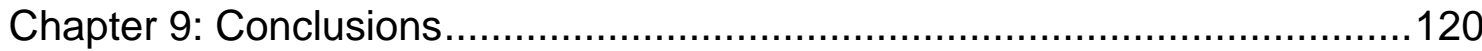

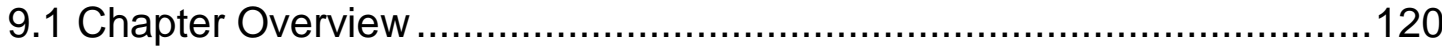

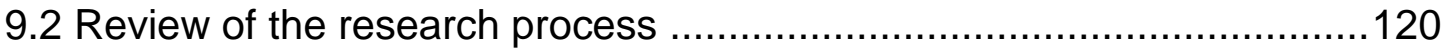

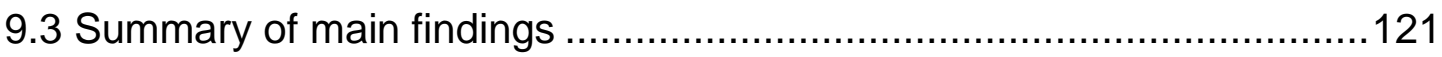

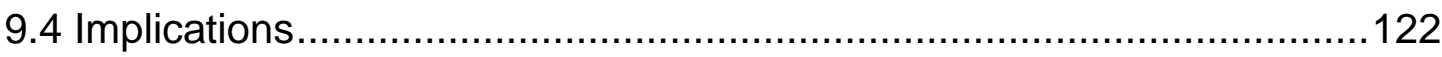

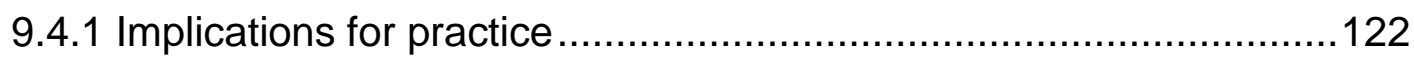

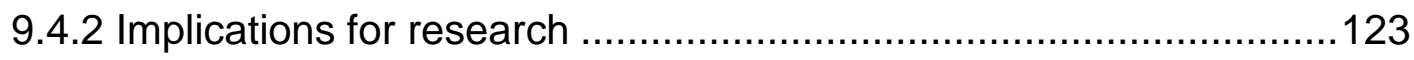

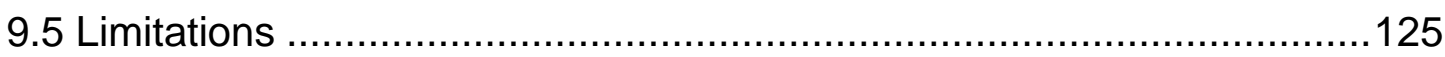

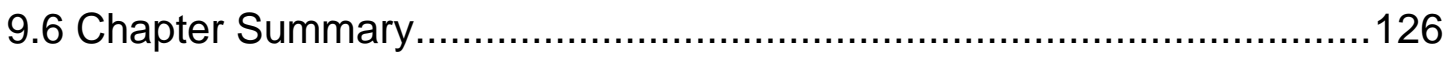

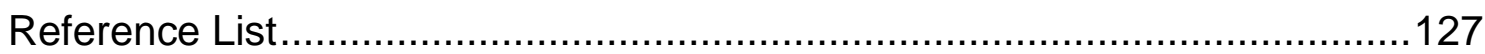

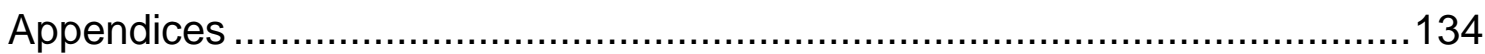

Appendix A - Information sheet for head teachers/supervisors .......................134

Appendix B - Consent form for head teachers/supervisors ............................137

Appendix C - Information sheet for teachers.............................................139

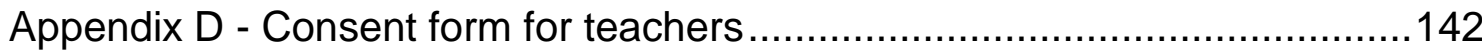

Appendix E - Interview of teachers' beliefs ................................................144 
Appendix F - Example of New Zealand observation field notes .................... 145

Appendix G - Example of Honduran observation field notes........................ 147

Appendix $\mathrm{H}$ - Information sheet for parents and guardians ........................ 149

Appendix I - Consent form for parents and guardians...........................151 


\section{List of Tables}

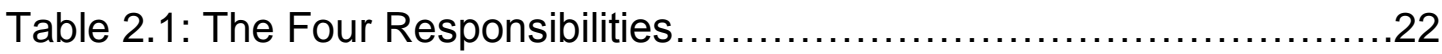

Table 8.1: Teachers' conceptualizations regarding children's leadership......99

Table 8.2: Teachers' practices regarding children's leadership................104

Table 8.3: Barriers/enablers for encouraging children's leadership............108

Table 8.4: Summary of teachers' beliefs and practices.....................113 


\section{List of Figures}

Figure 3.1: Comparative-embedded case study design .....................37

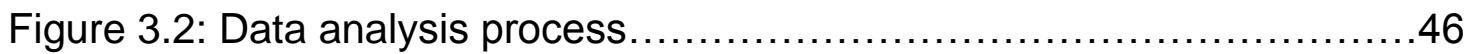




\section{Chapter 1: Introduction}

"Children are likely to live up to what you believe of them." (Lady Bird Johnson)

\subsection{Chapter Overview}

Societies are in urgent need of nurturing leaders who can help address issues, such as poverty, which affect a nation's growth and development. Encouraging leadership from early childhood education could nurture in young children the skills that would enable them to have a positive impact in society (Owen, 2007). Teachers have a critical role in nurturing children's leadership skills.

This chapter provides an overview of this study. It begins with a description of New Zealand and Honduran Early Childhood Education. A discussion of how the aims of the New Zealand and Honduran Early Childhood Curriculum foster children's leadership is provided before the researcher background. Then the rationale behind conducting a study about young children's leadership with comparison between New Zealand and Honduras is discussed. The purpose of the study, research questions and significance of the study are then outlined. The final section provides a description of the organisation of this thesis.

\subsection{New Zealand and Honduran Early Childhood Education}

Early childhood education in New Zealand involves children from 0 to 5 years of age. It is compulsory for all children in New Zealand to be enrolled in school at age six. However, most children start school shortly after they turn five (New Zealand Ministry of Education, 2012a). Early childhood services are classified as teacher-led and parent-led. The former includes kindergartens, education and care services, and home-based care ${ }^{1}$. In the latter, parents educate and

\footnotetext{
${ }^{1}$ Kindergartens are state sector early childhood provision. Education and care services may be privately owned or owned by a community group. Home-base care is provided at the educator's or children's home.
} 
care for the children. They include Kohanga reo, playcentres and playgroups ${ }^{2}$. Although early childhood education is not compulsory, according to Statistics New Zealand (2010) $80.9 \%$ of children between the ages of three and five attend formal early childhood education.

In 2002, the New Zealand Ministry of Education introduced a 10 year Strategic Plan for Early Childhood Education (New Zealand Ministry of Education, $2012 b$ ). One of the aims of the plan was that by year 2012, "all regulated staff in teacher-led services would be required to be registered teachers" (New Zealand Ministry of Education, 2012c). Although the Ministry of Education target established that all teachers would be required to be registered by 2012, the current requirement is that at least $50 \%$ of the adults who care for the children in teacher-led services must be qualified teachers. There are different training requirements for parent-led services as these are run by the parents.

Pre-school education in Honduras involves children from age 0 to 6 . Children begin primary education at age 6 (Secretaría de Educación de Honduras, 2003). Education in Honduras is divided into public and private education systems. Public education is funded and regulated by the government through the Ministry of Education. Private education is not funded by the government but, as with public education, is regulated by the Ministry of Education ${ }^{3}$. Within the public sector, the government provides compulsory funding from 5 years of age, through public kindergartens and public primary schools which also facilitate pre-school education. The government delegates the education of children 0 to 5 years of age to alternative centres such as Nongovernmental Organizations and private pre-school centres. The minority of the population has access to private education. Private preschool centres involve kindergartens, daycares, or private schools which also facilitate preschool education. Preschool education is not compulsory (Secretaría de Educación de Honduras, 2003). According to the National Institute of Statistics of Honduras,

\footnotetext{
${ }^{2}$ Kohanga Reo is a Māori immersion family programme for young children. Playcentres are early childhood organizations unique to New Zealand collectively managed by parents. Playgroups are run by parents and can be less formal than other early childhood services.

${ }_{3}^{3}$ Public centres offer education in Spanish. Private centres offer Spanish or bilingual (EnglishSpanish) education.
} 
Instituto Nacional de Estadística Honduras, (2010) the national pre-school education attendance rate is $44.5 \%$.

Honduran teachers were not required to have a specialized degree in early childhood education before 2012. Historically, the government has supported teachers through professional development on specific early childhood education topics. However, in January 2012, the government released a new law called "Ley General de Educación" (Secretaría de Educación de Honduras, 2011) translated into English as the General Law of Education, which states that all teachers must have a Bachelor's Degree in Education with specialized studies in the specific level of education they teach.

Although New Zealand and Honduran early childhood education is different in structure and in attendance rate, the early childhood curricula official documents in both countries implicitly include the encouragement of children's leadership as a primary aim.

\subsection{Children's Leadership in the New Zealand and Honduran Early Childhood Curriculum}

Te Whāriki (New Zealand Ministry of Education, 1996) is the New Zealand Early Childhood Curriculum. "It is the first national curriculum statement for the early childhood sector"; also "the first bicultural ${ }^{4}$ curriculum statement developed in New Zealand" (New Zealand Ministry of Education, 1996). Te Whāriki does not explicitly mention the encouragement of children's leadership as an objective. However, it is implicitly stated as an objective through three main aspects. First the document states throughout the objective to promote skills such as making decisions and communication. These skills have been identified by previous literature as examples of leadership skills (e.g., Hensel, 1991). Therefore the aims of Te Whāriki implicitly support the encouragement of children's leadership skills. Second it identifies the significance of free-play in early childhood centres to develop skills in children such as the ability to problem-solve and take

\footnotetext{
${ }^{4}$ The document is written in Māori and English text establishing the bicultural nature of all early childhood services.
} 
responsibility (New Zealand Ministry of Education, 1996). Therefore Te Whāriki implicitly supports the development of children's leadership skills through freeplay. Finally, it emphasizes the relationship between early childhood services and families as a catalyst of children's development. Previous studies identified the importance of communication between parents and teachers in order to support children's leadership (e.g., Bisland, 2004). Te Whāriki implicitly supports children's leadership by encouraging communication between teachers and parents. The influence of Te Whāriki in New Zealand teachers' beliefs and practices regarding children's leadership was explored in this study. The three aspects identified above are further discussed with references to support it in Chapter 2.

Currículo Nacional de Educación Prebásica, CNPB (Secretaría de Educación de Honduras, 2001) is the Honduran Ministry of Education Early Childhood Curriculum. It was introduced by the Honduran government in response to the "Propuesta de Transformación de la Educación Nacional" (Secretaría de Educación de Honduras, 2001) translated into English as "Plan of Transformation of National Education." In 2002, the Honduran government introduced a new document, Diseño Curricular Nacional para la Educación Prebásica (DCNPB) translated into English as the National Curricular Design for Pre-school Education in an attempt to complement the CNPB and increase the quality of preschool education.

The aim of the DCNPB and CNPB is to promote children's leadership. The DCNPB explicitly states as one of its objectives to develop leadership in the child, while the aims of CNPB implicitly encourages children's leadership. The CNPB curriculum is focused on encouraging academic skills in children such as math proficiency. However, this document also includes as an objective the encouragement of skills such as autonomy and independence. These skills have been identified in previous literature as examples of leadership skills (e.g., Hensel, 1991). Therefore, CNPB implicitly has the aim of encouraging children's leadership skills. Both documents are further explored in Chapter 2. CNB is the main Honduran early childhood curriculum that teachers are familiar with and therefore, is the document that appears to guide their practice. Although 
DCNPB specifically states the development of children's leadership as its objective, the influence of CNPB on teachers' beliefs and practices is of particular interest in this study.

\subsection{The Researcher Background}

My background is presented in this section as this study draws from a socialconstructivist philosophical paradigm, further discussed in Chapter 3 . Thus, it is understood that there is a need to acknowledge the researcher background as it could have an influence on my interpretation of the data in this study.

Perhaps my personal and professional backgrounds were the aspects that influenced me most to think about this topic and conduct this research. As the youngest of four siblings, my role in the family was to follow my siblings' example and learn through role modelling. Although I feel fortunate to have been the youngest, I was not naturally 'the leader.' In regard to my professional experience, I taught four years as an early childhood teacher in my country in a private bilingual (English-Spanish) school, in the capital city of Honduras, where I also had the privilege to study from age 3 through 17 . The school has a teacher-directed curriculum. The bilingual school experience gave me the opportunity to develop my leadership as a teacher and work as a team with other pre-school teachers. It also afforded me the opportunity to experience the potential of young children which led me to pursue a Master of Education in New Zealand.

I look back on the day I was sitting at a classroom at Victoria University of Wellington listening to a session of the Educational Leadership Course I took in the first trimester of this Master degree. The different definitions and approaches to leadership caught my attention. Particularly, I was fascinated with the concept that, within a group of people, everyone could take a leadership role, not only the person who is in a formal leadership position has the ability to lead. While listening to this concept, the first thought that came to mind was: if everybody could be a leader, then, can this concept be applied to 
young children? In brief, can young children lead? With this inquiry in mind, I began the journey of the present study.

\subsection{Rationale for the study}

Previous studies suggest leadership should be encouraged from a young age and teachers play a critical role in facilitating it (Bisland, 2004; Owen, 2007). Owen (2007) identifies leadership is a topic that has gained importance over the last century as society has become more complex and faces more challenges. She notes that in order to help solve worldwide problems, such as economic recessions, it is becoming more important for society to identify and nurture leaders. Several authors indicate leadership development should not wait until adolescence or adulthood (Karnes \& Stephens, 1999; Owen, 2007). Karnes and Stephens (1999) suggest that fostering leadership skills in children, such as self-awareness and problem solving can prepare them to make a change in their communities, schools, religious groups and countries. Similarly, Bisland (2004) argues that leadership skills should start to be encouraged as early as kindergarten. In addition, Owen (2007) argues, "all teachers have the capacity in their everyday classroom activities to enable young people to realise their leadership potential" (p. 5). The belief that children's leadership should be encouraged from early childhood education underpins this study.

Two main obstacles for developing leadership in children, indicated by previous studies, are the scarcity of research and also the absence of an agreed upon definition regarding children's leadership (Bisland, 2004; Mullarkey, Recchia, Lee, Shin, \& Lee, 2005). Although studies around children's leadership began in the 1930s, there is a paucity of research regarding this idea. Lee, Recchia, and Shin (2005) argue that although literature and research findings relating to leadership for older children, youth and adults are useful, it would be "inappropriate to directly apply them to young children" (p. 132). They explain that young children are not only developmentally different from other age groups, but the activities at an early childhood setting also differ from the activities at older age groups. Lee et al. (2005) indicate that research regarding leadership specifically in young children is needed. There appear to be few 
studies particularly about children's leadership in New Zealand. In Honduras, a search through various databases from 1970 to 2011 revealed no studies have been done related to young children's leadership. In addition, a problem for encouraging leadership is that there is no single definition (Bisland, 2004). Shin, Recchia, Lee, Lee, and Mullarkey (2004) suggest further studies need to be done regarding teachers' perceptions about young children's leadership in order to understand how they encourage or discourage this notion in their students. This study aims to raise awareness about young children's leadership and inform teachers' beliefs and practices that could support this concept. Adding to the literature of comparative studies about children's leadership is also an aim of this study.

Through my studies in New Zealand, I had the opportunity to visit early childhood centres in Wellington, and observed how teachers encourage leadership skills such as self-autonomy. In my particular experience as an early childhood teacher in my home country, the encouragement of children's leadership is not yet being applied in early childhood centres in Honduras. Nivala and Hujala (2002) argue comparing leadership beliefs increases our understanding of the concept in different countries. For this reason, a comparison between New Zealand and Honduran teachers' beliefs and practices regarding young children's leadership enabled me to look at similarities and differences among these two countries, so as to have a better understanding of this concept. Furthermore, this study recognizes the influential role of the teachers' cultural context in similarities or differences between the New Zealand and Honduran teachers' beliefs and practices.

Although New Zealand has a 'richer economy' than Honduras, low-socio economic sectors in each country make them comparable in order to conduct this study: "New Zealand has one of the richer economies compared to the rest of the world" (Statistics New Zealand, 2011). New Zealanders in general are well educated and have a good standard of living (Statistics New Zealand, 2011). However, according to the New Zealand Ministry of Social Development (2010) $15 \%$ of the population is low income and has insufficient economic resources to participate in the community, therefore restricting their quality of 
life (New Zealand Ministry of Social Development, 2010). Honduras is the second poorest country in Central America: "It is a lower middle-income country with persistent poverty and inequality challenges" (United Nations, 2011). Poverty is essentially a rural problem which affects $60 \%$ of the population, while $36 \%$ live under extreme poverty conditions. In urban areas, such as Tegucigalpa and other main cities, poverty rate is lowest. Although the population living in poverty in Honduras is different from the low-income population in New Zealand, sectors with characteristics as similar as possible were chosen in order to compare both countries. This study was conducted in low-socio economic sectors in the capital cities of each country.

\subsection{Purpose of the study}

The purpose of this study was to explore how teachers of four to five year old children in New Zealand and Honduras translate their beliefs about children's leadership into practice. A comparative case study design was used to look at similarities and differences between the two cases. Teachers from specific early childhood centres in the capital cities of each country, Tegucigalpa and Wellington, were the participants and units of analysis in this study. Teacher interviews, observations, and also documentation - early childhood curricula and children's portfolios/workbooks - provided the data for analysis.

\subsection{Research questions}

The study's main research question and sub-questions are as follows:

Main research question: How do teachers of four-to-five year old children in New Zealand and Honduras translate their beliefs about children's leadership into practice?

\section{Sub-questions:}

1. How do teachers conceptualize children's leadership?

2. How do teachers encourage children's leadership?

3. What are some of the barriers/enablers for teachers to encourage leadership in their students? 


\subsection{Significance of the study}

Previous research on children's leadership in early childhood education has been relatively limited and has tended to focus on the young leaders themselves (Hatch, 1990; Shin et al., 2004). Very few studies have focused on how teachers' beliefs and practices influence this idea (Mullarkey et al., 2005). The findings of this comparative study could increase our understanding of children's leadership, and also inform our understanding of the beliefs and practices that will assist in how to foster this concept.

\subsection{Organization of the thesis}

This thesis is presented in nine chapters. This chapter provides an introduction for the thesis. A review of literature relevant to the present study is presented in Chapter 2. Chapter 2 includes literature on leadership, children's leadership, teachers' beliefs, the relationship between teachers' beliefs and practices, and teachers' beliefs and practices regarding children's leadership. In addition, the chapter introduces The Four Responsibilities (Tamati, Hond-Flavell, \& Korewha, 2008) which was used as an initial framework of data analysis. Chapter 3 outlines the methodology used in this study with a discussion of the selection of a social-constructivist philosophical paradigm, qualitative approach and comparative case study strategy as the design of this study. It also includes an explanation of interviews, observations and documentation as methods of data collection. Finally, the process of data analysis is explained in detail, including a refinement of The Four Responsibilities framework which was modified in order to fit the findings of the study. Chapters $4,5,6$, and 7 present the findings of this study. Chapters 4 and 5 discuss the findings of the New Zealand teachers, and Chapters 6 and 7 discuss the findings of the Honduran teachers. Chapter 8 outlines a cross-case analysis and discussion of the findings. The chapter is framed according to the research questions. Chapter 9 reviews the research process and main findings and discusses the implications for practice and research that emerged from the findings of this study. 


\subsection{Chapter Summary}

This introductory chapter has presented the context of New Zealand and Honduran Early Childhood Education and introduced how the aims of the New Zealand and Honduran Early Childhood Curriculum encourage children's leadership. The chapter has also provided the researcher background and a rationale for conducting a comparative study between New Zealand and Honduran teachers' beliefs and practices regarding children's leadership. The research purpose, research questions and significance of the study have been presented. The organization of the thesis was also outlined. 


\section{Chapter 2: Literature Review}

\subsection{Chapter Overview}

This chapter presents a review of the literature relevant to this study. It begins with a description of leadership in order to contextualize the field of the study. This is followed by a section reviewing early and current studies, and also main debates about children's leadership. The next section describes literature supporting the fostering of children's leadership. It is further divided in four aspects: teacher-directed and child-directed curriculum; parents' support; playbased curriculum; and an explanation of how the aims of the New Zealand and Honduran curriculum support children's leadership. Previous studies conducted in New Zealand and Honduras regarding children's leadership are then outlined. The last three sections consist of a general definition of teachers' beliefs, followed by a description of teachers' beliefs in early childhood education and factors that influence those beliefs, and finally a description of the relationship between teachers' beliefs and practices with a further section explaining teachers' beliefs and practices regarding children's leadership.

\subsection{Definitions of leadership}

This study is particularly focused on children's leadership. However, it is considered necessary to present first conceptualizations regarding leadership more widely in order to contextualize the area of study. This section provides an understanding of key definitions regarding leadership in relation to this study.

There is abundant literature regarding leadership. However, many authors have stated that there is no agreed upon definition of leadership (Bisland, 2004; Dickson, Den Hartog, \& Mitchelson, 2003) and it still remains as an abstract concept (Karnes \& Stephens, 1999). Leadership has traditionally been conceptualized as a relationship between a leader and a follower. Bennis (2007) suggests that "in its simplest form, it is a tripod; a leader or leaders, followers and a common goal they want to achieve" (p. 3). However, authors 
such as Drath, McCauly, Paulus, Velsor, O'connor, and McGuire (2008) criticize Bennis' definition of leadership arguing the tripod suggests a traditional power and authoritative relationship between leaders and followers. Drath et al. (2008) proposed a further definition of leadership - direction, alignment, and commitment - suggesting leadership more as a collective work between leaders and followers to reach their common goal. This view of leadership supports new beliefs and practices of leadership, such as shared or distributed leadership, which do not depend on a leader-follower relationship (Drath et al.).

Harris (2008) defines shared or distributed leadership as that where within a group of people working together, 'everybody leads' but one person who holds a formal leadership role guides everybody to work as a team. Harris explains that distributed leadership has been criticized by other authors for suggesting a lack of formal leadership structures. However, Harris argues that this view of leadership implies a strong relationship between the formal leader and the rest of the team rather than the absence of a leader. The different views of leadership suggest the lack of an agreed definition of the concept in the literature. These views, however, could be a useful conceptual base with which to compare beliefs about children's leadership.

\subsection{Previous studies on children's leadership}

There is a scarcity of literature related specifically to young children's leadership (Mullarkey et al., 2005). Most of the studies regarding this notion have focused on defining children's leadership. Some of the early studies attempted to identify attributes of young leaders (Shin et al., 2004) identifying characteristics such as: independent (Parten, 1933); communicative (Fu, 1979; Fu, Canaday, \& Fu, 1982); initiates and inspires play (Fukada, Fukada, \& Hicks, 1997; Hatch, 1990); has cognitive abilities (Fu, 1979); has problem-solving skills (Hensel, 1991); and has a high level of social awareness (Fu, 1979; Hensel, 1991). These studies define children's leadership as a series of individual attributes (Shin et al., 2004). However, they seem to ignore broader aspects such as relationships between children. 
More recent research has defined children's leadership as a 'relational construct' (Mawson, 2010; Shin et al., 2004). Shin et al. (2004) suggest that children's leadership may be defined as the relationships among individuals; for example, relationships with peers and teachers. They explain that, in their study, children were leaders "when peers were willingly following them" (p. 313). Research that drew from this study by Lee et al. (2005) also suggests that it is important to explore children's leadership as the way children relate to others in the early childhood setting in order to get a better understanding of this complex notion. These studies indicate that children's leadership could also be defined as the individual traits a child demonstrates when interacting with peers and teachers.

One of the debates in the literature around children's leadership is whether the concept should be viewed as positive or negative in nature (Shin et al., 2004). Over the decades some researchers have identified children's leadership as both a positive and a negative concept. Parten (1933), an early researcher in the field, concluded that there are two types of leaders at preschool age: "the diplomat - the artful director, and the bully - the bossy leader" (p. 440). Similarly, Shin et al. (2004) proposed that children's leadership is a 'multidimensional construct.' They suggest that young leaders demonstrate pro-social - positive aspects of leadership such as showing social-awareness and suggesting play ideas, and also demonstrate a socially dominant - negative - aspect of leadership such as excluding others.

Some studies have described the negative young leaders who dominate other peers or break the classroom rules. For example, in their study, Lee et al. (2005) identified the 'negative leader' who challenges the teachers' authority by using humour and silliness to break the rules. Mawson (2009) also concluded that children show two types of leadership styles; the 'dictator'- autocratic- and the 'director' - democratic. Although Mawson did not directly link it; the dictator in his study appears to be related to the dominant, negative leadership suggested by Parten (1933) and Shin et al. (2004). However, the researcher explained that in his study the dictator did not break the rules as shown in previous studies, but rather used vocal force in order to gain leadership over 
peers. These studies suggest how children's 'negative leadership' can be enacted in an early childhood setting.

Other studies appear to focus on positive leadership in young children as they describe the concept as the ability to use power to direct and engage with others. For example, Hatch (1990) studied the leadership styles of two four-year old children. Hatch concluded that the first child demonstrated leadership by initiating play and the second child by maintaining play among peers. Fukada et al. (1997) reported that children's leadership is demonstrated in twodimensions: facilitation of play (initiating play) and consideration-evaluation of playmates (directing play or helping others). Mawson (2009) found that even though the boys' leadership in his study was confrontational sometimes, it was more often characterized by being peaceful. Similarly, he concluded that the girls' leadership was characterized by showing empathy among them and by sharing leadership. These studies possibly describe the pro-social characteristics described in Shin et al. (2004) as positive leadership. Thus, the features of children who demonstrate positive leadership have also been suggested in previous studies.

Another debate in the literature around children's leadership has been whether leadership should be encouraged in all children. Much of the literature for leadership development in young children has a focus on 'gifted children' (Bisland, 2004; Hensel, 1991). Within this view, it could be implied that only 'gifted children' are leaders. Similarly, Trawick-Smith (1988) questions the encouragement of leadership skills in all children, asking whether it would be ideal for society if everybody was a leader. On the other hand, Owen (2007) suggests that the belief that leaders are born, is a myth and that all children have the potential to become leaders (p. 5). Authors of literature regarding adult leadership support this argument. For example, Lambert (2002) argues that "everyone has the right, responsibility and ability to be a leader" (p. 38). Similarly, Day (2001) concludes that everybody can take 'leadership roles.' Other literature related to young children suggests that children can also take leadership roles in their classrooms, families and communities (Karnes \& Stephens, 1999; Owen, 2007). It is also argued that all children - not only 
'gifted' children - could be leaders, and leadership could start to be encouraged as early as kindergarten (Bisland, 2004; Hensel, 1991; Owen, 2007).

\subsection{Nurturing leadership skills in children}

The fundamental role that early childhood experiences have on children's future leadership is explored in the literature. Scheer and Safrit (2001) state:

"Programs that promote life skills of self-awareness (self-esteem),

social-interaction (getting along with others) and decision-making

(making choices) are the building blocks for future leaders” (p. 107).

Scheer and Safrit suggest an 'experiential-based discovery learning curriculum' in order to encourage life skills in children from age five through eight. Their proposed curriculum encourages "self-awareness through exploration, experience and action-oriented activities" (p. 109). Owen (2007) supports this statement by suggesting learning strategies for encouraging leadership such as experiential, action, and collaborative learning. She explains that the child learns through experiential learning by making meaning of the world through real-life experiences. Owen also describes action learning where children learn from experience and action, and collaborative learning where children learn from interacting and sharing knowledge with peers while the teacher is only a facilitator. Kolb's model of experiential learning suggests that learning occurs when one makes meaning of 'concrete and immediate experiences' (Elkjaer, 2009). This implies that for nurturing leadership skills, such as self-awareness and making decisions, children need a learning environment with hands-on activities in which they can learn by making meaning of their own experiences and by interacting with teachers and peers.

The next sections describe four themes that were identified from the literature as key aspects in order to foster children's leadership relevant to this study: teacher-directed/child-initiated curriculum, parents' support, play-based curriculum, and how the aims of the New Zealand and Honduran curriculum support children's leadership. 


\subsubsection{Teacher- directed/Child - initiated curriculum}

A key theme identified in the literature is that a child-initiated more than a teacher-directed curriculum fosters life-long skills in early childhood. ${ }^{5}$ Schweinhart and Weikart (1988) review previous studies that suggest 'teacherdirection instruction' will prepare children with the academic skills - such as proficiency in reading and math - to succeed in the short-term throughout school. However, 'child-initiated learning' will provide children with the social and intellectual skills - such as self-control, responsibility and initiative - that will prepare them for life. Helm (2004) supports these arguments suggesting childinitiated hands-on activities, where teachers empower children by listening to them and 'following their lead,' to encourage academic and life-long skills in children. Gmitrová and Gmitrov (2003) conducted a study comparing the impact of teacher-directed and child-directed pretend play on children's competence. They found an increase in cognitive and affective manifestations in the childdirected pretend play compared with the teacher-directed play. The researchers concluded that if children are not given the opportunity for child-directed play, the long-term capacities to develop skills such as problem solving and social cognition, as well as academic skills, may be reduced. Thus, it appears that a child-initiated curriculum supports children in nurturing leadership skills such as initiative, problem solving, self and social awareness.

The significant influence that teachers' child-directed practice can have on encouraging children's leadership has been identified in previous studies. Lee et al. (2005) suggest that teachers can support children's leadership by enabling them to make decisions about the activities and the materials they use to play, by assisting them to engage in collaborative play with peers, and by providing an environment that recognizes individual differences and strengths among children. Similarly, Shin et al. (2004) propose that teachers should provide children with an environment where they can feel competent and secure to engage with other peers freely. These researchers propose collaborative

\footnotetext{
${ }^{5}$ Schweinhart and Weikart (1988) define a teacher-directed setting as the one where "the teacher transmits spoken and written information to children and checks to make sure the information has been received through questions, paperwork, and tests" (p. 218). They define a child-directed setting as the one where the teacher sets the environment but the child has control of the activities.
} 
teaching strategies for supporting children's leadership within a child-centred and play-based curriculum early childhood setting.

Similarly, the important role that teachers have in encouraging children's leadership through teacher-assigned activities has been explored. Karnes and Stephens (1999) claim that children can develop self-awareness and problem solving through teaching strategies such as group play, collaborative work, and creative drama. Similarly, Hensel (1991) proposes teaching strategies such as role-play and conflict resolution, mediated by the teacher, and also teacher role modelling in order to encourage pro-social skills in children. These authors appear to report teacher-directed practices that could be applied in a teacherdirected context. Therefore, whether child-initiated or teacher-directed tasks, the literature appears to support teaching strategies that encourage children's leadership, focusing on building the child's confidence to be able to make decisions and to build relationships with the people around them.

\subsubsection{Parental support}

The role of parents in providing security for children and communicating with the teachers has also been identified by previous studies as a key aspect in supporting children's leadership. Owen (2007) stated that psychologists have strongly linked "attachment security" with interpersonal skills - such as empathy, conflict resolution, self-efficacy, and social competence - that enable leadership (p. 21). She explained that the attachment a baby has with his/her mother during the first years of its life provides the cognitive and emotional basis for developing leadership ability in the future. Therefore, she suggests parents and teachers can encourage and support attachment security by being 'consistent' and receptive to the needs of the children. Bisland (2004) proposes parents can encourage decision-making in children, by involving them in planning family activities, and role modelling effective leadership skills and behaviour. She concludes that parents and teachers can work together to provide the foundations for children to begin an effective leadership journey. These studies have identified parental support as a determining factor for children's ability to develop leadership skills. 


\subsubsection{Play-based curriculum}

Most of the early studies on children's leadership focused on measuring children's leadership but did not consider the influence of the environment of an early childhood setting (Lee et al., 2005). More recent studies suggest that a play-based curriculum is a key aspect to encouraging leadership among young children. Shin et al. (2004) suggest that within a play-based curriculum, children demonstrate their social characteristics when they try to interact with peers and also develop their individual leadership skills. Similarly, Lee et al. (2005) suggest that a play based curriculum enables children to "experience, exercise and develop leadership at their own pace" (p. 146). These studies imply that a play-based curriculum facilitates children to demonstrate their leadership skills when engaging in play with peers.

\subsubsection{How does the New Zealand and Honduran Early Childhood Curriculum support children's leadership?}

Both New Zealand and Honduran curricula appear to support the encouragement of children's leadership skills although in different ways. The New Zealand curriculum emphasizes play-based curriculum whereas the Honduran curriculum focuses on academic skills. Therefore, their approach to leadership is different as the New Zealand curriculum appears to be centred on self-choice while the Honduran curriculum appears to be centred on prescribing activities to the children. However, as mentioned in Chapter 1, both implicitly have as an objective to develop leadership skills in children.

The New Zealand Early Childhood Curriculum, Te Whāriki (New Zealand Ministry of Education, 1996) does not explicitly state as an objective the encouragement of children's leadership. However, it appears to have as an objective the encouragement of leadership skills in children through its principles, strands, and goals. The New Zealand Early Childhood Curriculum is organized in principles, strands, and goals which guide early childhood centres in providing activities and experiences that foster children's learning and development. First the curriculum suggests four broad principles which are: holistic development, empowerment, family and community, and relationships. 
Then it identifies the strands, goals and learning outcomes which derive from the four principles. The five strands, or 'areas of learning and development,' are: well-being; belonging; contribution; communication; and exploration. Each strand has goals and learning outcomes (knowledge, skills and attitudes) which are expected to be facilitated by experiences provided in the centre setting. In explaining the principles, strands and goals, Te Whāriki gives examples of encouraging skills such as communication, making decisions, confidence to express their ideas and to engage with others, and relationships with peers and teachers. These skills have been suggested by previous studies as features of young leaders. Thus, Te Whāriki implicitly states throughout the document the aim of encouraging leadership skills in children.

A free-play curriculum and parental support are two important aspects highlighted in Te Whāriki. In a New Zealand study regarding children's leadership, Mawson (2009), the researcher explained that in Te Whāriki, children's collaborative play has an important role in encouraging relationships among children. Mawson concluded that the leader appeared within the children's friendship groups. Therefore, the New Zealand free-play curriculum implicitly encourages children to demonstrate leadership qualities. In addition, family and community are stated as one of the principles. Based on the literature regarding the importance of parental support in order to encourage children's leadership identified in Section 2.4.2, Te Whāriki implicitly supports children's leadership by fostering communication between parents and teachers.

The Honduran Early Childhood Curriculum, CNPB (Secretaría de Educación de Honduras, 2001) implicitly encourages children's leadership skills through its 'areas of development.' CNPB is composed of three curricular areas of development: personal and social, relation with the environment, and communication and representation. Each area has its own 'blocks of learning' content that should be covered, 'standards' - learning goals for students and 'pedagogic orientations' - a guide for teaching practices. Ten of the fourteen main objectives of the 'areas of development' focus on developing academic skills in the children, such as competency in mathematics and science. The 
other four main objectives encourage social-emotional skills such as autonomy, self-esteem, communication, and problem-solving. These are leadership skills that have been identified in previous literature as examples of leadership skills. Although it appears that developing academic skills is the main focus of the curriculum, developing leadership skills appears to be implicitly stated as one of its objectives.

In 2002, the Honduran Ministry of Education proposed a new document where leadership encouragement is stated explicitly as one of its objectives. As introduced in Chapter 1, the document called Diseño Curricular Nacional para la Educación Prebásica, DCNPB (Secretaría de Educación de Honduras, 2002) states that one of the objectives of the 'centres of learning' is to "Promote the initiative, creativity and leadership of the children" (p. 21). The centres of learning, such as art and science, are spaces distributed around the classroom and equipped with materials for the children to play with. The children have one hour of free-play called 'play-work time.' The children play at the centres of learning particularly during this time. This reflects that the DCNPB encourages children's leadership skills through play work time.

In theory, the aims of the New Zealand Early Childhood Curriculum implicitly encourage children's leadership through its principles, strands and goals, and also through free-play and fostering parental support. The Honduran Early Childhood Curriculum implicitly encourages children's leadership through some of the objectives of the areas of development, and explicitly through play work time.

\subsection{Previous studies on children's leadership in New Zealand and Honduras}

A review of the literature shows three studies conducted in New Zealand regarding young children's leadership. Mawson (2009) conducted a study in the morning session of a kindergarten in Auckland, New Zealand, exploring the role of gender in determining how children demonstrate leadership roles during collaborative play. He then conducted a second study, (Mawson, 2010), 
comparing and contrasting gender differences in leadership styles during children's collaborative play in two early childhood settings: the morning session of a kindergarten, the setting he used in his first study, and a long day care centre in Auckland. In both studies he concluded that there were gender differences in leadership styles; the boys' style was more of a 'dictator' and the girls' style was more of a 'director.' This study also identified that children engaged in more mixed-gender play in the long day care centre than in the kindergarten. Although the two studies report characteristics of young leaders that could be useful to increase understandings of different leadership styles, studies that also explore teachers' approaches to these leadership styles could enable them to support this concept.

The third study is by Te Kōpae Piripino (2006) and was in a Māori ${ }^{6}$ immersion early childhood centre that was part of a three year 'Centre of Innovation' Research Project in New Zealand. The purpose of the research was to explore the relationship between 'whānau' (family) development and encouraging leadership at all levels in order to enhance children's learning and development (Tamati et al., 2008, p. 8). The research suggests a framework for defining leadership stating that it should be viewed according to four responsibilities: being responsible, having responsibility, taking responsibility and sharing responsibility. Table 2.1 describes The Four Responsibilities framework.

${ }^{6}$ Māori are the indigenous people of New Zealand. 
Table 2.1: The Four Responsibilities (Tamati et al., 2008, p. 26)

\section{Ngā Takohanga e Wha: The Four Responsibilities}

* Te Whai Takohanga - Having Responsibility having designated roles and positions of responsibility.

* Te Mouri Takohanga - Being responsible relates to an individual's attitude and actions. Being responsible is about being professional, acting ethically and appropriately, being honest, being positive and open to others and different perspectives.

* Te Kawe Takohanga - Taking responsibility is about courage, risktaking, having a go, taking up the challenges and trying new things.

* Te Tuku Takohanga - Sharing responsibility is about sharing power, roles and positions. But more than this is about relationships. Sharing responsibility denotes an interaction and engagement with others, being able to listen to others' point of view, acknowledging different perspectives and also asking for and providing assistance.

Te Kōpae Piripono (2006) suggests that all the members in the community, including children, be viewed as leaders. Although the framework was not designed only for young children, the researchers provide evidence of children's leadership within The Four Responsibilities. For example, they describe that children can have responsibility by assuming different 'roles' in the classroom setting; they can be responsible by showing self-confidence; they can take responsibility by taking risks, being confident and decision-makers; and they can share responsibility when negotiating with peers and teachers to reach a common goal (Tamati et al., 2008). 
The framework seems an encompassing conceptualization of leadership; it not only suggests the traditional view of leadership as a designated position, but also considers other definitions of leadership such as sharing power. Therefore, the framework suggests a well-established view of children's leadership according to The Four Responsibilities. In addition, the framework suggests leadership as an "individual and collective responsibility" (Tamati et al., 2008, p. 27). Having, being and taking responsibility could relate more to the leader as an individual, however sharing responsibility suggests a collective view of leadership. As leadership can be defined in different ways, this view of leadership could facilitate exploring children's leadership in diverse contexts.

Although leadership development has been recently stated in the Honduran pre-school curriculum as one of its objectives, the literature search did not uncover studies conducted in Honduras regarding children's leadership. There appears to be only one study regarding leadership in adolescents; an unpublished master thesis by Wiger (2010) from the University of Minnesota in the United States who conducted a project regarding leadership in 10 to 14 years old Honduran girls. The researcher analysed whether the girls in the study reflected the five dimensions - voice/assertion, decision-making, confidence, organization, and vision/ability to motivate others - of the leadership model proposed by CARE (Cooperative for Assistance and Relief Everywhere) by measuring them through the 'Girl Leadership Index survey' designed by the same organization ${ }^{7}$. Wiger concluded that the girls in her study did not show the five leadership dimensions proposed in the CARE leadership model; instead, four other leadership dimensions resulted. Thus, she proposes leadership as a 'multidimensional construct.' Although this study suggests a model of leadership which has already been applied in the Honduran context, it was not targeted to young children as it was designed to be applied specifically in adolescent girls. A leadership model designed for young children would provide a better conceptual base for exploring children's leadership.

\footnotetext{
${ }^{7}$ CARE is a non-governmental humanitarian organization which seeks to fight poverty on developing countries. It was initiated by the United States in the mid 1900's and has now 12 member organizations (CARE, n.d.). CARE and USAID (United States Agency for International Development) partnered to develop the Power to Lead Alliance in six countries including Honduras. This program encourages leadership in girls, between 10 and 14 years of age, in vulnerable communities in these six countries (USAID, 2012).
} 
The next sections of the literature review focus on teachers' beliefs and practices. An understanding of the term teachers' beliefs is provided first, followed by teachers' beliefs in early childhood education and finalizing with the relationship between teachers' beliefs and practices.

\subsection{Teachers' beliefs}

In order to provide an understanding of the term teachers' beliefs, it is considered important to define the construct 'belief' as it can be defined in different ways. This section starts with the definition of belief taken in this study followed by an understanding of teachers' beliefs.

The term belief is a construct in the literature and has been given many definitions (Pajares, 1992). Richardson (1996) defines beliefs as the "psychological held understandings, premises, and propositions about the world that are felt to be true" (p. 103). Some examples of the different names that beliefs have been given in the literature are: conceptual systems, attitudes, perceptions, judgments, implicit and explicit theories, and understandings (Pajares, 1992). Beliefs are personal to each individual (Luft \& Roehrig, 2007), they often take place unconsciously (Einarsdottir, 2003; Schommer-Aikins, Bird, \& Bakken, 2010), and they are considered true even though there is no evidence to demonstrate it (Einarsdottir, 2003). Thus, beliefs could be taken as any understanding an individual holds about reality.

Teacher beliefs can be defined as the understandings that teachers hold about teaching and learning, classroom environment and curriculum. Different studies of teacher beliefs have defined the concept similarly. For example, Abu-Jaber, Al-Shawareb, and Gheith (2010) defined teacher beliefs as teacher assumptions about students, their teaching strategies, curriculum and pedagogy. Pajares (1992) suggests that "all teachers hold beliefs" about their practice, students, and subject-matter (p. 314). Fang (1996) also argues that beliefs and theories are a part of teachers' general knowledge which influences their behavior in the classroom. Every teacher appears to hold personal beliefs 
about students' learning, teaching practice, and subject matter which could influence their classroom practice.

\subsection{Teachers' beliefs in early childhood education}

During the last two decades, early childhood education studies have focused on teacher's beliefs and theories regarding teaching and learning (Abu-Jaber et al., 2010). Researchers have particularly been focused on teachers' beliefs regarding different areas of child development, for example: literacy development (Lim, 2010); math instruction (Herron, 2010); or developmentally appropriate practice (Abu-Jaber et al., 2010; Hedge \& Cassidy, 2009).

There appear to be only two studies particularly about teachers' beliefs regarding children's leadership. The first is Mullarkey et al. (2005) who conducted a study about teachers' perceptions regarding classroom leadership in a university-affiliated centre in the United States that provided child care service for children between 6 months and 5 years of age. This study drew from a previous study (Shin et al., 2004) that explored the characteristics of young leaders. In their study, Shin et al. (2004) suggest further studies about teachers' perceptions regarding children's leadership in order to better understand the concept of children's leadership. Therefore, Mullarkey et al. (2005) explored teachers' perceptions identifying that, in their study, teachers described the young leaders with the pro-social characteristics suggested in previous studies; independence, initiation of play, and willingness to take risks. However, the researchers also identified an inconsistency between teachers' perceptions and their teaching practice (more detail about this study is provided in another section).

Owen (2007) conducted a project in schools in England and Wales with the purpose of 'creating leaders in the classroom.' Part one of the study involved exploring teachers' perspectives about young leaders and leadership potential. The top six characteristics that the teachers used to describe young leaders were: using initiative, showing responsibility, respecting others, interacting positively with peers, delegating tasks to peers and listening. Furthermore, the 
researcher provided evidence that $85 \%$ of the teachers in the study believed leadership should be encouraged from three years of age. The teachers in the study also identified some main barriers for developing children's leadership abilities: the need to comply with the topics demanded by the national curriculum; behavioural problems of some children having a negative leadership influence on peers; and classroom ratios, as some children are not confident to stand out in large groups. Although this study was not focused specifically on early childhood, it provided insights into how early childhood education and experiences nurture leadership.

A review of the literature found no cross-cultural studies about teachers' beliefs regarding children's leadership. However, there have been a few cross-cultural studies that have looked at early childhood teachers' beliefs regarding other concepts (Wang, Elicker, McMullen, \& Mao, 2008). Some of these studies include that of Izumi-Taylor, Samuelsson, and Rogers (2010) who focused on Japanese, American and Swedish teachers' perceptions regarding play; that of Wang et. al (2008) who focused on teachers' beliefs about Chinese and American preschool curriculum; and that of McMullen, Elicker, Wang, Erdiller, Lee, Lin, and Sun (2005) who compared teachers' beliefs on developmentally appropriate practice in five nations. The findings of these studies suggest the importance of cross-cultural studies for increasing cross-cultural understandings of teachers' beliefs regarding different concepts, such as children's leadership, in order to better understand how teachers' beliefs guide teaching practices in different socio-cultural contexts. The similarities and differences between the countries in these studies could also provide a platform with which to compare findings of other cross-cultural studies in early childhood education.

\subsubsection{Influential factors on early childhood teachers' beliefs}

Main factors that influence early childhood teacher beliefs about children's learning have been explored in the literature. Einarsdottir (2003) suggests three factors: enculturation which is the values and beliefs about pedagogy are greatly influenced by a teachers' culture, school culture - the beliefs of the school the teacher is part of, and schooling - any degree or training about teaching and learning. Furthermore, Vartulli (2005) states that experience, 
education (degree and/or training in early childhood education) and values influence teachers' beliefs. Brownlee and Chak (2007) also point out that professional development, courses, or any educational experience encourages teachers to reflect on their beliefs. These studies suggest that the culture to which the teacher belongs, the centres' culture, their teaching experience, and teaching degrees or professional development are important factors to consider in understanding teachers' beliefs about children's learning or leadership.

Cross-cultural studies in early childhood highlight that a teachers' culture influences personal beliefs. Izumi-Taylor et al. (2010), for example, suggest culture as a 'key factor' in determining teachers' perspectives since people from different countries look at different aspects of the same 'phenomena.' McMullen et al. (2005) concluded that beyond practical issues such as student ratios and class size, teachers' beliefs are strongly influenced by the philosophies of their own countries. For example, they suggest that being part of an individualistic or a collectivist society impacts which aspects of teaching and learning teachers value as important. Wang et al. (2008) found that cultural requirements should be considered when reflecting on teachers' beliefs and practices. They reported that the Chinese teachers showed more teacher-directed beliefs and practices than the American teachers. Wang et al. argued that the reason for this difference is because the Chinese alphabet is harder to learn than the English alphabet, therefore, the Chinese need more teacher-directed instruction before beginning primary school. These studies suggest that cultural difference is a fundamental aspect to consider when conducting a cross-cultural comparison of teachers' beliefs on a phenomenon such as leadership.

One possible method of analysing leadership cross-culturally as suggested by previous researchers is identifying or measuring dimensions of culture (Dickson et al., 2003). For example, in his study, Hofstede (1980) introduced the 'widely known' four culture dimensions: power distance, uncertainty avoidance, individualism versus collectivism, and masculinity versus femininity ${ }^{8}$. The

\footnotetext{
${ }^{8}$ Power distance is the extent to which a country accepts that power is distributed unequally. Individualism refers to societies where people are expected to take care of themselves whereas collectivism refers to societies where people expect their group to look after them. Uncertainty avoidance is the degree to which societies avoid uncertain situations. Masculinity implies
} 
researcher measured the cultural dimensions in 40 countries through a survey among managers of the company IBM. In subsequent research, Hofstede (2001) included additional countries. Other researchers such as Schwartz (1999) have also identified cultural dimensions of leadership. Schwartz suggested three dimensions of culture in his study: autonomy versus conservatism, hierarchy versus egalitarianism, and mastery versus harmony ${ }^{9}$. Dickson et al. (2003) review studies that have used Hofstede's cultural dimensions in order to study leadership across cultures. Dickson et al. argue that even though the four dimensions have been extensively critiqued, they have also been widely used and provided a feasible framework to guide studies regarding leadership. In addition, the authors suggest they "have been studied most extensively to date" when compared to other cultural dimensions such as those suggested by Schwartz (Dickson et al., 2003, p. 736). The four cultural dimensions identified by Hofstede $(1980,2001)$ can provide a useful platform to compare teachers' beliefs regarding children's leadership cross-culturally.

\subsection{Relationship between teachers' beliefs and practices in early childhood education}

Many studies have revealed teachers' beliefs about children's learning have an influential role in early childhood teaching practice. Vartulli (2005) describes beliefs as 'the heart of teaching' suggesting that "philosophical principles, theories, and belief systems guide teacher's expectations about child behaviour and the decisions they make in classrooms" (p. 78). She suggests that teachers who believe all children are capable of learning, promote more life-long skills such as self-autonomy and problem solving in their students. Some studies have shown a consistency between teachers' beliefs and practices. Brownlee and Chak (2007) found that the teachers in their study held three main beliefs regarding children's learning; aggregation, active understanding, and active

societies that value being tough and not looking after others whereas femininity implies societies that value warm relationships and care of the weak.

${ }_{9}$ Autonomy refers to societies that view a person as autonomous and finds meaning in own uniqueness whereas conservatism refers to societies where the person is viewed as finding meaning in the collectivity. Hierarchy indicates the value of unequal distribution of power whereas egalitarianism suggests emphasize on equality. Mastery refers to an emphasis on ambition, daring and success whereas harmony accepts the world as it is and emphasizes on fitting harmoniously. 
discovery. They reported a relationship between teachers' beliefs and practices as, for example; teachers that conceptualize children's learning as active understanding encourage the child to actively make meaning of learning experiences. Wang et al. (2008) also concluded that their results showed consistency between the teachers' teacher-directed beliefs and teacher-directed practices; they also showed consistency between the teachers' child-directed beliefs and child-directed practices regarding the early childhood curriculum.

In contrast, some studies have found an inconsistency between beliefs and practices. Nuttall (2005) found teachers' beliefs regarding the New Zealand early childhood curriculum were not always consistent with their practice. She identified the structure of activities at an early childhood centre as one aspect that inhibits teachers' ability to reflect on their beliefs and, therefore, translate their beliefs into practice. Similarly, Alvestad and Duncan (2006) looked at New Zealand teachers' understandings about the New Zealand Early Childhood Curriculum. They concluded that teachers view the curriculum as a significant guide to use in working with the children. However, in the long term, the degree to which teachers apply the curriculum in daily practice depends on each teacher's understanding about its theory and practice, and other factors such as professional development and support. Wang et al. (2008) also found that the teachers in their study stated that teacher-student ratios, lack of time and having to follow the supervisor's beliefs, were some obstacles that prevented consistent practice in relation to their beliefs. These studies indicate that teachers' understanding about the national curriculum; routines at an early childhood centre; and structural issues could influence whether teachers are able to apply their beliefs, such as those regarding leadership, into their teaching practice.

\subsubsection{Teachers' beliefs and practices regarding children's leadership}

Mullarkey et al. (2005) appears to be the only study that explores teachers' beliefs and practices regarding children's leadership. As mentioned in section 2.7, the researchers explained that initially the teachers in the study described their beliefs regarding young leaders with pro-social characteristics. However, the researchers found an inconsistency between the theoretical beliefs of 
teachers regarding leadership and how teachers promoted leadership in practice when their beliefs were challenged with the 'dilemmas' they encounter in early childhood settings. Mullarkey et al. describe the young leaders who often showed disruptive behaviour and also influenced other peers to follow this behaviour. The researchers stated that teachers ended up using "nonintervention strategies and shared authority" (p. 128) to approach this negative behaviour. The authors also identified the dilemma that teachers encounter in supporting children with pro-social leadership. An example of this is teachers having to balance supporting the needs of the strong leader against the needs of the rest of the children who are less verbal or more shy. They concluded that these dilemmas leave teachers with the conflict of following their ideal of encouraging children's leadership, or discouraging it in order to keep classroom management.

Mullarkey et al. (2005) pioneered the exploration of teachers' beliefs and practices regarding children's leadership and has significantly contributed to the literature on this idea. However, this study relied solely on teacher interviews as a data collection tool. Mullarkey et al. argued that they were more interested in what the teachers perceived than with the events in the classroom themselves. However, it can also be argued that the researcher cannot rely solely on teacher interviews in order to interpret teaching practices. Merriam (1988) suggests that observations enable the researcher to gather firsthand information of a phenomenon, which is not possible when one relies only on data gathered through interviews. Wang et al. (2008), who explored teachers' perceptions about the American and Chinese curriculum, concluded that not including an 'observation component' was one limitation in their study. The researchers stated that they only used self-reported practices to measure teachers' practices. They suggest further studies that include observing the teachers in their settings in order to better understand the relationship between teachers' beliefs and practices regarding leadership. 


\subsection{Chapter Summary}

This review of the literature has revealed the paucity of studies around children's leadership. Most of these studies have focused on defining characteristics of young leaders by looking at the young leaders themselves. The scarce literature around teachers' practices regarding children's leadership is dominated by opinion articles rather than studies (Bisland, 2004; Karnes \& Stephens, 1999). Recent literature has begun to reveal that teachers' beliefs and practices influence the way that children's leadership is enacted in early childhood settings, and also suggests more studies that could help reduce the gap between theory and practice. Future studies that explore the relationship between beliefs and practices have the potential to assist teachers to support emerging leadership in young children. By analysing the relationship between teachers' beliefs and practices this study can help fill the gap in the literature. There is also a clear gap in the literature on cross-cultural studies that address differences in theory and practice regarding children's leadership. Cross-cultural studies could increase our understanding of teachers' beliefs and practices in different socio-cultural contexts. The present study will explore how teachers of four to five year old children in New Zealand and Honduras translate their beliefs about children's leadership into practice, with a focus on similarities and differences between both countries. 


\section{Chapter 3: Methodology}

\subsection{Chapter Overview}

This chapter outlines the research methodology. There are several decisions that researchers need to make in selecting the plan of the study or research design (Creswell, 2009). In order to explain the plan for my study, I will describe the three components of a research design identified by Creswell (2009) including the researcher's philosophical paradigm or worldview, selected strategies of inquiry related to this worldview, and research methods which translate this view into practice. Each component is explained separately. After describing the research design, a further section explains the trustworthiness, ethical considerations and limitations of this study.

\subsection{Research Paradigm}

This study draws on a social-constructivist philosophical paradigm. Denzin and Lincoln (2000) state that all research is "guided by the researcher's set of beliefs and feelings about the world and how it should be studied" (p. 22). In order to justify the selection of the design, it is necessary to identify the beliefs the researcher brings to the study (Creswell, 2009). The research paradigm is the researchers' set of beliefs that guide their actions. A research paradigm may consist of the researcher's ontological premises - the nature of reality and the belief the researcher holds about it; epistemological premises - how the researcher creates knowledge about the world; and methodological premises the way the researcher acquires knowledge about the social world (Denscombe, 2010; Denzin \& Lincoln, 2000).

According to Creswell (2009), in a social-constructivist paradigm, the researcher assumes that individuals seek understanding about the world by making subjective meaning about their experiences. Creswell suggests the social constructivist researcher constructs or interprets the meaning that individuals have about the world and addresses the context the participants are part of in 
order to understand their cultural and historical setting. The constructivist paradigm also suggests that the researcher studies the participants in their natural settings (Denzin \& Lincoln, 2000), relying on the participants' views about a phenomenon through open-ended questioning (Creswell, 2009). In applying the social-constructivist worldview in this study, one can make the assumption that the New Zealand and Honduran teachers participating in this study have their own understanding about children's leadership, which also has a significant role in defining pedagogical practices (ontology). As a researcher, my role is to collect the data in the participants' natural settings (methodology) and interpret their beliefs and practices regarding children's leadership within their particular cultural context (epistemology).

\subsection{Strategies of inquiry}

The second aspect suggested in Creswell's (2009) framework of design is strategies of inquiry. Creswell defines strategies of inquiry as "types of qualitative, quantitative, and mixed methods designs or models that provide specific direction for procedures in a research design" (p. 11). The researcher selects the strategies of inquiry in accordance with the approach of inquiry quantitative, qualitative or mixed methods - of the study. Denzin and Lincoln (2000) suggest that qualitative research focuses on "processes that are not experimentally measured" (p. 8), as opposed to quantitative research which focuses on measuring the relationship between variables, not processes, a mixed methods approach combines quantitative and qualitative forms. The qualitative approach of inquiry taken in this study is identified in the next section, followed by a section describing the case study strategy of inquiry selected.

\subsubsection{Qualitative approach}

This study takes a qualitative approach in order to explore the idea of teachers' beliefs about children's leadership. There are two main reasons for taking this approach. The first is that qualitative research is an interpretive and naturalistic approach to the world (Denzin \& Lincoln, 2000) as it enables the researcher to explore and develop an understanding of the meaning individuals assign to a 
social phenomenon (Creswell, 2009). Drawing on the social constructivist paradigm, a qualitative approach is a means of exploring the meaning the teacher participants construct regarding children's leadership. The second reason is that early studies around children's leadership mainly focused on identifying characteristics of young leaders by measuring their features quantitatively (Fukada et al., 1997; Parten, 1933). According to more recent studies such as Shin et al. (2004), these studies "have provided little insights of descriptive information about leadership behaviour exhibited by young children" (p. 304). Shin et al. suggest that research providing rich description of children's leadership is needed as leadership behaviour cannot be quantified. My interest in this study was exploring instead of quantifying the notion of children's leadership. In addition, Creswell (2009) suggests a qualitative approach should be taken in order to approach topics where there is scant research. As children's leadership is an underexplored topic, this study takes a qualitative approach in order to develop an understanding about teachers' beliefs regarding children's leadership that could add to the literature about this notion.

An important characteristic about the qualitative approach is the significant role of the researcher in collecting and interpreting the data (Creswell, 2009; Patton, 2002). Patton (2002) identifies that, as opposed to quantitative research, where the measuring instruments are surveys or other measurement tools, "in qualitative inquiry the researcher is the instrument" (p. 14) of data collection. Creswell (2009) also states that qualitative research is interpretative, thus it is important for the researcher to identify the values, and gender or cultural background that may influence their interpretations during the study. As mentioned in Chapter 1, I acknowledge that my personal values and cultural Honduran background may have an influence on my interpretation of the data. However, as Creswell (2009) states, the goal of a research with a social constructivist worldview is to "rely as much as possible on the participants' view of the situation being studied" (p. 8). I will interpret the meaning that teachers construct about children's leadership. Denzin and Lincoln (2000) define this interaction between researcher and participants as 'co-construction of understanding.' In this co-construction of understanding, I rely on the participants' views about children's leadership. Section 3.5.2 explains that my 
interpretations of the findings were sent back to the teachers in order to assure I accurately presented their views.

\subsubsection{Case Study}

Qualitative research has several strategies of inquiry that help us understand and explain the meaning of social phenomenon (Merriam, 1998). The strategy selected for this research is case study. Merriam suggests that a case study can be defined in respect to the process of carrying out the investigation, which means identifying the case or bounded system, or as the end product of a research. A bounded system is a series of interrelated elements that form a whole and which has outlined boundaries (Johnson \& Christensen, 2008, p. 406). The two cases were Honduras and New Zealand. As the end product of the research, "a qualitative case study is an intensive, holistic description and analysis of a single instance, phenomenon or social unit" (Merriam, 1998, p. 27). In my study, the phenomenon is teachers' beliefs and practices about children's leadership. The case study strategy enabled me to explore the phenomenon holistically and descriptively. In addition, according to Yin (2003), the phenomenon in a case study is investigated in its real-life context assuming that the context is significant to the phenomenon of study. Therefore a case study is used in this study assuming that social and cultural context has an influence on my participant teachers' beliefs and practices.

There are alternative approaches within a case study as a research strategy (Yin, 2003). Yin differentiates two types; single and multiple case studies. A multiple case study as opposed to a single case study "involves collecting and analyzing data from several cases" (Merriam, 1998, p. 40). Multiple case studies have been called comparative case studies, collective case studies or multi-case studies (Merriam, 1998). Yin (2003) identifies comparative case method and multiple case studies as equivalent term; although he points out they have been referred as different forms by other authors. The selection of a multiple or comparative case study as a qualitative case strategy for this study is explained below. 


\section{Comparative case study}

Comparative social research identifies similarities and differences between macro-social units or societies in order to understand, explain, and interpret social phenomenon (Ragin, 1987). Schweisfurth (2001) found comparative case study to be an appropriate approach to address teachers' beliefs and experiences cross-nationally. This author argues that the interaction between the researcher and participants in a case-study "aimed to produce an in-depth knowledge, which is enhanced by being approached from two different cultural perspectives" (p. 212). In this study a comparative case study was selected in order to understand the uniqueness of each case and then compare and contrast both countries with the "potential to illuminate wider issues" (Schweisfurth, 2001, p. 221) or wider understandings about children's leadership.

One of the components of a case study design that the researcher has to decide upon is the units of analysis (Yin, 2003). Units of analysis are usually individuals, but can also be groups of people or programs (Patton, 2002). The number of units of analysis can define the type of multiple case study design. Yin (2003) suggests two types of multiple-case studies; holistic case studies, which have only one unit of analysis, and embedded case studies, which have more than one unit of analysis. This study has a multiple, or comparativeembedded case design, as the unit of analysis is eight participant teachers. In order to analyse data from each teacher, data is collected within the teachers' early childhood setting.

Figure 3.1 shows this case study's design. The two large circles intersecting represent the comparison between New Zealand and Honduras. The two early childhood settings selected from each country are represented by the medium size circles. Two participant teachers (e.g., T1 and T2) from each centre were the participants, units of analysis, in this study. 


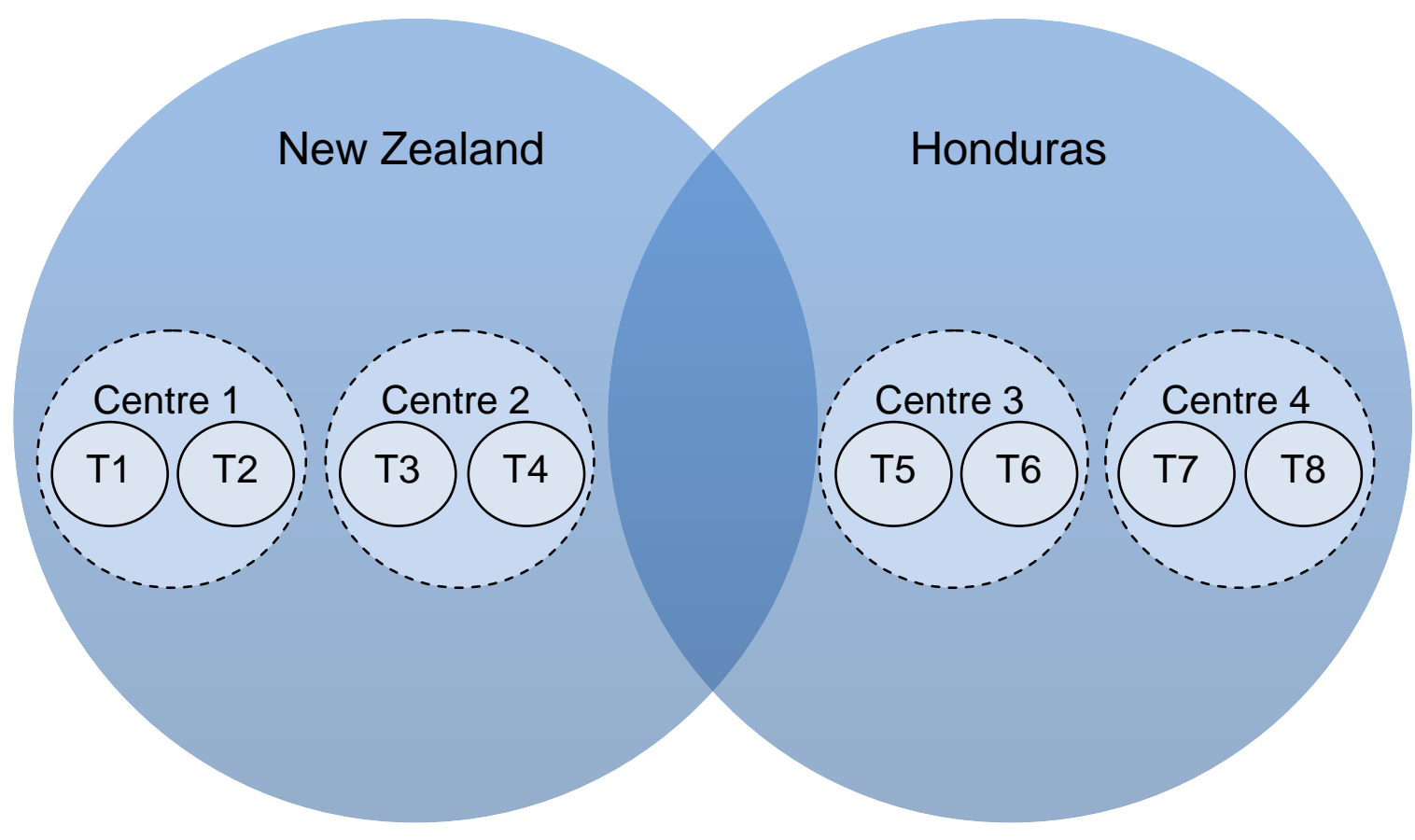

An explanation of the teacher participants and their settings is given in the next section.

\subsection{Research Methods}

The third element Creswell (2009) suggests in his framework for research design is the research methods. According to Creswell, "the research methods, involve the forms of data collection, data analysis and interpretation that researchers propose for their studies" (p. 15). In the next sections the research questions, setting, and participants chosen for this study are explained first followed by data collection and data analysis methods.

\subsubsection{Research questions}

Yin (2003) suggests the type of research question depends on the strategy of the study. Yin identifies the "how" and "why" research questions as part of a case study strategy. This study is guided by the following main research question: How do teachers of four-to-five year old children in New Zealand and Honduras translate their beliefs about children's leadership into practice? 
The study has three sub-questions which were drawn from two previous studies about children's leadership - Mullarkey, et al. (2005) and Owen (2007).

1. How do teachers conceptualize children's leadership?

2. How do teachers encourage children's leadership?

3. What are some of the barriers/enablers for teachers to encourage leadership in their students?

\subsubsection{The setting}

Data gathering took place in Tegucigalpa and Wellington. The focus of the study was on two early childhood centres in Tegucigalpa, and two in Wellington. Conducting the study in specific early childhood settings enabled a "fence in" or "delimiting" of each case (Merriam, 1988). Two centres in each country were chosen in order to increase the platform of comparison.

The early childhood centres were chosen from low-socio economic areas in each city. As explained in the introduction chapter, Honduras has a poverty rate of $60 \%$ (United Nations, 2011). Although New Zealand has a "good standard of living" (New Zealand Ministry of Social Development, 2010, p. 60) 15\% of its population is on a low income (New Zealand Ministry of Social Development, 2010). In order to investigate some of the issues of poverty, I wanted to focus this study in early childhood centres from low-socio economic areas.

The early childhood centres were purposefully selected. Patton (2002) suggests quantitative studies use statistics in order to select the samples randomly and generalize the findings. On the contrary, qualitative studies use purposeful sampling in order to select cases from where the researcher can get rich data. I purposefully selected the centres from which "the most could be learned" (Merriam, 1998, p. 61) in relation to my research question.

The early childhood centres in Tegucigalpa were selected first. They were both public centres; run by the government and education is free. The centres are well known within Tegucigalpa and the public sector. Thus, I selected both centres as I thought they could be a good representation of Honduran public early childhood education. In order to select those centres, I took the 
information letter (Appendix A) to the supervisors. I explained the purpose and process of the study to them, and asked if they were interested in their centres participating. The supervisors agreed and signed the consent form (Appendix B) providing written permission. Both early childhood centres had a morning and afternoon session. Each session was four hours long. This study was focused on teachers of four-to-five year old children; kindergarten. I selected two kindergarten classrooms from each centre. A detailed description of each centre is provided in Chapters 6 and 7.

With the aid of the Wellington Kindergarten Association, early childhood centres with characteristics as similar as possible to the ones in Honduras were then selected in Wellington. Kindergartens in New Zealand are managed by a Kindergarten Association and licensed by the Ministry of Education (New Zealand Ministry of Education, 2012). Both centres are 'free kindergartens' and provide 20 hours a week free of charge. The kindergartens had morning and afternoon sessions. The morning session was selected for this study as it had similar characteristics as the Honduran centres - the session was four hours long and the children attending were four year olds. A more detailed description of each centre is provided in Chapters 4 and 5 . It is important to note that kindergartens in Wellington are nowadays mainly long-day sessions. Therefore, I had a constrained choice of kindergartens that could be part of my study. In order to select the centres, I followed the same procedure as in Tegucigalpa. I first visited the early childhood centres and spoke with the head teachers. I explained the purpose and process of the study to them and gave them the head teacher information letter (Appendix A). They were asked if they were interested in their centres being part of the study. The head teachers signed the consent form (Appendix B) providing their consent.

\subsubsection{Participants}

Purposeful sampling was also used in selecting the participants in this study. I chose participants that could provide me with rich data in relation to my research question (Patton, 2002). In New Zealand the last level of early childhood education are children from age four to five. However, in Honduras, the last level of preschool education is children from age five to six. For the 
purposes of doing a comparative study and obtaining the closest comparison possible (Johnson \& Christensen, 2008), teachers of children from age four to five were asked to participate in the study.

After selecting the early childhood centres in Honduras, I asked the supervisors to give the teacher information sheet (Appendix $\mathrm{C}$ ) to the kindergarten teachers and ask if these teachers wanted to participate in the study. Centre 1 had 3 kindergarten teachers. The two kindergarten teachers, Ana and Blanca, from the morning session, volunteered to participate in the study. (Pseudonyms are used for the teachers and children). The two teachers from Centre 2 who volunteered to participate were Carol, from the kindergarten morning session; and Diana, from the afternoon session. Centre 2 also had 3 kindergarten teachers. The four teachers were then asked to sign the consent form (Appendix D). A description of each teacher is provided in Chapters 6 and 7.

The same procedure used in Tegucigalpa for recruiting the teachers was used in Wellington. After selecting the early childhood centres, I asked the head teachers to show the teacher information letter (Appendix $C$ ) to the teachers of the centre and ask who wanted to participate in the study. Centre 1 had four teachers, as well as the head teacher. Two teachers, Erica and Frances, volunteered as participants. As well as the head teacher, Centre 2 had three teachers. The two teachers who volunteered to participate were Grace and Jill. They were then asked to sign the consent form (Appendix D). A description of each teacher is provided in Chapters 4 and 5 .

\subsubsection{Data Collection}

This section describes the data collection procedure. Creswell (2009) suggests the steps in data collection involve "setting the boundaries for the study, collecting information through interviews and observations, documents, and also establishing the protocol for recording information" (p. 178). Several authors suggest that qualitative researchers should rely on multiple methods of data collection, data triangulation, to increase the validity of the study (Patton, 2002; Yin, 2003). Yin (2003) suggests using 'multiple sources of evidence' as one of the three principles of data collection in order to strengthen the case 
study by providing more accurate and convincing evidence. In line with these authors, this study used three data collection techniques: interviews, observations, and documents. A description of a pilot study conducted in preparation for data collection is explained below, followed by a description of each data collection technique.

\section{Pilot study}

Before fieldwork, I conducted a pilot study in one early childhood centre in Wellington. Yin (2003) discusses that a pilot study enables you to try out your data collection plan, in order to improve the content of your data sources and the procedure of your study. In order to test my data collection plan, I followed the steps I intended to use in my data collection. I located an early childhood centre to which I could have access. The setting was a long-day care centre with mixed-aged children. Although the characteristics of the centre were not exactly the same as the ones I was focusing on in my study, the pilot was useful to test my data sources and procedure. I interviewed one of the teachers of the centre and observed her for two days. At that point I was not sure how long each observation should be. The first day I observed her for two hours in the morning and one hour in the afternoon. The second day, I observed her for one hour in the morning.

When concluding the pilot study, I made the following adjustments in order to improve my data collection sources and procedure. I adjusted one of the interview questions as the teacher expressed it was not clear. Then I decided it was possible and useful to collect data in two hour periods. The procedure for recording field notes worked well. It should be noted that at the time I conducted the pilot study, I had not yet received the Approval letter from the Victoria University of Wellington Faculty of Education Ethics Committee in order to start data collection. Therefore I understood that I could not use any of the data that I recorded, in the pilot, in the thesis report.

\section{Interviews}

The first step of data collection involved conducting individual semi-structured interviews with each of my participant teachers. An interview enables the 
researcher to gain in-depth understanding of the participants' thoughts and beliefs about a topic (Johnson \& Christensen, 2008). Merriam (1988) proposes that an interview is useful in order to explore things, such as feelings and thoughts, which cannot be observed. Therefore the teachers were interviewed individually with the purpose of exploring in depth their beliefs about young children's leadership. Generally, qualitative research uses semi-structured interviews where the questions are more open-ended (Merriam, 1988). I asked nine open-ended interview questions (Appendix E).

After the teachers signed the consent form, each decided the time and place for the interview. As proved useful in the pilot study, the interview questions were given to the teachers a few days before the interview so they could start thinking about their responses. All the interviews took place at the teachers' early childhood centre and lasted between 45 and 60 minutes. During the interview, I followed an interview guide which "lists the questions or issues to be explored during the interview" (Patton, 2002, p. 343). The guide contained open-ended questions and also probes that I could use to encourage the teacher to expand more on a thought (Patton, 2002). At the end of the interview, I asked each teacher if there was anything they would like to add or further discuss.

The interviews were audio-taped and transcribed. The transcribed interviews were sent back to the teachers so they could check for accuracy; a process known as 'member checking' (Merriam, 1988). In the case of the Honduran teachers, I personally took the interview transcripts to each teacher's centre as they have limited access to the internet. The interview transcripts of the New Zealand teachers were emailed to them. This process helped to clarify ideas that were not clear in the transcripts. Two of the teachers also added information.

\section{Naturalistic Observations}

The second step of my data collection involved observing the teachers in their natural settings. Merriam (1988) suggests observations enable the researcher to gather firsthand information of a phenomenon, not relying only on data 
gathered through interviews. Observations confirm what is reported in the interviews (Patton, 2002). In order to collect data about teaching practices besides teachers' self-reported practices, I observed the teachers in their natural settings. Patton points out observations often cause anxiety in the participants, especially when they feel they are being evaluated. Therefore, I conducted the observations after the interview as an attempt to create trust between me and the teachers so they could feel more relaxed and able to demonstrate their natural teaching practice. The teachers were observed for two days for a period of two hours each day. I liaised with each teacher to set the time and days to conduct the observations.

I conducted naturalistic observations. Bodgan and Biklen (2007) define naturalistic as when researchers observe the particular setting with either paper and pencil, or video/audio recording equipment. I used paper and pen to record field notes during and after the observations. According to Bodgan and Biklen (2007) field notes consist of descriptive and reflective notes. Descriptive notes record as objectively as possible all the details the researcher observes in the field, including direct quotations (Bodgan \& Biklen, 2007; Patton, 2002). Reflective notes are used to record the researcher's reflections such as feelings, opinions, and inquiries (Bodgan \& Biklen, 2007). I took descriptive and reflective notes during the observations following my observation protocol which had the following headings: name of early childhood setting, date, time, activity, environment, description and reflection (see Appendix $F$ for an example of the New Zealand observation field notes and Appendix $G$ for an example of the Honduran observation field notes). In the description section I recorded the sequence of events I observed so I could remember afterwards details and conversations between the teachers and children. In order to keep an organized file of my observations, I recorded all my field notes in a computer database as soon as I concluded each observation. The Honduran field notes were written in Spanish and the New Zealand field notes in English to be as accurate as possible.

When observing the teachers, I also looked at their interaction with the children in order to observe children's responses - possible indicators of leadership - to 
teachers' practices. I asked for each parents' permission in order to observe their children. An information letter (Appendix $H$ ) was given to each parent explaining the purpose and procedure of the study. A consent form (Appendix I) was also provided so they could sign an agreement for their child to be observed. In Honduras the supervisors thought it convenient to gather all the parents together, as they dropped their children at the centre, to explain the purpose of the study to them. A few of the parents in Centre 2 were illiterate. Therefore, the teachers and I read the information letter and consent form to those parents. All the parents gave their consent. In New Zealand, the information sheets and consent forms were given to each parent as they dropped their child at the centre. All the parents gave consent except for the parent of a child in Centre 1. Therefore I did not observe or recorded any interaction between that child and the teacher.

On the second day of the observations, I also looked at pedagogical documentation in the form of children's portfolios/ workbooks. In New Zealand, the teachers use portfolios as a form of assessment. The teachers in Honduras assess children's learning through workbooks (a detailed description of the children's portfolios/workbook is provided in Chapters 4 and 6). The children's portfolio/workbooks enabled me to collect evidence of teachers' practice for encouraging leadership in the children. I took photographs of the pedagogic documentation to be used for data analysis.

\section{Documentation}

Besides interviews and observations, I also used documentation as a data source. Yin (2003) suggests that "documentary information should be the object of explicit data collection plans" (p. 85). The early childhood curriculum from each country was used throughout the research as the official government documentation that guides early childhood education. Therefore, the content of each curriculum was analyzed in order to determine its influence on the teachers' practices regarding children's leadership, and to compare and contrast teachers' beliefs and practices in both countries. Pedagogical documentation described in the observations section was also considered as documentation collected. 


\subsubsection{Data analysis}

Data analysis in qualitative research involves transforming data into findings by making meaning of text or images (Creswell, 2009; Patton, 2002). Yin (2003) suggests that in a multiple-case design, each individual case is analysed separately. Following that, a cross-case analysis enables the researcher to find similarities or differences between cases. In line with Yin, before I conducted a cross-case analysis, I first analysed the data from each case. This involved an analysis of the interviews and observations of the four teachers in New Zealand, and then the interviews and observations of the four teachers in Honduras. After the data for each teacher was analysed, I did an intra-country comparison. This meant a comparison of the four teachers within each country in order to gain an understanding of each case. Finally, both countries were compared and contrasted. The diagram below represents my data analysis process. 
Figure 3.2: Data analysis process

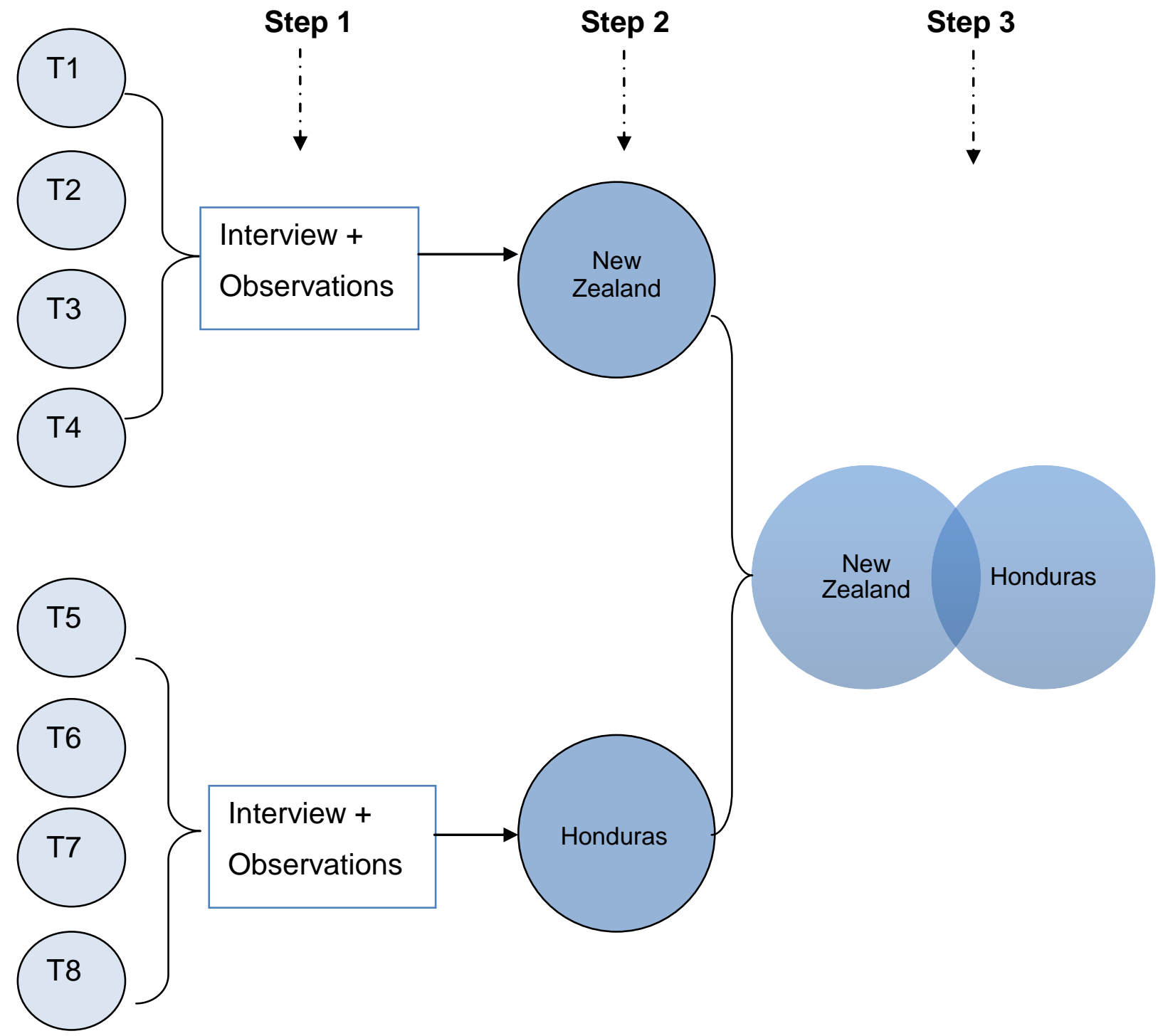

As shown in the figure above, the first step in my data analysis involved analysing the interview and observations of the teachers (e.g., T1) in each country. The interview analysis process will be explained first followed by the observations.

I used thematic analysis in order to analyse each teacher interview. Braun and Clarke (2006) define thematic analysis as "a method for identifying, analyzing, and reporting patterns (themes) within data" (p. 79). Braun and Clarke suggest six phases of thematic analysis. Each phase is explained below. 
1. Familiarizing yourself with your data: This stage involves transcribing the data in order to get immersed in it. I transcribed the eight teacher interviews. In order to be as accurate as possible, the New Zealand interviews were transcribed in English and the Honduran interviews were transcribed in Spanish. The rest of the analysis process for both countries was done in English.

2. Generating initial codes: This stage involves identifying data that appears interesting to the analyst in relation to the research question. The coding can be data driven, depending on the data, or theory driven where the researcher codes with a specific theory in mind. I began my data analysis driven by The Four Responsibilities framework (Tamati et al., 2008) explained in Chapter 2. The Leadership framework suggests that leadership can be defined according to four responsibilities: having responsibility; taking responsibility; being responsible; and sharing responsibility (see Table 2.1 for a detailed description of the framework). In this stage I identified all the data that could potentially be related to The Four Responsibilities.

3. Searching for themes: At this stage the different codes are sorted into potential themes and grouped within those themes. I began to sort my data into themes. Subsequently I grouped those themes under The Four Responsibilities. My major themes then became The Four Responsibilities and my sub-themes were the ones generated by the data. These sub-themes were identified by prevalence; they were repeatedly mentioned by the teachers throughout the interview or represented an important idea in relation to the research question.

4. Reviewing themes: This stage allows the refinement of themes by reviewing if themes need to be grouped or taken out. At this stage I reviewed my major themes and sub-themes. I noticed that I did not have enough data to support the theme 'being responsible' as suggested in The Four Responsibilities. Being responsible appeared not to be relevant in this particular study. One reason for this could be that I was looking at teacher beliefs and practices about children's leadership rather than at the leaders themselves. I could not 
really tell with my data whether or not a child is responsible. The characteristics of young leaders identified by the teachers that could be grouped under being responsible seem to fit better under sharing responsibility. Thus, I decided to take out this particular responsibility from the framework.

In addition, the New Zealand teachers' interview responses appeared to indicate that the teachers expected the children to take responsibility in order to have responsibility. This is explained further in Chapter 4 . Therefore these two responsibilities appear to best represent the New Zealand findings as one single theme. I decided to combine having and taking responsibility for the New Zealand case. Thus, the modified framework according to the New Zealand findings includes two major themes: (a) having and taking responsibility (b) sharing responsibility. For the Honduran case, the teachers' interview responses appear to indicate that the teachers give responsibility to the children for them to have responsibility. This is explained further in Chapter 6. Giving responsibility is not part of The Four Responsibilities framework; therefore, it was added to fit the Honduran findings. The theme sharing responsibility was not apparent in the Honduran findings. Thus, the modified framework according to the Honduran findings includes one main category: (a) having and giving responsibility.

5. Defining and naming themes: This stage involves 'defining and further refining' of the themes. At this stage I had defined and refined my major themes for each country. I then refined my sub-themes in light of the responsibilities' categories. I identified the data extracts that would provide an illustration of each sub-theme and provide the raw material to tell the 'story' of each teacher.

6. Producing the report: This stage involves the write-up of a concise, interesting and convincing account of the data. At this stage I wrote up a story for each teacher with direct quotations that illustrated each sub-theme and captured the essence of each teacher's beliefs and practices. These stories are found in the findings Chapters: 4, 5, 6, and 7. The findings are 
presented according to the teachers' early childhood centres. Therefore, Chapters 4 and 5 present the findings of the two New Zealand centres, and Chapters 6 and 7 provide the findings of the two Honduran centres.

After analysing each teacher interview, the observations for each teacher were analysed. First I coded each observation protocol by identifying teacher-children interactions that could represent each of the four responsibilities. When the major themes and sub-themes were defined, step 5 of the interview analyses, examples from the observations that best illustrated each sub-theme were selected in order to include them in the stories of each teacher.

The second step of the analysis, as indicated in Figure 3.2, was an intra-country country comparison. In this step, I identified the common themes between the teachers from each country. The themes were analysed by linking them with previous studies around children's leadership. The analysis also included using concepts derived from the early childhood curricula, in order to determine how this document guided the teachers' beliefs and practices.

The third step, indicated in the figure mentioned above, is an inter-country comparison or cross-case analysis. The themes from each country were compared and contrasted. Similarities and differences were analysed with links to the objectives of the early childhood curricula and also to previous studies. I particularly explored the themes in each country using cultural literature, which provided explanations of socio-cultural concepts that could influence the similarities or differences between the teachers' beliefs and practices. The cross-case analysis is presented and explained in detail in Chapter 8.

The next section of this chapter describes trustworthiness, ethical considerations, and limitations.

\subsection{Trustworthiness of the findings}

Trustworthiness is an important concept to consider in qualitative research in order to make the findings "noteworthy" to the reader (Schwandt, 2007, p. 299). 
Guba and Lincoln (1994) proposed four criteria to determine the trustworthiness of a qualitative study. Following Guba and Lincoln, these four criteria were considered in this study. Each criterion is explained below.

\subsubsection{Credibility}

Credibility refers to assuring the findings represent the participants' views (Schwandt, 2007). Member checking is a way to assure credibility. After transcribing each interview, the transcripts were sent to each teacher for them to check for accuracy. In addition, I also sent each teacher through email the story I wrote about their beliefs and practices in the findings chapter. This was done in order to check that they agreed with my interpretation of the interview, and also with the examples from the observations that I chose to illustrate their ideas from the interview. Unfortunately, this process could only be followed with the New Zealand teachers as I analysed my findings and wrote the report in New Zealand. The teachers in Honduras had limited access to the internet; therefore, I could not email them their findings story. This issue is further discussed in Chapter 9.

\subsubsection{Transferability}

Transferability deals with issues of generalizing the findings from case-to-case (Schwandt, 2007). Schwandt (2007) suggests it is the researcher's responsibility to provide enough detail about the case so readers can determine "the degree of similarity between the case studied and the case to which findings might be transferred" (p. 299). The findings of each participant teacher in this study is described in detail as to provide enough information so the reader can determine the degree the conclusions in this case study can be transferable to similar settings.

\subsubsection{Dependability}

Dependability ensures that the process followed by the researcher was "logical, traceable, and documented" (Schwandt, 2007, p. 299). In regards to these criteria, all data in this study such as interview and observations filed notes 
were documented in computer files and will be kept stored securely for five years after submitting this thesis.

\subsubsection{Confirmability}

Confirmability is concerned with assuring the researcher's interpretations are linked with the data (Schwandt, 2007). Schwandt (2007) suggests having a person, besides the researcher, examining the data and interpretations as a way to promote confirmability. In this study my supervisors assisted me in assuring the coherence between my data and interpretations.

\subsection{Ethical Considerations}

Ethical considerations for a qualitative researcher involve the obligation to protect the privacy and interests of participants during data collection, analysis, and in reporting the findings (Merriam, 1998). In order to ensure that the interests of my participants were not adversely affected by taking part in this study, I abided by ethical conditions approved by the Victoria University of Wellington Faculty of Education Human Ethics Committee. Some of these conditions included: gaining the consent of each participant, assurance of confidentiality, and a means of sharing the findings with the participants.

The participant teachers signed a consent form prior to participation in this study. I provided an information letter that explained in detail the purpose of the study and what was expected from them as participants. The information letter and consent form explained that their identity would be protected by giving pseudonyms to them and their early childhood centres. In addition, the letter explained that all information would be kept confidential and would not be attributed to them when reporting the findings. The teachers were also told they would receive a copy of the transcripts so they could check for accuracy. I transcribed all interviews and sent them back to each participant.

When finished with data collection, I took small gifts to each early childhood centre as a form of appreciation to the supervisors and teachers for their collaboration and participation in my study. A summary of the findings of this 
study will be provided to each supervisor/head teacher, and teacher participants. The parents who are interested in the findings could access the summary through their child's centre.

\subsection{Limitations}

This study used a particular research paradigm, strategy and methods in order to answer the research question. Several authors, such as Guba and Lincoln (1994) and Patton (2002), claim that there is no best paradigm or methodological approach for a specific study. Thus, it is important to acknowledge the limitations that every study faces as a consequence of selecting a particular design. Some limitations of this study are discussed below.

A limitation of this study is the "breadth versus depth" identified by Patton (2002) that I chose for the design of my study. For the purposes of a qualitative research, having small samples enabled me to provide more depth and breadth of my cases than having chosen larger samples as in quantitative studies. However, with just four teacher participants in each country my findings cannot be generalized to all New Zealand and Honduran teachers. In addition, considering the qualitative design itself, as I selected a comparative case study design, the focus of my study was the comparison between New Zealand and Honduras. Rather than examining in detail teachers' beliefs and practices in each country, I chose to examine each country with less depth in order to provide insights about teachers' beliefs and practices regarding children's leadership from two contexts. The limitations of this study are further discussed in Chapter 9.

\subsection{Chapter Summary}

This chapter explained the selection of the research design of this study. Underpinned by a socio-constructivist paradigm, I interpreted the meaning the teachers in New Zealand and Honduras construct about children's leadership. By using a comparative-case study strategy I identified similarities and 
differences between the beliefs and practices of the teachers in each country. Following the aim of qualitative research methods to explore in depth the phenomenon of study, semi-structured interviews, observations, and documents were used as data collection techniques. Data was analysed by using thematic and cross-case analysis. The findings were compared with The Four Responsibilities framework. The framework was modified according to the findings of this study. This methodology enabled me to develop an understanding about how teachers in New Zealand and Honduras translate their beliefs about children's leadership into practice. 


\section{Chapter 4: Centre 1 - New Zealand}

\subsection{Chapter Overview}

This chapter outlines the findings from Centre 1 in New Zealand. First a description of the centre followed by a description of the activities carried out during a typical day is provided. Then the findings for the two teachers are presented.

The findings for each teacher are presented either in relation to the themes that emerged from the ideas they repeatedly mentioned throughout the interview, or represent an important idea in relation to the research question. In order to explain each theme, quotes from the teacher interviews are provided as are, when relevant, observation vignettes. At the end of each teacher account, a summary of their findings in relation to The Four Responsibilities framework (Tamati et al., 2008) is given. This framework suggests that (a) having responsibility means having designated authoritative roles; (b) taking responsibility means trying new things or having a go; and (c) sharing responsibility is about relationships (Refer to Table 2.1 for a complete description of the framework). As explained in Chapter 3, the framework was modified according to the findings of this study. For the New Zealand teachers, the modified framework includes two main categories: (a) having and taking responsibility (b) sharing responsibility. The findings of each teacher are summarized according to those two categories.

\subsection{Centre Description}

Centre 1 is a kindergarten located in a low socio-economic area in Wellington. It is a half day kindergarten as it has a morning session for the older children (4 year olds) and an afternoon session for the younger children (3 year olds). The session observed in this study was the 4 hour morning session. At the time of the study, there were 42 children enrolled in the morning session from which the majority were of New-Zealand European ethnicity. The kindergarten had five 
teachers of which one was the head teacher. Each day of the week four teachers were on the floor interacting directly with the children and one teacher was off the floor and not interacting with the children. This teacher was working at the staff's office on the children's portfolios ${ }^{10}$. The four teachers on the floor rotated each day so that two teachers were with the children outside, and two with the children inside. They also rotated tasks such as facilitating the end of session mat time. The ratio of teacher to children was 1:10.

On the morning of the observation, the different areas of learning such as family, art, construction, blocks, library, computer, music, science, and literacy were distributed inside the classroom space. There was also a large space where mat time took place, a room where the children placed their lunchboxes, a kitchen, bathrooms, and a staff office. Outside, there was a very spacious playground. It had a roofed space with a carpentry table and an art table. It also had a large open space with a sand pit, a slide, a play house version of Wharenui ${ }^{11}$, climbing equipment, and a large storage room with toys.

The morning session at Centre 1 mainly consisted of child-directed activities and three main routines guided by the teacher: morning mat time, morning tea, and end of session mat time. On a typical day, the children arrive at the kindergarten with their parents and play at the different areas of learning. The session starts with morning mat time where the teachers and children usually do an activity together, then children give their morning news, and finally they sing the Whare ${ }^{12}$ song together. After mat time the children free-play at the areas of learning or in the playground until morning tea. At morning tea, the teachers and children sit at the mat, bless the food and eat together. When the children finish eating they go back to free-play. Finally, there is a mat time at the end of the session where one teacher facilitates an activity and the rest of the teachers and children follow it.

The two teachers who volunteered to participate in this study were Erica and Frances. Erica has a Bachelor of Education in primary teaching and a

\footnotetext{
${ }^{10}$ The children's portfolios are a form of assessment.

${ }^{11} \mathrm{~A}$ Wharenui is a Māori meeting house.

${ }^{12}$ Whare means house.
} 
Postgraduate Diploma in early childhood. She has two years and nine months of experience in early childhood teaching. Frances has a Diploma of Teaching Early Childhood Education and has fifteen years of experience as an early childhood teacher.

4.2.1 Erica; "All children have some form of leadership...in their own skills, in their own interests, and talents."

Erica articulated her belief that all children have leadership potential. She stated,

Each child has leadership skills in different ways....you got the more insular child but somehow they might be really good at puzzles...it's not just those loud, opinionated children that are leaders...maybe it's not getting in front of the group like traditional kind of leadership.

Erica expressed her belief that all children can demonstrate some form of leadership by indicating in the interview three key beliefs regarding children's leadership; taking ownership, showing initiative, and sharing. She also practiced three techniques supporting her beliefs; being inclusive, being a facilitator and encouraging the children to work together. Each belief is explained below. The teaching practices are explained in relation to each belief. A further section identifies a key idea indicated by Erica regarding the documents Te Whāriki (New Zealand Ministry of Education, 1996) and Te Manawa (Wellington Kindergartens, n.d.) being a support for teachers at the centre to encourage children's leadership. The last section presents barriers suggested by Erica to encouraging leadership.

\section{Taking ownership}

When Erica was first asked in the interview 'What comes into your mind when you think about young children's leadership?' she said, "Taking ownership is a big thing; believing in what they are doing." Erica indicated that for her, taking ownership includes two aspects: children making decisions and sharing ideas. As for children making decisions she gave this example, 
Today one of the kids came up and said 'Erica can we do three blind jellyfish?' It's a game at mat time. I said 'oh yeah'...one week we had three days and did three blind jellyfish each day. So they're taking leadership there, the ownership of their learning.

The example above shows Erica's belief that children take ownership of their learning by deciding the activities they want to do. An indicator of her leadership belief of sharing ideas was when she stated, "Being able to share ideas is a form of leadership as they are taking on ownership." She also referred to the child who shares ideas when she said, "Like sharing news for example, not all kids like to do that. But if they're given the opportunity."

When Erica was asked in the interview 'what are the advantages of encouraging leadership in all children' she said,

If it is inclusive in all children, encouraged in the same way. But everybody has the opportunity to have a go such as sharing news. If they are interested it's fine, if not they got a lot more school life...but every day we have news.

Erica articulated that in practice she encourages children's leadership "by inclusive teaching." She saw this as, "Everyone is the same, valuing all ideas and opinions."

Further when asked if there are any disadvantages of encouraging leadership in all children Erica replied, "Too teacher-directedness I think it's not okay." Then she gave this example, "If a child is forced by a teacher, for example, to share news at mat time." During the observations, Erica was observed asking a girl, Lucy, if she would like to share a story she drew on her own,

Erica: What is your story about?

Lucy: It's about mermaids.

Erica: Are you okay if we see it at mat time?

Lucy: Yes

Erica: Ok, go put it over there.

During mat time, Lucy was observed sharing her story. This example reflected Erica's belief that children should be given equal opportunities to demonstrate leadership according to their interest; whether it is by sharing news in front of 
the group - like Lucy did - or playing by their own as evident in the following quote:

Like we've done amazing artwork together as a group...some children don't tend to do artwork, they'll rather [be] outside roaring around but leadership within their play and that's cool.

\section{Showing Initiative}

When Erica was asked in the interview what she thought about children's leadership she also said she thought about initiative. She described this as, "Either showing initiative in choosing an activity or in their games...even their interest, their ideas." She gave this example,

I did a Matariki ${ }^{13}$ display... and I was asking them 'I kind of need some stars for the wall'...one girl said 'I know, l'll do my hands' so she used her initiative and she traced around her hands...that was her showing leadership as how she would create stars.

In practice Erica said she encourages children's leadership by "being more as a facilitator." She saw this as, "Stepping back and observing, responding to their interests and observing their dispositions." Erica expanded on this and said "I try to be not too in their face." These examples suggest that by being a facilitator, Erica encourages children to demonstrate initiative through showing their own interests.

\section{Sharing}

Another belief about children's leadership Erica raised in the interview was sharing. She described this as:

Helping each other, working together, cause you've got that shared leadership...Problem solving as part of that.

When she was asked how she encourages children's leadership she said, "By encouraging them to work alongside each other." One observed example of this was when two girls were close to the art centre fighting for two feathers.

Erica: Excuse me. I have a purple feather and a pink one, what do we do? Sharing right? Which one do you want?

\footnotetext{
${ }^{13}$ Matariki celebrations occur in New Zealand to celebrate the Māori New Year.
} 
Eve: Purple

Erica: Which one do you want?

Natalie: Pink and purple

Erica: If she wants purple, which one can you have?

Natalie: Pink

(Each girl took one feather and continued playing. Erica left the centre and moments later, Natalie came to Erica).

Natalie: Excuse me. We swapped because she wanted that one.

Erica: Well done, that's a pretty good idea there.

This example illustrates Erica's belief of encouraging children to problem solve as a part of learning to work together.

\section{Te Whāriki and Te Manawa as a support for encouraging children's leadership}

Erica suggested a holistic view of the child enables teachers to see some form of leadership in every child. She said, "Each child is unique and they got various strengths and interests. Like a holistic approach to the child not just what you see there." She indicated that this holistic view is facilitated by communicating with the parents, "Actually talking to mum and dad you get more of a view." When Erica was asked how the early childhood curriculum encourages children's leadership, she explained that it enables teachers to see the child holistically by fostering communication between parents and teachers,

Te Whāriki has a holistic approach to the child and is very family focused...Communication with the parents is very important...I mean kids are quite often different with their parents at home.

Moreover Erica explained that with the new document they use at the kindergarten, Te Manawa (Wellington Kindergartens, n.d.), the teachers at the centre now look to get parental involvement through the profile books,

With this document the way we do our profile books now, instead of us going 'welcome to kindergarten', we give the book to the parents and they do the introductory page first. They draw pictures, put photos. It's been a great way to get that family involvement cause we only see the children a snippet. 
Te Manawa, Criteria for Curriculum Implementation, is a document underpinned by Te Whāriki (New Zealand Ministry of Education, 1996) and supported by the Ministry of Education's Assessment framework for early childhood learning, Kei Tua O te Pae (New Zealand Ministry of Education, 2009). The document was produced by the Wellington Kindergarten Association to support teachers on implementing the curriculum and documenting children's learning.

When Erica was asked how the centre supported her to encourage leadership, she replied by explaining Te Manawa (Wellington Kindergartens, n.d.),

With Te Manawa there is a real focus of children taking ownership of their learning. How we now set the resources for the children to choose. I think not setting up the art table, that's made a huge change.

This statement indicates that for Erica, Te Manawa is also a useful guide to provide an environment where children are encouraged to make decisions.

\section{Barriers to encouraging leadership}

When Erica was asked 'what are some barriers for developing a child's leadership' she indicated two main teaching practices. The first barrier she suggested is "teacher-directedness." She explained this as, "Too much teacherdirectedness; teacher's ideas imposed on children." This was an example she gave,

A child was making an airplane, a house, and runway at the carpentry table. And I said 'That looks like a control tower. Oh no, what did I say!' Like putting my idea, I was devastated. I honestly try not to. You ask open questions to get them thinking what they're up to. Then he was telling everybody 'look at my control tower'.

The second barrier she gave is "not inclusive." She explained this as, "I think each child can be included."

\section{Summary of Erica's beliefs and practices and relationship to leadership framework}

Erica's belief and practice about taking ownership is related to having and taking responsibility. According to Erica, taking ownership suggests that young leaders make decisions or share ideas. Making decisions is understood as 
children being decision-makers and sharing ideas is understood as having a go (Tamati et al., 2008). When deciding to have a go at an activity, children also have designated positions of responsibility (Tamati et al., 2008). Erica's belief and practice around initiative is understood as taking responsibility since young leaders try new things by showing their interests (Tamati et al., 2008). The concept of sharing, suggested by Erica, corresponds to sharing responsibility as young leaders engage with others (Tamati et al., 2008). Te Whāriki (New Zealand Ministry of Education, 1996) and Te Manawa (Wellington Kindergartens, n.d.) are thought by Erica as key documents that support teachers at the centre to encourage children to have, take and share responsibility, while teacher directedness and not being inclusive are thought as barriers.

\subsubsection{Frances; "Letting them make their own decisions."}

Frances articulated her belief that all children have leadership potential; however, she was not going to force a child into taking a leadership role. She stated,

All children have leadership potential, but in my opinion, I'm not going to push a child into being a leader if they don't want to do it. I go with the children's interest. If they are showing interest in the leadership roles then I will support it. But if there is a child whose quite shy and don't really want to be pushed into that leadership role then I would not push them.

Frances' belief regarding children demonstrating leadership by deliberately taking a leadership role is explained below. Her practice of supporting young leaders in taking such a role is presented in relation to her belief. Frances' belief that teachers should enable children to lead their play is then presented, followed by a key idea indicated by Frances about routines at the kindergarten being a barrier for children's leadership.

\section{Taking a leadership role}

When Frances was asked in the interview 'what are some indicators of a child demonstrating leadership' she replied, 
I see it quite a lot at the family corner, there might be five or six children in there, and one person is taking the lead...you often hear them telling you what to do.

Later Frances emphasized being articulate is a key characteristic of young leaders,

They generally verbalize what they want to do. They are articulate, they tell you their ideas.

Being articulate was further emphasized when she commented, "To me leadership is mainly communicating what they want, what they need." Frances gave the example of a group of girls, who had made an art show,

So one little girl decided she wanted to stick the pictures all around like an exhibit. And she was telling her friends what to do and letting them share their ideas. But you can clearly see who the main person is. The other kids might be sellotaping, but the leader is the one that's expressing all the ideas.

This statement suggests Frances' beliefs about young leaders being the children who take leadership roles through articulating their ideas.

In the interview Frances also indicated "being confident" and "creative and innovative" as characteristics of young leaders. She described creative and innovative as, "Leaders think of new ways to do things." During the observations two girls, Valerie and Emma, showed their ideas to Frances.

(After decorating a painting at the art centre, the girls approached Frances).

Frances: Oh, I like the sprinkles.

Valerie: It's the chicken pox.

Frances: (Laughs) it's the chickenpox.

(A while later the girls decorated a toy wooden house. Valerie ran up to Frances).

Valerie: Frances, come and see our houses!

Frances: Oh, it's lovely. That's a good idea.

The example above can be used to illustrate Frances' belief regarding young leaders' confidence and creativity.

In practice Frances encourages children's leadership by providing opportunities for them to articulate their ideas. When she was asked in the interview how she 
encourages children's leadership she replied, "Just giving the children lots of opportunities to contribute their ideas to the programme." She also sees $T e$ Whāriki (New Zealand Ministry of Education, 1996) as supporting leadership through three of its strands: communication, belonging, and contribution.

Mainly I think communication because we teach them the language to use so they can articulate what they want it to happen in kindergarten...also communicating with the parents for me is huge for the curriculum.

Regarding belonging and contribution, Frances stated, "They [the children] feel that they belong here, that we listen to their ideas, like they contribute to the programme."

When Frances was asked in the interview if she thought there are any disadvantages for encouraging leadership in all children she replied, "The disadvantage I think is pressure from the teacher... if a child is forced to take a leadership role or taking the lead if they don't want to." It appears that Frances uses the terms taking a leadership role, taking charge and taking the lead interchangeably to describe young leaders. On the other hand she indicated it would be a disadvantage not giving children the opportunity to play a leadership role,

On the other end of the spectrum if the children don't get the opportunity to play those leadership roles, like taking mat time, I think that could be quite tricky because they don't get to voice their opinion.

Frances further elaborated her belief of providing opportunities for children to take charge and that it is up to them to take the opportunity. She gave this example,

We don't actually really get them to take charge formally, it's free play so they do it...if they want to it's okay. If they don't want to that's okay as well, so it's sort of empowering them to make their own choices, therefore they start leading.

The examples above reflect Frances' belief about children deciding on taking a leadership role rather than being a role given by the teachers.

\section{Leading their play}

When Frances was asked in the interview what she thought about children's leadership she replied, 
I think it's giving children the opportunity to direct their own play. To make decisions about where they play, what materials they use, who is involved in their play.

This statement suggests that, for Frances, when leading their play children make decisions about the activities they do and resources they play with. Frances indicated she encourages children's leadership by letting them lead their own play. "My role is just to support and extend children's leadership...step back and let them lead their own play."

Frances articulated the environment at the kindergarten provides a great example of encouraging leadership.

Our environment is set up now so that we don't set up the tables. And I

think that's a great example of encouraging leadership in this kindergarten because they [the children] make decisions of what they want to do...they lead their play here.

Frances further explained that with the implementation of Te Manawa (Wellington Kindergartens, n.d.), they changed the environment at the kindergarten in order to provide more choice to the children.

Before what we would do was put a painting activity on the table, it was our choice. Now with Te Manawa we just provide as much stuff as we can possibly fit in the kindergarten and let them [the children] decide....they are choosing what they want to do rather than us deciding for them.

The examples above reflect Frances' idea about the significance of providing an environment where the children can make decisions in order to demonstrate leadership by leading their own play.

\section{Barriers to encouraging leadership}

In the interview Frances repeatedly mentioned her disagreement with the routines at the kindergarten. She emphasized three main routines they have at the kindergarten as barriers for children's leadership: decorating birthday hats, morning tea, and mat times. The specific way children have to decorate their party hats on their birthday is thought by Frances to be a teacher-directed activity. She explained,

My philosophy is that children are always evolving. You got to go with what they're interested in. I think that with those particular routines you are 
not catering for individual children. You are catering just for what you want

to happen or it's a teacher-directed activity.

One example of this routine was observed at the art centre when Frances helped a boy cut and write number five on his birthday hat.

A second routine Frances identified as a barrier is morning tea time routine as children are stopped from playing in order to eat at a specific time. Frances said,

The other one would be morning tea. I see it as a barrier because we have to stop playing for morning tea.

The third barrier Frances identified is the routine of mat times,

We have a specific system. You got to do three songs, news, and the

Whare song. So it's quite 'this, this, this'...letting the children have more responsibility can be a bit difficult with routines.

\section{Summary of Frances' beliefs and practices and relationship to leadership framework}

Frances' beliefs and practices about children's leadership are related to having and taking responsibility as children take a leadership role and lead their play. Taking a leadership role is understood as having a go and leading their play is taken as children being decision-makers (Tamati et al., 2008). When deciding to take a leadership role children also have designated roles of responsibility (Tamati et al., 2008). For Frances, a number of the routines at the kindergarten were seen as significant barriers for children to have and take responsibility.

\subsection{Chapter summary}

Erica's and Frances' beliefs and practices about children's leadership relate to taking responsibility since young leaders can make decisions/lead their play, show initiative and take a leadership role. Both teachers believe that teachers should give children the opportunity to take a leadership role. When deciding to do so, the children also have roles of responsibility. Erica and Frances identified Te Manawa (Wellington Kindergartens, n.d.) as a useful document to support teachers in giving choices to the children. Erica also described her belief and practice regarding the concept of sharing. Frances highlighted the routines at the kindergarten as main barriers for encouraging children to demonstrate 
leadership. Erica, on the contrary, focused on describing the supportive environment at the kindergarten and mentioned two teaching practices as possible barriers for encouraging leadership. Both teachers indicated teacherdirectedness as a barrier. 


\section{Chapter 5: Centre 2 - New Zealand}

\subsection{Chapter Overview}

This chapter outlines the findings from Centre 2 from New Zealand. A description of the centre is first provided followed by the activities carried out on a typical day at the centre. The findings for the two teachers are presented as in chapter 4.

\subsection{Centre Description}

Centre 2 is located in a low socio-economic area in Wellington. It is a half day kindergarten as it has a morning session for the older children (four year olds) and an afternoon session for the younger children (three year olds). The session observed in this study was the four hour morning session. At the time of the study, there were 40 children enrolled at the morning session. It was a very multicultural kindergarten with children from different ethnicities including New Zealand European, Māori, South American, and different Asian countries. The kindergarten had four teachers including the head teacher. The four teachers worked with the children in groups of two: during the first two hours of the session, two teachers were with the children outside, and two with the children inside. For the last two hours the two teachers who were outside went inside, and the two teachers who were inside went outside. The ratio of teacher to children was 1:10. Therefore, only when there were less than 30 children at the kindergarten did one of the four teachers work at the staff office on the children's portfolios.

The space inside the kindergarten was divided in three sections. The entrance was at the middle section, with the art and literacy area and a door for entrance to the staff room. In the left section, there were benches for the children to place their lunchboxes, and the bathroom and kitchen. In the right section, there was a big space for mat time, the music area and the area of puzzles and blocks. Next to the mat was a small section only for the family corner. The outside 
playground contained a roofed area with cushions at the floor and a rope hung from the roof for the children to swing; there were also tables where the children sometimes played puzzles or ate. The playground also had an unroofed area which had a small sandpit and a large area with wooden climbing equipment.

The session at Centre 2 mainly consists of child-directed activities and an end of session mat time guided by the teacher. In a typical day, the children arrive at the kindergarten with their parents and free-play at the different areas of learning or in the playground until it is time for mat time - which takes place at the end of session. The centre has a rolling morning tea so there is no specific time for tea; each child decides at what time he/she wants to eat. Finally there is a mat time at the end of session where one of the teachers facilitates an activity and the other three teachers and children follow it.

The two teachers who volunteered to participate in this study were Grace and Jill. Grace has a Bachelor of Teaching, Major in Early Childhood Education. She has one year of experience as an early childhood teacher. Jill has a Diploma of Teaching and 28 years of experience as an early childhood teacher.

\subsubsection{Grace; "Being aware of consequences and other people."}

Grace articulated her belief that all children have leadership potential. She said, I think all children can, or do have leadership potential. But perhaps they haven't got that message from the adults who care for them...So with the role modelling they get from home and if they have security and they get encouragement to take turns and to share and they are articulate, then they have leadership potential.

Regarding children's leadership, Grace indicated three key beliefs; being secure, taking a leadership role, and being aware of others. She incorporated; encouraging confidence and capability, empowerment, and encouraging children to take turns and share, into her practice to support her beliefs. Each belief is explained below. The three teaching practices are explained in relation to each belief. The last section describes the barriers to encouraging leadership indicated by Grace. 


\section{Taking a leadership role}

When Grace was asked in the interview to give examples of children's leadership she said,

They are making decisions and taking responsibility. Telling other when things are happening.

Telling others when things are happening suggests Grace's belief of children taking a leadership role. Later in the interview she gave an example,

Children might take the lead. For example, "I am the mum and you are the cat'.

Grace identified being able to articulate their needs as a tool for leadership.

I think being able to articulate is a tool, is a part of leadership. It's using words not fists or negative actions such as sulking, whining... be able to articulate to the adult if they are needing to have things sorted. That helps children feel stronger and help them get their message across to others.

Grace suggested she encourages children to be articulate by empowering them to take a leadership role,

For children who are not articulate or don't put their hands up, especially at group times, those are the times for teachers to empower that child to take charge as to give them the opportunity.

She gave the example of a time at the kindergarten where each child used to get a turn in choosing their peers to wash their hands for lunch,

I can recall a four year old child who was quite happy to let other people make decisions... This child was chosen...he just 'grew' because he had been empowered to take charge...they were waiting for him to give commands... he said 'They did it! I told them go and they did!'

This example reflects Grace's belief and practice of empowering children to take a leadership role. She argued,

They might not like it, some might be born to it, some might come to it later, but I think they need to be given the opportunity... and it's the opportunities that the adults give to the children that enable them to experience leadership.

One observed example of Grace empowering the children was when she told Charlie to help Vera climb a tree at the playground. 
(Vera told Jane she was going to climb the tree).

Grace: Ask Charlie, he is the expert.

(Jane approached Charlie who was close to the tree).

Grace: Tell Vera what to do.

Vera: What do we do Charlie?

Charlie: Okay, we can go up that tree.

Vera: You can go up and then?

Charlie: This is a good way up (Charlie started climbing showing Vera how to do it).

In this example Grace is empowering and enabling Charlie to take a leadership role by saying "Tell Vera what to do." This example also shows that Grace is encouraging Charlie's confidence and capability and also encouraging the children to share; these two aspects will be described on the sections below.

Grace elaborated on her belief about empowering children for leadership when she was asked in the interview 'what are the advantages of encouraging leadership in all children' and she replied, "They will get the ability to make decisions and to give commands." She further argued,

If all children have a go in being a leader, then even though they may not like it or not be good at it, they will understand what it feels like and they will have empathy for leaders.

\section{Being secure}

Grace also indicated her belief regarding children's leadership as that of children being secure. She suggested that for her, being secure involves two aspects: being secure in their environment and being secure within themselves. Grace's belief of being secure in their environment suggests that children feel secure through an understanding and knowledge of the routines and people around them. An example of this view was when asked in the interview her belief about children's leadership and Grace said,

It's about children being sure of their security. So they know what the

routines are and they know the adults around them.

Being secure in their environment was further evident when Grace explained it as an indicator of children's leadership, 
Rather than being concerned about not being fed or not knowing who is going to collect them and not having security at home. So if they got all that, then they have all the foundations there, so they're ready to take on looking after other people.

An indicator of children being secure within themselves was when Grace commented,

When children are confident and capable they feel secure in themselves.

When they are secure in themselves they are able to articulate such as 'no, it's so and so's turn', and not be so concerned with themselves.

This statement reflects Grace's belief that children demonstrate being secure within themselves by feeling confident and capable to articulate and help others.

Grace explained that teachers can encourage children's confidence and capability.

We often say to children use your words... take a deep breath tell me again; with that sort of encouragement you are able to build confidence and capability. In doing that they are secure and they might see that happening for somebody else and be able to encourage others.

In the example observed of Charlie showing Vera how to climb the tree, one possible interpretation could be that Grace encouraged Charlie to feel confident and capable about climbing the tree and sharing his expertise with Vera.

\section{Being aware of others}

When Grace was asked in the interview her thoughts about children's leadership she replied,

When children look at other children or to other children or consider other children, listening to other children .....being aware of others.

Then Grace was asked to give some indicators of children's leadership and said, "I think being aware of other people." She gave this example, "Some children are very thoughtful about taking turns." Grace elaborated her belief about being aware of others when explaining the advantages of encouraging leadership in all children,

If they have had turns then it is shared leadership and I think communities would be stronger and more capable. It's not about me being the boss; it's about my turn now- your turn tomorrow and we share. I think teamwork. 
When Grace was asked in the interview how she encouraged children's leadership she replied, "We are very strong on taking turns, sharing and caring for others." The following conversation between Charlie and Vera was observed while Charlie was climbing the tree:

Vera: It's my turn. You got up by yourself, l'll go up.

Charlie: Watch me, this is how you do it.

Vera: I can't go up the tree when you and me...you can come down and me up (Charlie started coming down).

Charlie: Down, down. Now you know what to do.

This example reflects that Charlie and Vera are taking turns to climb the tree; sharing by listening to each other; and also caring for each other. Grace might have encouraged them in previous engagements to share and be aware of each other.

\section{Barriers to encouraging leadership}

When Grace was asked in the interview 'what are some barriers for encouraging children's leadership' she replied the realities of routines,

The realities of routines, just the constraints of life, really. Maybe time, maybe the program, maybe interactions, all these things can take away from the teaching/learning moment.

Grace went on highlighting the short length of the session as a particular barrier to interact more with the children and see leadership opportunities,

I think the short length of the session to be able to see opportunities for leadership. To be able to follow and monitor behaviour ... If you got more time with the children, you got more time for interaction.

Grace further explained the importance of the interaction between teachers and children in order to promote leadership,

I consider the quality of relationships and interactions is at the core of a teacher's practice. I think the length of the session time would make a difference to promoting leadership in children.

\section{Summary of Grace's beliefs and practices and relationship to leadership framework}

Grace's belief and practice regarding young leaders is related to having and taking responsibility. According to Grace, young leaders demonstrate leadership 
by taking leadership roles and being secure. Taking leadership roles is understood as having a go. Being secure is taken as children having the confidence and capability to take up the challenges (Tamati et al., 2008). When taking a leadership role children are empowered to have designated roles of responsibility (Tamati et al., 2008). A main belief and practice around young leaders mentioned by Grace is being aware of others, which corresponds to the concept of sharing responsibility since young leaders share and interact with others (Tamati et al., 2008). For Grace, the short length of the session could be a barrier to encourage children to demonstrate leadership.

5.2.2 Jill; "The children that inspire others to join an activity."

Jill articulated her belief that all children have leadership potential. She said,

I think I tend to agree with it. I don't see why some of those skills that leaders have we couldn't help lots of children have them .... I think we should be able to help children get some of those leadership skills.

Jill indicated two key beliefs regarding children's leadership; taking a leadership role through organizing and influencing other peers, and being aware of others. Her teaching practice supported her beliefs by encouraging children to organize, to influence and interact with each other. Each belief is explained below. The teaching practices are described in relation to each belief. A further section identifies a key idea indicated by Jill about play-based curriculum as a catalyst for children's leadership. The last section suggests a barrier mentioned by Jill to encouraging leadership.

\section{Taking a leadership role}

When Jill was asked in the interview what she thought about children's leadership, she said, "They are the ones who organize games that other people are attracted to." She gave this example,

I taught this boy who knew about barbecues. So in the playground he set

up barbecues... before we knew, there were all these people around him.

Jill further elaborated her belief about being the organizer when she was asked for indicators of children's leadership and she replied, "They have ideas and they are articulate." She gave this example, "Leaders say 'you can do this' 
...they organize the role others play." This statement indicates Jill's belief that having ideas and being able to articulate those ideas enables children to take a leadership role through organizing a game. During the observations, a group of children were observed marching in line at the playground. Each child had an elephant mask on their face and one girl, Amy, was in front of the line telling the rest of the children,

Amy: Elephants jump, stump, stop.

(The children went inside the kindergarten marching and lined up at the mat).

Amy: Inside, outside. No, it's your turn.

This example can be seen as Amy taking a leadership role through organizing the rest of the children in the game.

In the interview Jill stated that, besides the teachers' practice, the family environment also influences leadership in children. She said,

I think it's not just the teachers. I think is their whole life experiences....I

think the children that are really good leaders have already come with

those attributes from home.

Jill went on explaining that teachers can also help children develop leadership skills.

There are other children that haven't had those experiences, but I think

they could get those skills...we can help them with language or

understanding.

She gave this example, "By using encouraging comments...Last week somebody did this puzzle work and we said 'high 5."

In the interview Jill also indicated her belief that young leaders take a leadership role through "influencing others" to join in their play. When Jill was asked in the interview her beliefs about children's leadership she replied,

They are the children who influence others to follow them by joining in their play or changing their play to doing something else.

She gave the example of the boy organizing a barbecue. "Somewhere along his game, there were all these people hooked up in his game." Jill further referred to the children who influence others when she was asked 'what are the advantages of encouraging leadership in all children' and gave this example, 
If a child is wanting to play a game, it's like they have to have the leadership skills to hook everybody in. If they can't, it means they are still learning those skills.

Jill articulated that teachers can encourage children's ability to influence and organize others.

Communication, managing, and inspiring people, are all skills that you can learn.... don't see why we couldn't help lots of children to have them.

\section{Being considerate of others}

When Jill was asked to give examples of children's leadership, she gave the example of three boys playing rocket ships,

I do remember one incident a girl wanted to join in and two of the boys said 'girls can't join'. But one of the boys was different from the others, he actually gave his place to the girl that wanted to join in. I thought that was really 'including kind' of play.

Jill explained that the boy who included others was a better leader than the other boys,

The game was getting other people interested in their game. So I thought the other two boys were the leaders, but this boy was a better leader because he included and the game carried on peacefully.

When Jill was asked how she encourages children's leadership, she replied, "Me as a teacher, I think I probably focus on relationships." She gave these examples, "Encouraging empathy with each other, and helping and getting along with others." One observed example of this were three girls, Debbie, Valerie and Rita, rolling on some cushions in the playground. Valerie and Rita approached Jill to tell her something about Debbie,

Jill: Debbie you had a turn, it's Rita's turn now, it's turn taking.

(Valerie and Rita went back to Debbie and all made a line to have a

turn to roll at the cushions. Jill watched them and said)

Jill: Good sharing Debbie.

The example above illustrates how Jill encouraged the girls to get along with each other. 


\section{Play-based curriculum as a catalyst for children's leadership}

In the interview, Jill repeatedly referred to pretend play, specifically, the playbased curriculum suggested in Te Whāriki (New Zealand Ministry of Education, 1996) as encouraging leadership attributes. When she was asked 'in what ways the early childhood curriculum supports children's leadership' she responded,

The play-based curriculum allows children lots of interactions...I think because they're free to mix in and out of groups, I think that allows leadership qualities.

Jill also referred to the play-based curriculum when asked how the centre supported her in encouraging children's leadership,

We don't go from table top to table top activities. We let children make choices and decisions...I think it's just the curriculum and the way we do things in New Zealand.

At the end of the interview Jill further commented on this idea,

When they organize mums and dads games... because there are no adults there, and they're setting up, getting the props ....I think that's where those leadership qualities develop.

During the observations, a group of boys were observed playing at the art centre. They were getting small cardboard boxes from a large box which was placed against a wall close to the art centre. The boys were taping the boxes together. Jill approached the art centre and one of the boys, Bobby, told Jill,

Bobby: Look at my machine!

Jill: A machine! Good idea.

After a while, 5 more boys joined the boys who were initially making the 'machines.' This example shows that Bobby and the other boys, who started the game, demonstrated their leadership qualities of inspiring others to join their play. It also reflects that by having the choice to decide what they want to play and the resources that they want to play with, Bobby demonstrated his leadership attributes by developing the idea of creating a machine out of cardboard boxes.

\section{Barriers to encouraging leadership}

Overall, Jill felt the kindergarten had a positive environment to encourage children to assure their leadership qualities. When she was asked in the 
interview for barriers to encourage children's leadership she solely mentioned teacher-student ratios as a barrier to have more time to work with the children, I just think the number of our ratios is too high. Because sometimes you are working with this person and you can't see it through and you're pulled away because somebody else got hurt or whatever. It would be good if maybe as teachers we didn't have to do the domestics.

\section{Summary of Jill's beliefs and practices and relationship to leadership framework}

Jill's belief and practice regarding young leaders as taking a leadership role through organizing and influencing others is related to having and taking responsibility. Organizing others is taken as trying new things and influencing others is understood as taking risks (Tamati et al., 2008). When taking responsibility children also have designated roles of responsibility in games (Tamati et al., 2008). Being considerate of others, according to Jill's belief and practice, corresponds to sharing responsibility as children share power and engage with others (Tamati et al., 2008). The early childhood play-based curriculum is thought by Jill as a significant facilitator to encourage children to have, take and share responsibility, while she only mentioned teacher-student ratios as a barrier.

\subsection{Chapter Summary}

Grace and Jill focused their beliefs and practice about children's leadership on sharing responsibility as they highlighted being aware or considerate of others as a key feature of young leaders. Grace believes that being secure enables children to take leadership roles. When taking leadership roles, as highlighted by Grace, young leaders seem to be aware of other peers. Similarly, Jill believes that young leaders take leadership roles by organizing and influencing others, but more importantly, they are considerate of others. Jill highlighted the play-based curriculum suggested in Te Whāriki (New Zealand Ministry of Education, 1996) allows teachers to encourage children to demonstrate leadership. Grace explained the realities of routines as barriers to encouraging leadership, while Jill mentioned teacher-student ratios as barrier. 


\section{Chapter 6: Centre 3 - Honduras}

\subsection{Chapter Overview}

This chapter outlines the findings from Centre 3 from Honduras. A description of the centre is provided before the activities carried out at a typical day at the centre are described. Then the findings for the two teachers are presented.

As in Chapters 4 and 5, the findings for each teacher are presented in relation to the themes that emerged from the ideas they repeatedly mentioned throughout the interview, or represent an important idea in relation to the research question. In order to explain each theme, quotes from the teacher interviews are provided as are, when relevant, observation vignettes. At the end of each teacher account, a summary of their findings in relation to The Four Responsibilities framework (Tamati et al., 2008) is given. In contrast to the modified framework presented in previous chapters for the New Zealand teachers, the modified framework for the Honduran teachers includes one main category: (a) having and giving responsibility. Tamati et al. (2008) suggest that having responsibility means having designated roles of responsibility. In this study, giving responsibility is understood as allocating opportunities and assigning tasks. The findings of each teacher are summarized according to the category of having and giving responsibility.

\subsection{Centre Description}

Centre 3 is a pre-school centre located in a low socio-economic area in Tegucigalpa. The centre is a half day centre as it has a morning and afternoon session. Each session is four hours long. The centre offered education for children between four and six years of age; Kindergarten (4 year olds) and Preparatoria (5 year olds). It had three Kindergarten groups of children; groups A, B, and C. Groups A and B attended the morning session and group C attended the afternoon session. The groups observed in this study were $A$ and 
B. The centre had three Kindergarten teachers. There was one teacher for each group of children and no teacher aides.

The children from groups $A$ and $B$ were taught inside a classroom which was divided into two sections by a removable wall. Each group was taught in a different section of the classroom. There was only one entrance to both classes via the section of group A. The children's tables and teacher's desk were distributed in the middle of the classrooms and between 6 to 11 children sat at each table. The centres of learning were distributed against the walls of each class. At the front of the classrooms was a whiteboard from where the teachers stood in order to teach. Occasionally the two groups merged in one section of the room and were taught by one teacher. In this way, the teachers worked together sharing their roles.

The session at Centre 3 mainly consists of teacher-directed activities and one hour of play-work time directed by the children. After the supervisor opens the gate of the centre, the children walk to their classroom with their teacher. They sit at their tables and the session begins with 'initial activities' - the teachers direct a morning prayer and sing greeting songs with the children. During the session the teachers mainly direct the children on completing the activities of their two workbooks - they have one for "colouring" (subject matter content) and one for "activities" (fine motor skills). The session also has one hour of playwork time where the children play with the toys from the different centres of learning which include: music, construction, dramatization and communication. Finally there is a half hour 'rest time period,' where the children eat and go to the playground afterwards.

The teachers from groups $A$ and $B$ volunteered as participants in this study. Ana has a Bachelor's Degree in teaching English and is a primary school teacher. She has nine years of experience in teaching pre-school education. Blanca is currently studying a Bachelor in Educational Administration. She has ten years of experience in teaching pre-school education. At the time of the study, there were 26 children enrolled in each kindergarten section. Thus, the ratio of teacher to children for the participant teachers was 1:26. 
6.2.1 Ana; "The children capable of controlling the group."

Ana articulated her belief that all children could be leaders but she also thinks they are born with the ability or they have had a leadership influence at home. She stated,

I believe that all children could be leaders but I also think a child is born with innate abilities to lead.... They are also influenced by home factors.

The belief indicated by Ana regarding the young leaders being the children who take leadership roles through being independent and controlling is explained below. Ana's practice of assigning tasks to the young leaders is explained in relation to her belief. A further section describes the barriers to encouraging leadership suggested by Ana.

\section{Taking a leadership role}

When Ana was asked in the interview what she thought about children's leadership she said, "They are independent children." Later when asked "what are some indicators of a child being a leader she replied, "They are independent and have high self-esteem." She gave this example,

They have confidence in themselves, they are sure of what they do.

Sometimes other children tell them 'this is what you have to do'. But the leaders say 'no' because they are sure of what they have heard. Of course, they are independent. They don't need the teacher to be on top of them.

This statement reflects Ana's belief that young leaders are independent and have confidence in themselves.

A belief regarding children's leadership that Ana highlighted in the interview is being a controller. When she was asked in the interview her belief about children's leadership she also said, "They are children capable of controlling the group, either for good or for bad." She further mentioned this belief when she was asked to give indicators of children's leadership and said, "Is a controller." This was an example she gave,

At play time is when we observe the most, because there is a group of children that decide to go play to a certain centre of learning. But the child 
who we consider a leader says 'no' and takes the group to the centre where he wants to play.

This comment suggests that, for Ana, young leaders take a leadership role by controlling other peers.

Another belief regarding children's leadership Ana suggested in the interview is following instructions. When she was asked her belief about children's leadership she replied, "They are active children with the facility to follow instructions." She gave this example,

The crayons are placed on the middle of the table, the child who is considered a leader follows those instructions. Another child doesn't; he grabs them and takes them to his place... so that child goes and tells them to put them back because the teacher said so.

Ana went on to explain that children can follow instructions for good or for bad. When she was asked for some indicators of children's leadership she replied, "They follow instructions, sometimes for good and sometimes for bad." She gave the example of a child following instructions for "bad,"

I think this would not be very good but, when it is not time to play, that child induces the others to go play; to stop doing what they are doing in order to go play... This would be a 'negative influence' child.

This comment suggests that, for Ana, the child that follows instructions for "bad" influences other children negatively by inducing them to play when they are supposed to be doing something else. Ana further referred to the negative influence children when she commented,

We have had leaders with negative influence, we've had that frequently.

What happens is that we have to interfere in order to control them because they disorganize the group completely.

Ana indicated she encourages leadership by enabling the positive influence children to take a leadership role through controlling the group. When asked in the interview how she encourages children's leadership she replied,

By developing their independence. For example, when we observe that a child is very influential in the group we do it so he can do it in a good way, because he sometimes does it for bad... So we take that child so he can control his group. 
This statement indicates that Ana encourages leadership in the child who influences negatively for him to "control the group for good." Throughout the interview, Ana often used the pronouns 'he' or 'him' when referring to the 'negative influence' child. In addition, it appears that she uses the words controller and influential interchangeably to describe young leaders. During the interview, she gave the description of 'independent child' and 'controlling young leader' to the same child.

Later Ana gave a more detailed explanation of how she encourages children's leadership, "We do it mainly with discipline and the organization of materials." She gave this example,

We tell a child he is going to direct this group so that everybody is working, and they are the ones who inform us. Because it is hard. We are scattered in the classroom and sometimes I am working with a group and I leave him taking care of another group. We give them a certain type of authority to control a group.

The examples above suggest that Ana encourages children's leadership by assigning tasks to the influential child so he can "control the group for good" instead of doing it for "bad," and also to help her control a group. This practice will be discussed in Chapter 8. During the observations, the children were painting a picture from a page of their workbook. Ana was walking around the classroom helping the children paint their picture. She passed by one of the children's tables and told a boy, "You are going to tell me which children are talking and throwing papers at the floor." This example can be used to show that Ana assigned tasks to the boy so he could help her control that table.

When Ana was asked in the interview how the centre supported her to encourage children's leadership she replied,

When we have a child with negative influence, the office takes measures such as suspend him one day. She [the supervisor] talks to the parents and it is explained to the child that he is suspended for a day because he disorganizes the group.

This explanation possibly indicates that, for Ana, the centre supports her with the children who influence in a negative manner. 


\section{Barriers to encouraging leadership}

When Ana was asked in the interview 'what are some barriers for encouraging children's leadership' she mentioned the parents' lack of cooperation,

Well, sometimes the parents. We want to develop something in the child and the parents do not cooperate. We have a boy here who is very spoiled. If we tell him to make a line, no, he wants to go first. When it's time to work he doesn't do it. We spoke with his mother and she said that his father is like that.

Ana further mentioned discipline as a barrier which she also related to the parents,

Another thing is discipline which is also related with the education they have at home. If a child does whatever he wants at home, he wants to do the same thing at kindergarten.

The examples above reflect that, for Ana, parents' lack of cooperation by spoiling the children and not disciplining them at home is a barrier for the teachers at the kindergarten to encourage leadership.

\section{Summary of Ana's beliefs and practices and relationship to leadership framework}

Ana's belief regarding the young leader who takes a leadership role by being independent and controlling is related to having responsibility as children are enabled to have designated roles of responsibility (Tamati et al., 2008). Ana's practice is understood as giving responsibility as she assigns tasks to the independent and controlling child so he can control a group. Ana suggested parents as a main barrier to encourage children to have responsibility in a positive manner.

6.2.2 Blanca; "The way they cope when being among others."

Blanca articulated her belief that leadership potential is innate or is not demonstrated by some children. She stated,

I think that leadership is something innate of each person. And some of them [the children] might be leaders but they do not demonstrate it...sometimes they are timid. 
The belief indicated by Blanca of the young leader demonstrating leadership through having the willingness to take a leadership role in classroom activities is explained below. Her practice of allocating opportunities for children to participate is explained in relation to her belief. A practice highlighted by Blanca regarding integrating all children in classroom activities is then explained followed by what Blanca views as barriers to encouraging leadership.

\section{Taking a leadership role}

When Blanca was asked in the interview what she thought about children's leadership she gave the example of participative children,

They always want to be the first in everything, they like to participate in everything, when giving out, let's say a workbook, when we are giving out crayons.

Later when Blanca was asked to give some indicators of children's leadership she said, "They are participative." She gave this example,

I have a girl, for example, if we play music; she always wants to be at the front to be directing others.

This comment suggests Blanca sees highly participative children as often wanting to take a leadership role.

Blanca suggested the curriculum encourages the children to take leadership roles in games through the 'area of personal and social development.' When Blanca was asked how the early childhood programme encourages children's leadership, she replied,

In pre-school we work with three areas of learning. For me, the area of personal and social development is where the children demonstrate leadership. It has family and affective games... When we play, somebody has to come to the front. I believe the one that goes to the front is the leader.

When Blanca was asked 'what are the advantages of encouraging leadership in all children' she suggested that all children would have the opportunity to participate in activities.

I think that if I encourage leadership in all children, they would participate in any activity, inside as much as outside kindergarten. 
Later, when asked how she 'encourages children's leadership'; she suggested she allocates opportunities for children to participate in class.

I ask who wants to direct the prayer. When giving out workbooks there are some children that always know their classmates. When l'm teaching the class as well, and they are answering my questions or they are participating, they talk about the topic of the week.

During the observations, Blanca stood in front of the class to review the topic of the week, the plants, with the children. Blanca was asking questions about the topic and some children answered her questions or participated by talking about the topic. This example can be used to reflect Blanca's practice of allocating opportunities for the children to participate in class.

\section{Integration}

Blanca highlighted integration as a practice to give all children the opportunity to take a leadership role in teacher-directed activities. This belief was apparent when she was asked in the interview how she encourages children's leadership and she gave the example of when she sent children to the whiteboard to take charge of activities,

When I want them to participate at the whiteboard, I sit them all at their tables and then I send them one by one. I try to integrate them all.

During the observations, it was apparent that Blanca sent some children to the whiteboard to take charge in the activities she provided for them. However, she often taught her students and Ana's students at the same time, so it was observed that usually only a few of the children had the opportunity to take a leadership role.

When Blanca was asked how the centre supported her in encouraging children's leadership, she suggested by giving children the opportunity to participate in extra-curricular activities.

Generally in this kindergarten, where they give us the opportunity for the children to demonstrate their leadership is maybe when we make school assemblies, or when we go to activities outside kindergarten. For example, the parade of the environment is coming soon, then the science fair. 
Blanca went on explaining that usually only certain children are taken to those events. "But generally not all children are included. We only take up to 10 to 15 children from each classroom." Blanca suggested that all children should be given the opportunity, rather than only certain children,

I believe that it would be ideal to encourage leadership in all children. Not giving the opportunity only to a certain group, but include all the children.

This comment indicates Blanca's belief that all children should be given the opportunity to participate in activities.

\section{Barriers to encouraging leadership}

When Blanca was asked in the interview 'what are some barriers for encouraging children's leadership' she reiterated that all children should be given the opportunity to participate and get involved in classroom activities.

Sometimes the time of the session is an obstacle for not letting children participate and also not integrating them. That is why I try that maybe the child who did not participate one day does it the day after. I try to make it that not the same children participate, I look to integrate them all instead.

This statement shows that, for Blanca, the time of the session is an obstacle for encouraging children to participate in activities and to integrate them all in the activities.

\section{Summary of Blanca's beliefs and practices and relationship to leadership framework}

Blanca's belief about taking a leadership role through participating in classroom activities corresponds to having responsibility as children have designated roles of responsibility (Tamati et al., 2008). Blanca's practice is understood as giving responsibility since she allocates opportunities for children to participate in class. A practice highlighted by Blanca in order to encourage all children to have responsibility, is to integrate the children by giving them all the opportunity to take leadership roles. For Blanca, lack of time is a barrier to integrate all children and encourage them to participate. 


\subsection{Chapter Summary}

Ana's and Blanca's beliefs about young leaders relate to having responsibility as children take a leadership role through being independent, controlling or participative. Both teachers' practice in order to encourage these beliefs is understood as giving responsibility since they assign tasks and allocate leadership opportunities to the children. A difference between both teachers is that Ana believes the children with leadership potential should be given more opportunities for leadership, while Blanca highlighted integrating all children in order to give them all opportunities for leadership. For Ana, the main barrier to encouraging children's leadership is parents, while Blanca indicated the lack of time as a barrier. 


\section{Chapter 7: Centre 4 - Honduras}

\subsection{Chapter Overview}

This chapter outlines the findings from Centre 4 from Honduras. A description of the centre is first provided followed by the activities carried out on a typical day at the centre. Then the findings for the two teachers are presented as in chapter 6.

\subsection{Centre Description}

Centre 4 is a pre-school centre located in a low socio-economic area in Tegucigalpa. The centre is a half day kindergarten as it has a morning and afternoon session. Each session lasts four hours long. The centre offered education for children between ages three and six: Pre-Kindergarten (three year olds); Kindergarten (four year olds); and Preparatoria (five year olds). There were three groups of Kindergarten children; groups A, B, and C. Groups A and $B$ attended the morning session and group $C$ attended the afternoon session. The groups observed in this study were $A$ and $C$. The centre had three Kindergarten teachers. There was one teacher for each group of children and no teacher aides.

Centre 4 had two floors. The office, Pre-Kindergarten, Preparatoria, music, English and library room were located on the bottom floor. The Kindergarten classrooms, one of Preparatoria and the computer room were located on the top floor. There were two classrooms for Kindergarten. The two classrooms for the groups that were part of this study had the children's tables and a teacher's desk distributed in the middle of the classroom. Between 6 to 12 children sat at each table. The centres of learning - such as construction, music, library, dramatization, science, art and cognitive development - were spread against the walls of each classroom. At the front of the classrooms was a whiteboard where the teachers stood in order to teach. 
The session at centre 4 mainly consists of teacher-directed activities and one hour of play-work time directed by the children. When the bell rings at the centre, the children walk to their classrooms with their parents. The session begins with 'initial activities' where the teacher and children say a prayer and sing greeting songs together. During the session, the children work on three main teacher-directed activities: a workbook of "skills" (which covers mostly subject matter content), worksheets to complement the workbook, and a fine motor skills notebook. In addition to the activities provided at the first Honduran centre, the children at this centre have music, library, computer and English class once a week. As at the other Honduran centre, the children also have one hour of play-work time and finally half an hour of 'rest time' every day.

Carol, the teacher from group A, and Diana, from group C, were the teachers who volunteered as participants in this study. Carol is a primary school teacher and is currently studying a degree in Psychology. She has 6 years of experience in teaching pre-school education. At the time of the study, there were 42 children enrolled at her classroom. Therefore, the ratio of teacherstudent in Carol's group was 1:42. Diana has a Bachelor in Pedagogy and has 32 years of experience in teaching pre-school education. At the time of the study, there were 38 children enrolled in her classroom. Thus, the ratio in Diana's group was 1:38.

\subsubsection{Carol; "They want to command others."}

Carol expressed her belief that all children have leadership potential. However, the environment of the children influences whether or not they can develop their ability. She stated,

For me all the children could be leaders. However, in our environment, for example, in our family environment, one cannot even say an opinion....and sometimes we [teachers] that we have the idea of how we can help the children, we don't do it.

Carol's belief regarding the young leaders taking a leadership role through being the main person in group activities and influencing others is described below. Carol's teaching practice of assigning tasks to the children is explained 
in relation to her belief. A further section describes parents and teachers as main barriers indicated by Carol to encouraging leadership.

\section{Taking a leadership role}

When Carol was asked for some indicators of children's leadership she said, "They want to be the main person." She gave the example when the children play of being the teacher. "The leaders want to be the teacher; they want to command others." This comment suggests Carol's belief that young leaders have the willingness to take leadership roles in games by being the "main person."

When Carol was asked 'what are the advantages of encouraging leadership in all children' she indicated that children will become secure enough to take a leadership role,

I believe that we develop their self-esteem. They become more secure children...Even we are scared of being leaders, of carrying out a certain task, because it has not been encouraged. So we have to encourage it from the seed. I believe it would be a change for everybody.

Further when asked 'are there any disadvantages to encourage leadership in all children' she replied giving too much authority to young leaders without providing guidance on how to use that authority,

For me the only disadvantage is giving too much authority to a young leader without guiding them not to use it to manipulate others.

When Carol was then asked how she encourages children's leadership she indicated she assigns tasks to the children, "Mainly by assigning them tasks." She gave these examples,

For example, when the children learn to recognize their peers' names, one child is assigned to give out the workbooks; also the crayons. Another thing one assigns is to direct the line, making sure everybody goes in order.

When asked how the curriculum encourages children's leadership, Carol indicated that it does so by giving responsibilities to the children so they can direct others, 
The curriculum encourages leadership by assigning responsibilities to the children through topics that teach the child to be responsible and direct activities.

The examples above reflect that, for Carol, leadership can be encouraged by assigning tasks to the children so they can take a leadership role through directing other peers. For Carol, by directing other peers children are enabled to be the "main person."

In the interview Carol highlighted her belief about the young leader being the child who takes a leadership role by influencing peers either positively or negatively. When she was asked in the interview what she thought about children's leadership she replied,

They are the children who influence the rest of their peers by making others follow their instructions, their behaviour. Some influence positively and others negatively with respect to leadership.

Regarding the children with positive influence she gave this example, "They impose that this is what is going to be done at play time and the children follow." As with the children with negative influence she said,

Maybe one as a teacher has given certain instructions and the children come and impose their own instructions. And sometimes the rest follow their instructions and not the teachers'.

The example above indicates that Carol sees children as 'negative influence' when they persuade others not to follow the teachers' instructions. Through the interview Carol often appeared to refer to the 'negative influence' child. She constantly used the pronouns 'he' and 'him' when illustrating her responses and, through body language and gestures, it was made clear that she was referring to the same child in her classroom. For example, when asked what are some indicators of children's leadership she replied,

He is not a shy child. He is not afraid of saying what he thinks. Because sometimes we as teachers want things to be done our way and maybe we are not right...So the easiest thing to do is take him to the other classroom.... accepted him because I don't like rejection.

During the observations, Carol commented about a boy, Kevin, who was not originally from her class, but the other teacher's classroom management techniques were not successful in keeping the boy focussed on what he needed 
to do. Therefore, she agreed that it was best he be transferred to her class. In the interview she also commented,

Right now the children are a little bit out of control for the same reason; because I transferred that child to my class. So the children get out of control. But he has improved a lot. And I assign him tasks. So that is a way to guide them. When children influence negatively, one guides them so they can change their behaviour.

This comment indicates that Carol sees Kevin as a 'negative influence' child as he persuades other children to misbehave. The comment above also suggests she assigns tasks to the 'negative influence' child so he can behave and influence positively. Carol gave further evidence of her practice of assigning tasks to the negative influence child when she explained in the interview,

For example, when one has a child who misbehaves, one assigns him tasks. That is one way of controlling him to make him feel important...Is a way to encourage him to behave. So one tells him 'you are going to help me but you have to be settled down; sited'.

One example observed was when Carol was in front of the classroom explaining the worksheet the children had to do. She asked Kevin to hold the worksheets and told him, "Hold this, but you need to stay here." Moments later, Carol told Kevin to give one worksheet to each child. This reflected that Carol assigned tasks to Kevin to encourage him to influence in a positive manner.

\section{Barriers to encouraging leadership}

When Carol was asked 'what are some barriers for encouraging children's leadership' she indicated the parents,

First of all the parents don't even listen to their children. They don't have time for them. Also the family environment...I have heard about teachers saying that a child misbehaves, and maybe they are children who have been abused at home.

Although Carol views parents as a barrier to encourage children's leadership, she saw teachers as a main barrier to encourage children to influence positively. She believes teachers can help children develop their self-esteem instead of destroying it, 
More than the parents; teachers are a barrier for children's leadership because they destroy their self-esteem by emphasizing their negative side...if we are saying things that are going to destroy their self-esteem and at home as well.

She gave an example of how teachers can encourage a child's self-esteem, "One way of giving more security to the child is by listening to him instead of rejecting him for misbehaving." Carol further argued,

For me to encourage leadership one does not have to look at the negative side of the children...but look at their positive side and the negative try to make it into positive.

This statement reflects that ideally, for Carol, children should influence positively and teachers can help children demonstrate a positive influence rather than emphasizing their negative side.

\section{Summary of Carol's beliefs and practices and relationship to leadership framework}

Carol's belief about young leaders taking a leadership role through being the main person and influencing others is related to having responsibility as children have designated roles of responsibility (Tamati et al., 2008). Carol's practice around the children who take a leadership role is understood as giving responsibility as children are assigned tasks in order to direct activities. For Carol, parents and teachers are barriers to encourage children to have responsibility in a positive manner.

7.2.2 Diana; "The one who stands out in a group."

Diana articulated her belief that children's leadership potential is innate or significantly influenced by the child's environment. She stated,

I believe that leadership is innate. It could be genetic, or above all, I

believe it has to do with the environment where the children develop. If the environment is positive there is going to be a positive leadership.

Diana indicated her belief regarding young leaders as the children who take a leadership role through standing out and collaborating with the teacher. Her belief is described below. Two teaching practices indicated by Diana, allocating opportunities and assigning tasks to the young leaders, are explained in relation 
to her belief. A further section describes a key idea indicated by Diana regarding parents being a main barrier for children's enactment of positive leadership.

\section{Taking a leadership role}

When Diana was asked what she thought about children's leadership she replied, "Mainly it is the child who stands out." Diana gave these examples,

When we make groups, he tries to organize groups. When we play, he has the voice of authority. When we go to school assemblies, he participates.

Then, when asked to give some indicators of children's leadership, she said, "They are the ones who participate more." These statements suggest Diana's belief that young leaders take a leadership role in group activities through standing out among peers.

Diana also indicated her belief that the young leader takes a leadership role through collaborating with the teacher. When she was asked in the interview what she thought about children's leadership she replied, "The one who helps the teacher, the one who collaborates in all the activities." She further indicated this belief when asked for indicators of children's leadership, "They are collaborative." Later, Diana was asked to explain what she meant by collaborative children. She gave this example,

For example, some children have problems holding the crayon, paste, and there are others who are already very clever at that. So then, one tells them "come and help me with this girl so she can hold the crayon properly".

This example reflects Diana's belief regarding young leaders taking a leadership role by collaborating with the teacher. During the observations, Diana asked the children to help her with different tasks as obvious in the following quotes:

(The children were at a school assembly and Diana told a girl)

Diana: Carla, go to the back so that you can be watching the group from the back.

(The children were playing clay and Diana said)

Diana: Valerie pick up the clay, Carla; the tablecloths. 
These examples suggest Diana's practice of assigning tasks to the young leaders. In the interview Diana also indicated allocating opportunities in her practice to encourage children's leadership. When asked how she encourages children's leadership she replied,

I ask the children: Who wants to explain the topic? All of them say 'me, me, me', so one chooses one child.

One observed example was while Diana was explaining the topic of the week, she asked one boy to come to the front and started asking him questions about the topic. Diana could have allocated opportunities for the boy to participate in class.

When Diana was asked how the centre supported her in encouraging leadership she replied,

The centre supports us in all the activities. For example, with the participation of the children inside and outside kindergarten.... The children stand out in Art, English.

This statement suggests that, for Ana, the centre supports her to encourage leadership by allocating opportunities for the children to participate and stand out in activities. Diana gave another example of the centres' support,

For example, when we go to museums, there are always two or three children who are going to keep order, taking care of the line, helping the teacher.

Diana further explained that these activities encourage children's leadership by enabling them to direct other peers. She said, "The children observe that they can direct and command others. They love to give commands."

\section{Barriers to encouraging leadership}

In the interview, Diana consistently spoke about parents being a barrier to encourage positive leadership in children. She emphasized three main barriers related to the student's parents: the parents' low-socio economic level, parents' negative influence and parents' lack of cooperation with the teachers.

When Diana was asked her belief regarding children's leadership she said, "Sometimes there could also be a negative leadership which one has to guide." 
She explained that the negative influence is due to the fact that the children at the kindergarten are from a low socio-economic level,

The problem of these children is that they are from low socio-economic level. They are children whose parents are drug addicts, alcoholics, prostitutes, so there is no positive leadership; no good guide at their house. So they come to demonstrate a regular leadership here.

When she was asked for the advantages of encouraging leadership in all children she replied, "When there are many leaders in a country, the country is rich at all levels." Further, when asked if there are any disadvantages of encouraging leadership in all children she referred to the negative influence of parents,

When leadership is negative, it is a disadvantage.....So the disadvantage is outside kindergarten. When the children go home after kindergarten they get lost again because their parents don't have that level to encourage leadership.

Diana referred again to the parents when asked how the early childhood curriculum encourages children's leadership,

The curriculum is made for children to be independent, to develop children who can cope anywhere with habits, with behaviour, with values. The problem for me is the parents. If the country doesn't work on family we are not doing anything.

Diana emphasized her belief about parents' bad influence when asked 'what are the barriers for encouraging children's leadership. She replied, "The most fundamental aspect is the parents. That is what l've always believed, if the family is doing badly, the child is doing badly." Diana also emphasized the parents' low socio-economic level, "Another thing is the low socio-economic level of the family." She further explained the lack of cooperation of the parents is also a barrier,

Another obstacle is the lack of cooperation from the parents. Without the parents no educational institution can operate.... We have school for parents where we give them workshops about particular topics, but the majority of the parents don't come. 
Summary of Diana's beliefs and practices and relationship to leadership framework

Diana's belief about young leaders taking a leadership role through standing out and collaborating with the teacher relates to having responsibility as children are enabled to have designated roles of responsibility (Tamati et al., 2008). Diana's practice is understood as giving responsibility since she assigns tasks and allocates opportunities to the children. Parents are considered by Diana as a significant barrier for children not to have positive responsibility.

\subsection{Chapter Summary}

Carol's and Diana's beliefs regarding young leaders is understood as children having responsibility, since young leaders take a leadership role through being a "main person," influencing others, standing out or collaborating with the teacher. Their practice regarding these beliefs is understood as giving responsibility since the teachers allocate opportunities and assign tasks to the children. For Carol, the parents are a barrier for encouraging children's positive influence. But above all, she believes that teachers are the main barrier by stressing the children's negative side. On the contrary, Diana believes that parents are the main barrier for children to demonstrate positive leadership. 


\section{Chapter 8: Cross-case analysis and discussion}

\subsection{Chapter Overview}

This chapter outlines a cross-case analysis and discussion of the New Zealand and Honduran findings. In order to answer the main research question, How do teachers of four-to-five year old children in New Zealand and Honduras translate their beliefs about children's leadership into practice, I considered it necessary to first present an analysis and discussion of the three sub-questions as the main research question is derived from the sub-questions. Therefore each sub-question is presented in a separate section followed by an analysis and description of the main research question. For each question, an intracountry comparison is presented in order to provide an understanding of each case, followed by an inter-country comparison, or cross-case analysis. The emergent themes from each country are explained with examples from the interview data and, when relevant, examples from the observations are presented. The themes are also discussed with links to relevant literature.

\subsection{Sub-question 1: How do teachers conceptualize children's leadership?}

This section answers the first sub-question. The table below indicates the main themes that emerged from the New Zealand and Honduran case data analysis about teachers' conceptualizations regarding children's leadership. It also states the common theme between both countries. 
Table 8.1: Teachers' conceptualizations regarding children's leadership

\begin{tabular}{|l|l|l|}
\hline \multicolumn{1}{|c|}{ New Zealand } & \multicolumn{1}{c|}{ Honduras } & $\begin{array}{c}\text { New Zealand + } \\
\text { Honduras }\end{array}$ \\
\hline $\begin{array}{l}\text { Taking a leadership } \\
\text { role }\end{array}$ & Taking a leadership role & Taking a leadership role \\
\hline Shared leadership & & \\
\hline Leading their learning & & \\
\hline
\end{tabular}

In the following sub-sections, the themes referred to in the table above are explained and discussed. In the cross-case analysis section, the main similarities and differences between New Zealand and Honduran teachers' beliefs are indicated. A cultural difference regarding leadership beliefs between both countries is discussed with links to the cultural dimension of "power distance.' Power distance is one of the four dimensions of culture, proposed by Hofstede (1980), mentioned in Chapter 2. The theory of 'power distance' was initially introduced by the Dutch social psychologist Mauk Mulder (Hofstede, 1980). Hofstede (1980, p. 98) defines 'power distance' as "the degree of inequality in power between a less powerful Individual (I) and a more powerful Other (O)." Power distance as a cultural dimension is defined in Section 8.2.3. Out of Hofstede's four cultural dimensions, the findings of this study appear to fit well with 'power distance.' Hence, the dimension is briefly explained and discussed in the cross-case analysis section.

\subsubsection{New Zealand}

The first belief regarding young leaders common among all of the New Zealand teacher interview findings is taking a leadership role. In the interview, the teachers described young leaders as confident and articulate children who deliberately take a leadership role in games or share ideas during mat time. For example, Frances said the young leader is "the person telling everybody what to do." Similarly, Jill said that young leaders are "the children that have ideas, they are the children that can articulate, that inspire and organize games." The four teachers interviewed suggested being confident, articulate, and creative as characteristics of children who take a leadership role. As mentioned in Chapter 
2, Fu et al. (1982) concluded that young leaders are communicative and Hatch (1990) suggested that they inspire play. Thus, the findings of the present study are consistent with previous studies that identified key characteristics of young leaders.

The second belief that emerged from the New Zealand teacher interview findings is their belief in the concept of shared leadership, which they saw as sharing and being aware of others. In the interview Erica, Grace, and Jill specifically suggested shared leadership. For example, Erica described it as children "working together" and Jill defined it as "including others." These findings are consistent with recent research on children's leadership such as Lee et al. (2005) and Shin et al. (2004) who defined children's leadership as the relationships that children have with other peers or teachers. Similarly, literature on adult leadership, such as Harris (2008), defines shared leadership as working as a team with other people. In addition, Grace's belief of young leaders as those who are "mindful of other children" fits well with the concept of sharing responsibility suggested by Tamati et al. (2008) as leaders listen to and assist others. Therefore, the findings of this study suggest that young children can also demonstrate a shared leadership by working with and assisting peers in an early childhood setting.

The third belief regarding children's leadership indicated by Erica and Frances is that children lead their own learning. In the interview, the two teachers explained that by leading their learning the children make decisions about the materials they play with and the activities they carry out through the session. For example, Frances described this concept as children "leading their play," and Erica described it as "taking ownership of their learning." During the observations, it was often observed that the children in both New Zealand centres lead their learning. However, it seems that it was highlighted more in the interview by the teachers from Centre 1 - Erica and Frances. One possible explanation could be that the teachers at Centre 1 particularly use the document Te Manawa (Wellington Kindergartens, n.d.) as a guide to encourage children to make decisions (refer to Section 4.2.1 for explanation). These findings correspond to those of Brownlee and Chak (2007) who found that the 
teachers in their study believed children's learning is active discovery. They reported that the teachers described that concept as children learning through play by actively operating the materials provided by the teachers. It appears, in the present study, that the teachers' belief about children leading their learning suggests that children can lead their own actions in an early childhood setting if teachers give them the opportunity.

\subsubsection{Honduras}

One theme that emerged from all the Honduran teacher interview findings is that young leaders are the powerful children who take a leadership role in the early childhood setting. For example, Ana highlighted that the young leader is capable of "controlling" other peers. Blanca stressed that the young leader "always wants to participate and direct others." Similarly, Carol said that when role-playing, "the young leaders imitate their parents and the voice of authority is demonstrated." These findings are aligned with Bennis' (2007) view of leadership. He suggested leadership as a tripod - a leader, follower and a shared goal. Drath et al. (2008) described this tripod as a power relationship between leaders and followers. It seems that the Honduran teachers believe that the children who take a leadership role demonstrate power over their peers.

A further belief indicated in the teacher interviews is that the child who takes a leadership role exerts power over peers by having a negative or positive influence on them. Ana, Carol, and Diana regarded young leaders as those who exert a positive or negative influence on peers. For example, Carol said, "The young leaders are the ones who influence positively or negatively" over their peers. The children who influence their peers to follow the teachers' instructions seem to be the children who influence positively. An example of this is Ana's statement, "The young leader has the ability to follow instructions." She also spoke about the young leader telling the other children to do as the teacher had said.

Ana then gave an example of a child who influenced negatively who, in this study, appeared to be the child who persuaded other peers not to follow the teachers' instructions, "When it is not time to play, that child induces the others 
to go play." These findings are consistent with the study of Lee et al. (2005) and Mullarkey et al. (2005) which identified the negative leader as the child who challenges the teachers' authority by using silliness and humour to break the classroom rules. However, an apparent difference with the previous studies is that Ana, Carol, and Diana did not describe the child who influenced negatively as being silly and humorous. They described him as being independent and confident; the same characteristics they used to describe the positive leaders. Therefore, it seems that the teachers in this study believe that positive and negative leaders are powerful in the same way: they are independent, confident, stand out and are participative. The clear difference between influencing positively and negatively appears to be whether they induce other peers to comply or not to comply with the teachers' instructions.

\subsubsection{Cross-case analysis}

All the New Zealand and Honduran teachers identified taking a leadership role as a common belief regarding children's leadership, as shown in Table 8.1. The teachers in both countries appear to describe the child as a leader when s/he takes a leadership role in games or stands in front of the group during group activities. Thus, the belief of the leader-follower relationship is apparent in both countries. For example, in the interview, Frances (New Zealand teacher) stated, "You can clearly see who the main person is, they initiate the play." Similarly Carol (Honduran teacher) stated, "When role-playing, they want to be the main person, they want to command others." However, there appears to be a difference on how the teachers describe the child who takes a leadership role. The teachers in New Zealand highlighted that the young leader shares ideas or organizes games. In contrast to the New Zealand teachers' view, influencing positively or negatively, having the voice of authority, and commanding others were characteristics highlighted by the Honduran teachers. Therefore, the belief of a stronger power relationship between leaders and followers was more apparent in the Honduran findings.

One possible explanation of the difference between the New Zealand and Honduran teachers' beliefs could be the influence of cultural 'power distance.' Power distance as a dimension of culture is defined as "the extent to which the 
less powerful members of organizations within a country accept that power is distributed unequally" (Hofstede, 2001, p. 98). In cultures that have high power distances between individuals, institutions will usually be more hierarchical and the division of power is considered significant (Drath et al., 2008). Hofstede (1980, 2001) conducted a study to measure countries' differences in power distance. Hofstede (2001) measured power distance in 50 countries. His findings classified the country with highest power distance as number 0 and that with the lowest power distance a 50. The author concluded that New Zealand showed a 'low power distance' as it was positioned as number 47. Guatemala, one of Honduras neighbouring countries, was positioned as number 2 and therefore Hofstede concluded that Guatemala showed a 'high power distance.' Dickson et al. (2003) supports this argument by reporting studies which found that in cultures with 'high power distance' such as Mexico, authoritative and directive leadership is valued. They stated "Cultures of developing countries tend to share such characteristics as being higher on power distance" (p. 739). On the other hand, cultures with 'low power distance' such as the United States seem to value participative leadership.

As has been suggested by a number of authors, leadership could be understood differently across cultures (Dickson et al., 2003; Drath et al., 2008). Izumi-Taylor et al. (2010) concluded that culture has a particular influence on teachers' beliefs. New Zealand's 'low power distance' culture and Honduran 'high power distance culture' may influence a difference in the participant teachers' beliefs regarding children's leadership. In addition to taking a leadership role, the New Zealand teachers indicated that children can demonstrate leadership by leading their learning and showing a shared leadership. In contrast, the Honduran teachers highlighted the young leader who directs or influences other peers. The New Zealand teachers in this study appear to show that they value children's participative leadership, while the Honduran teachers appear to value children's directive leadership. 


\subsection{Sub-question 2: How do teachers encourage children's leadership?}

This section answers the second sub-question. The table below identifies the main themes that emerged from the New Zealand and Honduran case data analysis about teachers' practices regarding children's leadership. It also shows the absence of a common practice between the teachers in both countries.

Table 8.2: Teachers' practices regarding children's leadership

\begin{tabular}{|l|l|l|}
\hline \multicolumn{1}{|c|}{ New Zealand } & \multicolumn{1}{c|}{ Honduras } & \multicolumn{1}{c|}{$\begin{array}{c}\text { New Zealand + } \\
\text { Honduras }\end{array}$} \\
\hline $\begin{array}{l}\text { Providing } \\
\text { opportunities: } \\
\text { Empowering }\end{array}$ & Allocating opportunities & No similarities found \\
\hline $\begin{array}{l}\text { Fostering relationships } \\
\text { between the children }\end{array}$ & Assigning tasks & \\
\hline Being a facilitator & & \\
\hline
\end{tabular}

In the following sub-sections, the themes referred to in the table above are explained and discussed. In the cross-case analysis section, the main differences between New Zealand and Honduran teachers' practice are indicated and discussed.

\subsubsection{New Zealand}

The first teaching practice suggested by all the New Zealand teachers to encourage children's leadership is empowerment. Te Whāriki, New Zealand Ministry of Education (1996) defines empowerment as "giving power or authority that enables a person to take an action or role" (p. 99). Frances stated that teachers do not assign formal roles to the children, "it's sort of empowering them, and therefore they start leading." Grace also said, "It is all about empowering the children for leadership." It appears that the teachers in this study empower the children by allowing them to decide on leading a game or sharing ideas. These findings are aligned with $T e$ Whāriki where it is also stated 
that "Play activities in early childhood invite rather than compel participation" (New Zealand Ministry of Education, 1996, p. 40). Thus, through empowerment the teachers appear to provide opportunities for children to take a leadership role.

The second teaching practice indicated by three of the four teachers - Erica, Grace, and Jill - in the interview findings is encouraging relationships between the children to support them in developing leadership skills. For example, Jill stated that she particularly focuses on "relationships to encourage social skills" such as leadership. Fostering relationships is aligned with Scheer and Safrit (2001) who described programmes that encourage social interactions between the children as one of the building blocks for leadership. The findings of this study are also related with that of Lee et al. (2005) and Owen (2007) who found that teachers can support children's leadership through collaborative learning where children interact and engage in play with peers.

The third teaching practice that emerged from the NZ interview findings is being a facilitator. Erica and Frances indicated that they encourage children's leadership by being a facilitator of children's play. Erica described being a facilitator as "stepping back and observing." Similarly Frances stated she encourages leadership by "stepping back and letting them lead their own play." These findings are consistent with Owen (2007) who proposed collaborative learning for encouraging children's leadership where children are encouraged to interact with peers. Owen explained that the teacher is just a facilitator and enables children to make meaning of their own experiences. Hensel (1991) and Lee et al. (2005) also found that to encourage leadership, teachers should give children the opportunity to make decisions in their play.

\subsubsection{Honduras}

One teaching practice indicated by Blanca and Diana is that teachers allocate opportunities for the children to take a leadership role. For example Blanca said, "I ask who wants to direct the prayer." Diana also stated, "We have many activities that encourage leaders. The children present a topic in class. They stand out in art, choir, English." These findings differ from previous studies such 
as Lee et al. (2005) and Owen (2007) who suggested teaching strategies that promote decision making in children. The teachers in this study seem to choose the activities in which the children can have the opportunity to take a leadership role rather than the children choosing the activities themselves. As mentioned in Section 8.2.2, Bennis (2007) suggests a view of leadership of a power relationship between leaders and followers. Thus, the teachers appear to focus on encouraging leadership by enabling the children to have power over peers in classroom activities.

Another teaching practice suggested by Ana, Carol and Diana is encouraging children's leadership by assigning tasks to the influential children. According to the interview responses, it appears the teachers assign tasks to the children who influence positively to allow the students to help the teachers in directing the group. For example Diana said: "There are always two or three children who are going to take care of the line, helping the teacher." For the children with negative influence, the teachers may assign them tasks for them to direct a group as a way of monitoring their behaviour. For example, Ana stated that she assigns tasks to the negative influence child "so he can control the group for good." Similarly Carol said, "I assign him tasks, is a way of guiding him to change his behaviour." These findings are consistent with Mullarkey et al. (2005) who concluded that the teachers in their study encounter the dilemma of supporting children's leadership while also "trying to curtail the young leaders' behaviour for the purpose of classroom management" (p. 128). The teachers in this study appear to need leaders to help them maintain classroom management. However, it becomes problematic when children with negative influence come into prominence. The teachers may then rely on assigning them tasks for a double purpose: to encourage 'positive influence' and discourage 'negative influence' of these young leaders so they can help direct the group instead of 'disorganizing it.'

\subsubsection{Cross-case analysis}

As shown in Table 8.2, there seems to be no common practice between the Honduran and New Zealand teachers regarding children's leadership. Although the teachers from both countries encourage children to take a leadership role by 
providing opportunities for the children to lead games or group activities, there appears to be a difference in how those opportunities are provided. The teachers in New Zealand discussed how they empower the children to make the choice about being the leader in games or sharing their ideas with others. On the other hand, the teachers in Honduras stated they ask the children if they want to talk about the topic of the week or participate in school assemblies. These findings suggest that the teachers in New Zealand tend to empower the children to decide on the activities they want to lead, whereas the Honduran teachers appear to allocate the activities where the children can take leadership roles.

A child-directed focus, as opposed to a teacher-directed focus, regarding encouraging children's leadership is an apparent difference between the New Zealand and Honduran teachers' practice. As shown in Table 8.2, besides empowering the children to take a leadership role, the New Zealand teachers foster relationships between the children and are facilitators of children's learning. These teaching strategies are consistent with Lee et al. (2005) who emphasized child-centred teaching strategies to support children's leadership, such as enabling them to make decisions and engage in play with peers. These two strategies, however, appear not to be used in the Honduran context. One possible explanation could be that the activities at the Honduran centres are mainly directed by the teacher. It appears that the teachers do not focus on encouraging the children to decide on the activities they want to do and activities they want to play with, or engage in play with peers. As also shown in Table 8.2, besides allocating opportunities for children to take a leadership role, the Honduran teachers assign tasks to the influential children. Assigning tasks aligns to Schweinhart and Weikart's (1988) description of teacher-directed activities as those where the teacher transmits information to the children. Assigning tasks to positive influence leaders for them to help the teacher to direct the group, and assigning tasks to negative influence leaders to encourage them to influence positively, was only identified in the Honduran context. One possible explanation is that the child who induces other children to follow or not to follow the teacher's instructions is not apparent in a child-directed context as the activities are more directed by the child than by the teacher. A further 
explanation for the differences between the teaching practices in both contexts is provided in Section 8.4.3.

\subsection{Sub-question 3: What are some of the barriers/enablers for teachers to encourage leadership in their students?}

This section answers the third sub-question. The table below shows the main barriers and enablers that emerged from the New Zealand and Honduran case data analysis for teachers to encourage children's leadership. It also states the common barrier identified in both countries and the absence of common enablers between both.

Table 8.3: Barriers/enablers for encouraging children's leadership

\begin{tabular}{|c|c|c|c|}
\hline & New Zealand & Honduras & $\begin{array}{c}\text { New Zealand + } \\
\text { Honduras }\end{array}$ \\
\hline Barriers & $\begin{array}{l}\text { - Teacher- } \\
\text { directedness } \\
\text { - Contextual } \\
\text { factors: daily } \\
\text { routines, lack } \\
\text { of time, ratios }\end{array}$ & $\begin{array}{l}\text { - Parents' lack of } \\
\text { support } \\
\text { - Contextual } \\
\text { factors: lack of } \\
\text { time, ratios, } \\
\text { curriculum }\end{array}$ & $\begin{array}{l}\text { - Contextual factors: } \\
\text { routines/curriculum, } \\
\text { lack of time, ratios }\end{array}$ \\
\hline Enablers & $\begin{array}{l}\text { - Play-based } \\
\text { curriculum, } \\
\text { giving choices } \\
\text { - Communication } \\
\text { with parents }\end{array}$ & $\begin{array}{l}\text { - Extracurricular } \\
\text { activities }\end{array}$ & $\begin{array}{l}\text { - No common } \\
\text { enablers found }\end{array}$ \\
\hline
\end{tabular}

In the following sub-sections, the themes referred to in the table above are explained and discussed. Most of the themes emerged from the teacher interviews. However, there are a few themes that emerged from the observations that were also considered relevant in the discussion, even though they were not highlighted by the teachers in the interviews. 


\subsubsection{New Zealand}

The New Zealand findings suggest a play-based curriculum and giving choices to the children as enablers to encourage children's leadership, whereas teacher-directedness is indicated as a barrier. In the interview, Erica and Frances specifically identified teacher-directedness as a barrier. For example, Erica described it as "Teacher control, imposing ideas on the children." The two teachers also stressed that by using Te Manawa (Wellington Kindergartens, n.d.) as a guide, the centre largely supports them in giving choices to the children. In addition, Jill highlighted that the play-based curriculum in New Zealand enables the children to demonstrate their leadership qualities. Although particularly stressed only by Jill in the interviews, the play-based curriculum was apparent in both centres during the observations. These findings are consistent with Shin et al. (2004) who reported that a play-based curriculum enables the children to develop their individual leadership qualities and also demonstrate social skills when interacting with peers. Thus, having the curriculum and centre support in order to provide choices to the children may enable the New Zealand teachers to encourage children's leadership.

The interview findings indicated that Frances, Grace and Jill considered contextual factors as the other barrier for them to encourage children's leadership. Frances stressed her disagreement with the routines in the kindergarten. For example she stated,

We've got one girl who is very interested in being a leader and she wants to do mat times every day, I would be happy to let her do it...but letting that child have more responsibility can be a bit difficult with the routines. Similarly, Grace stated that the "realities of routines," such as lack of time, are barriers for teachers to follow-up leadership behaviour. Jill also mentioned teacher-student ratios as a barrier. The findings of this study are related to those of Owen (2007) who found that classroom size and shortage of time, due to external pressures, hinder teachers' opportunity to encourage leadership skills. Although Owen's (2007) study was conducted with teachers of children ages 5-18, primary and secondary school, these two barriers appear to be similar to the ones suggested by the New Zealand teachers. 


\subsubsection{Honduras}

The apparent barrier for teachers to encourage children leadership, as indicated by the Honduran teacher interviews, is parents' lack of support. In the interview, Ana, Carol and Diana identified parents specifically as a main barrier. For example, Diana indicated parents' lack of support had a negative influence on the children. She said, "Out of kindergarten there is negative leadership; they don't have good guidance at home." Similarly, Carol suggested parents' lack of support for not providing security to the children. She said, "They don't even listen to their children. They don't have time for them." These findings are consistent with Owen (2007) who suggested that the security that parents provide to the children in their early years is fundamental for children to be able to develop leadership skills. Bisland (2004) also proposed that parents can encourage leadership by role modelling leadership behaviour. In addition, Diana indicated parents' lack of support by not communicating with the teachers. She stated, "The problem for me is the parents. One cannot communicate with them." Similarly, Ana said, "Parents do not cooperate." These findings fit well with Bisland (2004) who suggested that parents and teachers can work together in order to provide a leadership basis for children. It appears that having the parents' support by providing security to the children, and also communicating with the teachers could support the Honduran teachers in encouraging children's leadership. Parental support will be further discussed in the next chapter.

The other barriers for teachers to encourage leadership identified in the Honduran teacher interviews are constraints of time, teacher-student ratios, and curriculum. In the interview, Blanca was the only teacher who specifically identified the short time of the session as a barrier to enable the children to participate. She said, "Sometimes we don't have time because some activities are longer." Even though not mentioned particularly as a barrier, Diana also commented, "The children narrate a story in front of the group. Due to time issues some go one day and others the next day." In respect to teacher-student ratios, none of the teachers specifically indicated it as a barrier in the interviews. However, this was an apparent barrier identified during the observations. The ratio was an average of $30: 1$ in both Honduran centres. It was observed that not 
all the children had the opportunity to direct activities. Moreover, Carol commented during the observations that they do not play every day since they get "left behind" with work and it is also hard with "so many children." These barriers are consistent with Owen (2007) who reported that external pressures such as needing to cover the 'topics prescribed' and classroom ratios are barriers for teachers to encourage leadership.

In addition, Shin et al. (2004) found that free-play is an enabler for children to develop leadership qualities. The Honduran document, DCNPB (Secretaría de Educación de Honduras, 2002) explained in Chapters 1 and 2, has the aim of encouraging leadership in the child through 'play work time.' As described in Section 6.2, during play work time the children play at the centres of learning. However, during the observations, the children appear to have limited time for 'play-work.' In the interview, two of the teachers suggested not being familiar with the DCNPB. Ana said: "I am not very familiar with the DCNPB." Blanca also said: "We do not have the DCNPB, what we have is the CNPB." Although the DCNPB is an official curriculum document, the teachers appeared not to be familiar with the document and its content. This aspect is further discussed in the next chapter. The teachers appeared to focus on following the aims of the CNPB (Secretaría de Educación de Honduras, 2001) which are mainly to cover specific academic topics. The findings of this study suggest that curriculum constraints hinder teachers' ability to support leadership through free-play.

The Honduran interview findings suggest one leadership enabler teachers can use is the centres' support for children to participate in extracurricular activities. For example, Blanca said the centre supports the teachers to encourage leadership through "participation in school assemblies and participation in activities outside kindergarten." Similarly, Diana said, "The centre supports us with the participation of the children inside and outside kindergarten." These findings are similar to Bisland's (2004) argument about extracurricular clubs, sports, and student assemblies being common activities for schools to support leadership. However the teachers in the present study were asked in the interview 'how the centre supported them to encourage leadership,' rather than 
'how the centre supports leadership.' Blanca and Diana appear to have answered a different question than the one asked.

\subsubsection{Cross-case analysis}

The common barrier for teachers to encourage children's leadership identified in both countries' data analysis is contextual factors. For example, Grace (New Zealand teacher) stated:

In the reality of teaching every day, you are dealing with forms and regulations, the ratios are higher...maybe time, maybe the programme. All these realities provide challenges for a teacher to foster leadership.

Similarly, the 'realities' mentioned by Grace were identified during the Honduran teachers' observations. However, in respect to ratios, a clear difference is that in the Honduran settings student-teacher ratios are higher - 30:1 as compared to $10: 1$ in the New Zealand settings. There also appears to be contextual factors consisting of time, routines (New Zealand), and curriculum (Honduras) that obstruct the encouragement of student leadership in both countries. These findings suggest constraints for the teachers in this study to enable the children to take more leadership roles.

There are also apparent differences between the barriers/enablers for New Zealand and Honduran teachers to encourage leadership, which could be due to a difference in the objectives of the national early childhood curricula. The New Zealand early childhood curriculum (New Zealand Ministry of Education, 1996) is based on free-play. In contrast, the Honduran early childhood curriculum (Secretaría de Educación de Honduras, 2001) is based on topics that teachers need to cover by the end of the year. Teacher-directedness was identified by the New Zealand teachers as a barrier for encouraging children's leadership, whereas it appears to be the Honduran teachers' daily practice. Also the enablers to encourage leadership identified by the New Zealand teachers, play-based curriculum and giving choices, suggest child-directed opportunities. In contrast, allocating opportunities for children to participate in the classroom or in extra-curricular activities, as identified by the Honduran teachers, suggests teacher-directed opportunities. Therefore, the findings of this study indicate that the objectives of the national curriculum influence a child-directed teaching 
practice in New Zealand as opposed to a teacher-directed practice in Honduras. This practice appears to influence the differences of barriers/enablers between both countries. In addition, as mentioned in Chapter 2, Te Whāriki (New Zealand Ministry of Education, 1996) focuses largely on communication between teachers and parents. This aspect is not emphasized as much in the Honduran early childhood curriculum. Lack of support from the parents was identified by the Honduran teachers as a main barrier for them to encourage leadership, while the teachers in New Zealand appear to consider communication with the parents as an enabler.

\subsection{Main research question: How do teachers in New Zealand and Honduras translate their beliefs about children's leadership into practice?}

This section answers the main research question. The table below summarizes how the New Zealand and Honduran teachers translate their beliefs into practice. It is based on Table 8.1, which showed teachers' beliefs, and Table 8.2 , which showed teachers' practices in each country.

Table 8.4: Summary of teachers' beliefs and practices

\begin{tabular}{|l|l|l|}
\hline & \multicolumn{1}{|c|}{ New Zealand } & \multicolumn{1}{c|}{ Honduras } \\
\hline Teachers' & • Taking a leadership & $\bullet$ Taking a \\
beliefs & role & leadership role \\
& $\begin{array}{l}\text { - Shared leadership } \\
\text { - Leading their } \\
\end{array}$ & \\
\hline learning & \\
practices & - Empowering & - Allocating \\
& Fostering & opportunities \\
& relationships & Assigning tasks \\
& Being a facilitator & \\
& & \\
\hline
\end{tabular}


In the following sub-sections, the relationship between teachers' beliefs and practices is explained and discussed along with main barriers or enablers.

\subsubsection{New Zealand}

The interview findings revealed a relationship between the New Zealand teachers' child-directed beliefs and child-directed practices regarding children's leadership. These findings correspond to those of Wang et al. (2008) who found a consistency between teachers' beliefs and practices regarding the early childhood curriculum. As shown in Table 8.4, the teachers first conceptualize children's leadership as the children deliberately taking a leadership role. Therefore, they empower the children so they can lead games or 'mat time.' Secondly, teachers showed their belief concerning children sharing leadership. Thus they foster relationships between the children to encourage them to work together and be aware of others. The third belief regarding children's leadership the teachers indicated is children leading their own learning. Therefore, by being a facilitator, the teachers enable the children to lead their play and make decisions. These findings also highlight the New Zealand teachers' childdirected beliefs and practices regarding children's leadership.

Another relationship between New Zealand teachers' belief and practice appears to be their belief that all children have leadership potential and therefore this underpins their provision of leadership opportunities for all children. For example, in the interview, Erica said "It is not only those loudopinionated children who are leaders." Grace also said "I think all children can or have leadership potential.... but I think they need to be given the opportunity to experience leadership." These findings are consistent with Owen (2007) who found that $85 \%$ of the teachers in her study believed children's leadership should be encouraged from kindergarten. Owen argues that all children have leadership potential and leadership should be encouraged in all children from a young age.

The New Zealand play-based curriculum and support from the early childhood centres to give choices to the children were indicated in the New Zealand teacher interviews as enablers for teachers to transfer their beliefs into practice. 
For example, Jill stated, "For me the play-based curriculum is really the thing that helps support leadership." These findings correspond to Brownlee and Chak's (2007) and Einasdottir's (2003) statement that teacher's beliefs are influenced by the culture the teachers are part of and the centres' culture. The New Zealand teachers' beliefs appear to influence their teaching practice. Thus, the child-directed objectives of the New Zealand early childhood curriculum and centres may enable the teachers to transfer their child-directed beliefs regarding leadership into practice.

These teachers also indicated, in the interviews, that they do not always have the facilities to practice in conformity to their beliefs due to contextual factors and teacher-directedness. In particular, the teachers highlighted 'realities' such as shortage of time, higher ratios, and routines are sometimes obstacles for teachers to encourage leadership. For example, in the interview, Frances stated, "I think specially lack of time...they want to continue with their projects and things and its tidy-up time. You know...we have to stop now." These findings are consistent with Wang et al. (2008) who found structural issues such as classroom ratios and lack of time are barriers for teachers to not always practice in accordance with their beliefs. The findings are also similar to Nuttall (2005) who identified the 'structural realities' at an early childhood centre as an obstacle for teachers to reflect about their beliefs and translate them into teaching practice.

\subsubsection{Honduras}

The interview findings indicated that the Honduran teacher-directed practices regarding children's leadership are influenced by their teacher-directed beliefs. Similarly to the New Zealand findings, the Honduran findings also correspond with Wang et al. (2008) which found consistency between teachers' beliefs and practices regarding the early childhood curriculum. As shown in Table 8.4, the teachers conceptualize children's leadership as taking a leadership role by participating, standing out in activities, or directing others. Therefore, the teachers allocate opportunities for children to take leadership roles. The teachers also indicated that the child who takes a leadership role can influence their peers positively or negatively. Thus, the teachers assign tasks to the child 
in order to encourage a positive influence and discourage negative influence. As opposed to the New Zealand teachers' child-directed beliefs and practices, the Honduran findings suggest teachers have teacher-directed beliefs and practices regarding children's leadership.

This study also found, as indicated in the teacher interviews, that the Honduran teachers generally believe leadership is innate and therefore they appear to encourage leadership in the children with leadership potential. When the teachers were asked in the interview if all children had leadership potential, three of the four teachers, Ana, Blanca and Diana, said leadership is innate. For example Diana said "I think leadership is innate... not all have the ability." Similarly, Ana said, "When the child is born, he already has leadership abilities or not...we could encourage it but not all of them will develop the skill, or will not develop it the same way." In addition, the teachers indicated the children with leadership potential are the ones who participate in the activities inside and outside the classroom. For example, Ana said, "With that child we work more than with the others as we noticed he develops the skill more." These findings fit well with previous literature, which focuses on leadership development on 'gifted children' (Bisland, 2004; Hensel, 1991).

The early childhood centres' support of extracurricular activities was also indicated in the interview findings as an enabler for teachers to translate their beliefs into practice. For example, Diana said, "The children participate in activities inside and outside the classrooms." These findings correspond to Brownlee and Chak (2007) and Einasdottir (2003) who stated that culture and school culture have an influence on teachers' beliefs. The Honduran teachers' beliefs appear to influence their teaching practice. Thus, the teacher-directed objectives of the early childhood curriculum and the teacher-directed opportunities that the centres provide may enable teachers to transfer their teacher-directed beliefs regarding student leadership into practice.

The teachers further indicated in the interviews that lack of parental support and contextual factors are barriers for them to not always practice in relation to their beliefs. It was apparent in the interviews that the teachers ideally would want 
the young leaders to positively influence their peers instead of negatively. However, parents' negative influence and lack of cooperation may be a barrier that prevents teachers from applying their beliefs into practice. The teachers also identified lack of time and curriculum pressures as barriers to give all children the opportunity to participate in classroom activities. Although not mentioned by the teachers in the interview, it appeared during the observations that student-teacher ratios also impede teachers from giving all children the opportunity to participate during class on a daily basis. These findings are aligned with Wang et al. (2008) who identified structural issues such as curriculum and student ratios as obstacles for teachers to transfer beliefs into practice. The findings are also similar to Nuttall (2005) who found an inconsistency between teacher's beliefs and practices as structural realities constrain teachers to reflect about their beliefs and transfer them into practice.

\subsubsection{Cross-case analysis}

The interview findings from both countries support the literature regarding the relationship between teachers' beliefs and practices. A number of authors have suggested that teachers' beliefs guide teachers' practice (Fang, 1996; Pajares, 1992; Vartulli, 2005; Wang et al., 2008). For example, Brownlee and Chak (2007) found, in their study, that teachers who believe that children learn through active understanding and discovery encourage the children to make their own meaning of experiences. In the present study, the New Zealand teachers' child-directed beliefs appear to influence their child-directed practices, and the Honduran teachers' teacher-directed beliefs appear to influence their teacher-directed practices. In addition, the New Zealand teachers' belief that all children have leadership potential may influence teacher practices, such as empowerment, enabling their students to have opportunities for leadership. Similarly, the belief of Honduran teachers that leadership is innate appears to influence their practice to allocate opportunities so that talented children can have leadership opportunities.

The objectives of national curricula and of early childhood centres may significantly influence the way teachers in New Zealand and Honduras transfer their beliefs into practice. The play-based curriculum suggested in Te Whāriki 
(New Zealand Ministry of Education, 1996) and the centres' objectives of giving choices to the children are possible influential aspects of New Zealand teachers' child-directed beliefs and practices regarding children's leadership. Similarly, the objectives of the Honduran early childhood curriculum to cover particular topics (Secretaría de Educación de Honduras, 2001) and the centres' objectives for children to participate in extra-curricular activities possibly guide the Honduran teachers' teacher-directed beliefs and practices. Wang et al. (2008) recommend that, in addition to early childhood education general goals worldwide, specific cultural requirements should be considered when analyzing teachers' beliefs and practices across cultures. The findings in this study suggest that the teachers' beliefs and practices regarding leadership are in accordance with the early childhood education requirements of each country.

Another important influence on teachers' beliefs and practices regarding leadership in both countries could be the dimension of cultural 'power distance' discussed in Section 8.2.3. Wang et al. (2008) suggests that "cultural influences are necessarily reflected on early childhood teachers' beliefs and classroom practices" (p. 228). The New Zealand teachers' child-directed beliefs and practices may reflect a 'low power' distance culture were participative leadership appears to be valued. In contrast, a 'high power' distance culture where directive leadership appears to be valued is possibly reflected in the Honduran teachers' teacher-directed beliefs and practices. Dickson et al. (2003) suggests that "previous studies show that power in distance in society has an impact on different aspects of leadership" (p. 740). Thus, the findings of this study add to the literature of the effect that power distance could have on teachers' beliefs and practices regarding the idea of children's leadership.

Finally, it should be noted that, according to the interview findings, contextual factors may be barriers for the New Zealand and Honduran teachers to translate their beliefs into practice. Fang (1996) argues it is not unexpected to have inconsistency between teachers' beliefs and practices. Fang discusses how previous researchers have identified the complexities of the classroom as constraints for teachers to align their beliefs to their practice. The findings of the present study also suggest contextual factors - such as teacher-student ratios, 
curriculum pressures or routines and lack of time - are barriers for teachers to practice according to their beliefs. Previous studies have focused on quantifying the relationship between beliefs and practices (Abu-Jaber et al., 2010; Wang et al., 2008) or have conducted extensive observations in order to determine the consistency between beliefs and practices (Nuttall, 2005). Although the observations carried out in the present study were useful to explore this relationship more deeply, they were not sufficient to determine if there is a consistency between the teachers' self-reported practices and their practice in the classrooms as it was not the focus of the study. However, the interview and observations data analysis suggests that although the New Zealand and Honduran teachers' beliefs appear to be related to their practice, the findings indicate the significant influence that contextual factors can have on teachers' beliefs and, consequently, on teachers' practice (Fang, 1996) regarding children's leadership.

\subsection{Chapter Summary}

This chapter presented a cross-case analysis and discussion of the findings of this study. The analysis discussed the main research questions and its subquestions by providing an understanding of the New Zealand and Honduran context and also the main similarities and differences between them. Cultural differences and curricula objectives were identified as prominent aspects for differences between the New Zealand teachers' child-directed and the Honduran teachers' teacher-directed approach to the concept of children's leadership. The conclusions of this study are discussed in the next chapter. 


\section{Chapter 9: Conclusions}

\subsection{Chapter Overview}

This concluding chapter begins by providing a review of the research process in this study. A summary of the main findings follows. A section outlining the implications for practice and research is then provided before limitations of this study are discussed.

\subsection{Review of the research process}

This thesis has explored New Zealand and Honduran teachers' beliefs and practices regarding children's leadership. The idea of children's leadership has been underexplored in previous literature (Shin et al., 2004). In particular there have been very few studies exploring teachers' beliefs regarding children's leadership and how they translate their beliefs into practice (Shin et al., 2004). In addition, there appear to be few studies in New Zealand and none in Honduras around this idea. This study sought to inform our understanding of beliefs and practices that could assist teachers in supporting young children's leadership.

The literature review outlined in Chapter 2 provided an overview of literature relevant to this study. It revealed a gap in the literature regarding cross-cultural studies particularly focused on young children's leadership. It also indicated the need for exploring teacher beliefs regarding children's leadership in order to understand how teachers encourage or discourage this notion. The purpose of this study was to explore how New Zealand and Honduran teachers of four-tofive year old children translate their beliefs regarding children's leadership into practice. The study intended to answer the following main research question and sub-questions:

Main research question: How do teachers of four-to-five year old children in New Zealand and Honduras translate their beliefs about children's leadership into practice? 


\section{Sub-questions:}

1. How do teachers conceptualize children's leadership?

2. How do teachers encourage children's leadership?

3. What are some of the barriers/enablers for teachers to encourage leadership in their students?

A comparative-embedded case study was used to examine the similarities and differences between New Zealand and Honduran teachers' beliefs and practices. Teacher participants from specific early childhood centres in each country provided the data for analysis. Data was collected through semistructured interviews, observations and documentation. The Four Responsibilities (Tamati et al., 2008) was used as an initial conceptual framework for analysis. This framework was modified alongside the teacher interview analysis which followed the six phases of thematic analysis suggested by Braun and Clarke (2006). The analysis then involved an intra-country followed by an inter-country comparison, where similarities and differences between both countries were identified.

\subsection{Summary of main findings}

The individual and cross-case analysis revealed significant differences between New Zealand and Honduran teachers' beliefs and practices regarding children's leadership. The New Zealand teacher's interview findings, presented in Chapters 4 and 5 , indicated that the teachers expected the children to take responsibility in order to have responsibility. In addition, the teachers indicated their beliefs and the importance of their practice in encouraging children to share responsibility. In contrast, the findings from the Honduran case, discussed in Chapters 6 and 7, suggested that teachers need to give responsibility to children in order for the children to have responsibility. The teachers did not emphasize beliefs and practices concerning the concept of sharing responsibility. The need to adapt the framework differently to fit the findings of each country highlighted the differences between both contexts.

Chapter 8 discussed the answer to the main research question. The intracountry comparison indicated that the New Zealand and Honduran teachers 
translate their beliefs regarding children's leadership into practice. However, there is an apparent difference between New Zealand teachers' child-directed beliefs and practices and Honduran teachers' teacher-directed beliefs and practices (The teachers' beliefs and practices of each country were explained in detail in Sections 8.2.and 8.3). The cross-case analysis provided possible explanations for this difference. The objectives of the early childhood curricula and the cultural dimension of 'power distance' were identified as influential in explaining differences between New Zealand and Honduran teachers' beliefs and practices (The objectives of the early childhood curricula and cultural power distance were described in Section 8.5.3). The lack of parental support was also identified as a major barrier for the Honduran teachers to encourage children's leadership while in New Zealand it was identified as an enabler. One similarity indicated by the teachers in both countries was that contextual factors were barriers to teachers translating their beliefs into practice.

\subsection{Implications}

In light of the findings, this study has implications for practice and future research as described below.

\subsubsection{Implications for practice}

This study provided an understanding of New Zealand and Honduran teachers' beliefs and practices regarding children's leadership. As discussed in Section 9.2, children's leadership is a topic underexplored in the literature with the role of teachers in supporting children's leadership seldom addressed (Shin et al., 2004). In line with Mullarkey et al. (2005) a contribution of this study is exploring teacher's beliefs regarding young children's leadership. Specifically providing insights into how teachers' beliefs and practices influence children's leadership is a significant finding of this study. An implication for teachers is to think about the concept of children's leadership and what is their own belief regarding this idea. This study found a relationship between teachers' beliefs and practices; to support children's leadership, teachers are encouraged to reflect on how their beliefs guide their teaching practice regarding children's leadership. 
Another implication for practice is encouraging stakeholders to reflect on how they can support teachers in providing leadership opportunities for young children. This study provided an understanding of the significant role of head teachers/supervisors, Kindergarten Associations, and the Ministry of Education in supporting teachers to encourage children's leadership in early childhood centres. In the Honduran context, the document DCNPB, explained in Chapters 1 and 2, was introduced by the Honduran Ministry of Education in order to complement the national Early Childhood Curriculum. The DCNPB establishes the aim of promoting leadership in the child through 'play-work time.' As discussed in Chapter 8, two of the four teachers in this study indicated they were not familiar with the content of this document and children appear to be given limited time for play. An implication for the Honduran Ministry of Education could be to provide and encourage professional development regarding DCNPB's aim of promoting children's leadership to teachers.

\subsubsection{Implications for research}

The findings of this study indicated the importance of parental support for teachers to encourage children's leadership. Two important aspects regarding parental support were identified in Section 8.4.2; providing security to the children, and promoting communication between parents and teachers. Owen (2007) previously identified the role of parents in providing security for children from an early age, and Bisland (2004) indicated the importance of communication between parents and teachers in order to support children's leadership. Communication between teachers and parents is highlighted in the New Zealand Early Childhood Curriculum and also indicated in the New Zealand teacher interviews as an enabler to encourage children's leadership. The lack of support from parents, by not providing security to the children and not communicating with the teachers, was identified from the teacher interviews as the main barrier for Honduran teachers to encourage leadership in their students. An implication for future studies is to explore further these two aspects in order to increase our understanding of the significant role of parents in promoting children's leadership. 
This study provided an understanding of contextual factors as significant barriers for New Zealand and Honduran teachers to transfer their beliefs into practice. Previous studies such as Nuttall (2005) have identified that the structure of activities at an early childhood centre inhibits teachers' ability to reflect about their beliefs and practice in accordance to them. Similarly, Wang et al. (2008) concluded that structural issues such as lack of time and classroom ratios are barriers for teachers to transfer their beliefs into practice. Fewer routines and longer sessions were identified by the New Zealand teachers as aspects that could support them in order to encourage children's leadership. Teacher-student ratios and curriculum pressures were identified as main factors that hinder Honduran teachers from promoting children's leadership. Future research could explore more in depth the influence of contextual factors on the consistency between teachers' beliefs and practices regarding children's leadership. As discussed in Section 8.5.3, previous studies have conducted extensive observations in order to determine the relationship between beliefs and practices. Future studies could conduct more teacher observations in order to examine further the consistency between teachers' self-reported practices regarding children's leadership and their practice in early childhood settings.

The findings of this study highlighted the influence of culture on teachers' beliefs and practices. As summarized in Section 9.3, an apparent difference between New Zealand teachers' child-directed and Honduran teachers' teacher-directed beliefs and practices was found in this study. In line with previous cross-cultural studies (Wang et al., 2008) this study identified that cultural influences are reflected in teachers' beliefs and practices. Particularly, the cultural dimension of power distance was identified in this study as a possible explanation for the New Zealand teachers to value children's participative leadership and for the Honduran teachers to value children's directive leadership. For example, the New Zealand teachers indicated that they value children leading their learning and sharing leadership. In contrast, the Honduran teachers indicated that they value children to direct and influence their peers. Future comparative studies could further explore the influence of culture on teacher's beliefs and practices. For example, there are other cultural dimensions mentioned in Section 2.5 that could also have an influence on teachers' beliefs and practices cross-culturally. 
Investigating cultural dimensions in teaching could help increase our understanding of the influence of culture on teachers' beliefs, and, consequently on teachers' practices regarding children's leadership.

\subsection{Limitations}

A limitation of this study was not being able to validate my interpretation of the findings with the Honduran teachers. As explained in Section 3.5.1, the limited access Honduran teachers had to the internet was an obstacle in sending them the findings through email. This limitation reflects some of the issues of poverty faced by low socio-economic sectors in Honduras. In order to address as far as possible this limitation, I personally took the interview transcripts to each teacher during fieldwork in Honduras so they could check for accuracy. In addition, I carefully translated the transcripts from Spanish to English to try to maintain as close as possible the meaning of the original data. I also sought help from a native English speaker, who speaks Spanish fluently, to check that sample vignettes were translated objectively. These two procedures helped increase the credibility of the findings.

Another limitation could be that the teachers behaved differently for the purposes of being part of this study. Bodgan and Biklen (2007) suggest "the observer effect" or the "Heisenberg effect" as the change in behaviour of the person being studied due to the presence of the researcher ( $p$. 38). The teachers may have modified their behaviour due to my presence at the early childhood centre. In the future, this effect could be reduced by conducting several observations. Due to time constrains, each teacher could only be observed for two days. However, adding the observation component to teacher interviews as a method of data collection is a strength of this study. Previous studies, specifically around teachers' perceptions regarding children's leadership, have relied on interviews to inform the analysis and findings of their studies. Conducting interviews and observations in the present study provided a deeper understanding about teachers' beliefs and practices and also increased the validity of the findings. 
Finally, this study was framed as small sample size with only four teachers from each country. However, as identified in Chapter 3, Patton (2002) suggests qualitative research selects small sample sizes with the purpose of obtaining rich data from the samples. This was a small study with the purpose of obtaining rich description of teachers' beliefs and practices. In addition, a limitation of this study was not being able to examine in detail the beliefs and practices of the teachers in each country, as my focus was the comparison between New Zealand and Honduras. However, the study has the advantage of providing a cross-cultural understanding about children's leadership. This has the benefit of potentially raising cross-cultural awareness, and of informing our understanding of teacher beliefs and practices that could support children's leadership. Furthermore, the study adds to the literature of cross-cultural studies regarding this idea.

\subsection{Chapter Summary}

This chapter began with a review of the research process which involved the research aims, the gap in the literature identified and addressed in this study, and the methodology. The next section provided a summary of the main findings. The implications for practice, such as encouraging teachers to reflect on how their beliefs guide their practice regarding children's leadership, were identified. Research implications, for example exploring further the role of parents in supporting children's leadership, were considered and discussed. Limitations of this study, including not being able to examine in detail the beliefs and practices of the teachers in each country, were also reviewed.

Taking into consideration the implications for practice and research as well as the limitations within this study, the benefits of comparing the beliefs and practices of teachers in two countries are advantageous to educators and researchers as it potentially raises cross-cultural awareness about children's leadership, and adds to the literature about comparative studies regarding this idea. 


\section{Reference List}

Abu-Jaber, M., Al-Shawareb, A., \& Gheith, E. (2010). Kindergarten teachers' beliefs toward developmentally appropriate practice in Jordan. Early Childhood Education Journal, 38(1), 65-74.

Alvestad, M., \& Duncan, J. (2006). "The value is enormous - it's priceless I think!" New Zealand preschool teachers' understandings of the early childhood curriculum in New Zealand - a comparative perspective. International Journal of Early Childhood, 38(1), 31-45.

Bennis, W. (2007). The challenges of leadership in the modern world: Introduction to the special issue. The American Psychologist, 62(1), 2-5.

Bisland, A. (2004). Developing leadership skills in young gifted students. Gifted Child Today, 27(1), 24-56.

Bodgan, R., \& Biklen, K. (2007). Qualitative research for education: An introduction to theories and models (5th edition). Boston: Pearson.

Braun, V., \& Clarke, V. (2006). Using thematic analysis in psychology. Qualitative Research in Psychology, 3(2), 77-101.

Brownlee, J., \& Chak, A. (2007). Hong Kong student teachers' beliefs about children's learning: Influences of a cross-cultural early childhood teaching experience. Australian Journal of Educational \& Developmental Psychology, 7, 11-21.

CARE. (n.d.). Who we are. Retrieved from http://www.careinternational.org/About-Care/

Creswell, J. (2009). Qualitative, quantitative, and mixed methods approaches. Thousand Oaks, California: Sage Publications.

Day, D. (2001). Leadership development: A review in context. Leadership Quarterly, 11(4), 518-613.

Denscombe, M. (2010). Ground rules for social research: Guidelines for good practice (2nd ed.) New York: Open University Press.

Denzin, N., \& Lincoln, Y. (2000). Introduction: The discipline and practice of qualitative research. In N. Denzin \& Y. Lincoln (Eds.), The handbook of qualitative research (2nd ed., pp.1-28).Thousand Oaks, California: Sage Publications. 
Dickson, M., Den Hartog, D., \& Mitchelson, J. (2003). Research on leadership in a cross-cultural context: Making progress, and raising new questions. The Leadership Quarterly 14(6), 729-768.

Drath, W., McCauley, C., Paulus, C., Velsor, E., O'connor, P., \& McGuire, J. (2008). Direction, alignment, commitment: Toward a more integrative ontology of leadership. The Leadership Quarterly, 19(6), 635-653.

Einarsdottir, J. (2003). Beliefs of early childhood teachers. In O. Saracho \& B. Spodek (Eds.), Studying teachers in early childhood settings (pp.113133). Connecticut, United States: Information Age Publishing.

Elkjaer, B. (2009). Pragmatism: A learning theory for the future. In K. Illeris (Ed.), Contemporary theories of learning (pp. 74-89). London: Routledge.

Fang, Z. (1996). A review of research on teacher beliefs and practices. Educational Research, 38(1), 47-65.

Fu, V. R. (1979). Preschool leadership-followership behaviours. Child Study Journal, 9, 133-140.

Fu, V. R., Canady, H., \& Fu, D. T. (1982). Creativity and leadership in preschoolers. The Journal of Genetic Psychology, 141, 291-292.

Fukada, H., Fukada, S., \& Hicks, J. (1997). The relationship between leadership and sociometric status among preschool children. The Journal of Genetic Psychology, 158(4), 481-486.

Gmitrová, V., \& Gmitrov, J. (2003). The impact of teacher-directed and childdirected pretend play on cognitive competence in kindergarten children. Early Childhood Education Journal, 30(4), 241-246.

Guba, E., \& Lincoln, Y. (1994). Competing paradigms in qualitative research. In N. Denzin \& Y. Lincoln (Eds.), The handbook of qualitative research (1st ed., pp. 105-117). London: Sage Publications.

Harris, A. (2008). Distributed leadership: According to the evidence. Journal of Educational Administration, 46(2), 172-188.

Hatch, T. C. (1990). Looking at Hank, looking at Ira: Looking at individual fouryear-olds, especially their leadership styles. Young Children, 45(5), 1117.

Hedge, A., \& Cassidy, D. (2009). Kindergarten teachers' perspectives on developmentally appropriate practices (DAP): A study conducted in 
Mumbai (India). Journal of Research in Childhood Education, 23(3), 367381.

Helm, J. (2004). Projects that power young minds. Educational Leadership, 62, 58-62.

Hensel, N. (1991). Social leadership skills in young children. Roeper Review, 14(1), 4-6.

Herron, J. (2010). An evolution of mathematical beliefs: A case study of three Pre-K teachers. Journal of Early Childhood Teacher Education, 31(4), 360-372.

Hofstede, G. (1980). Culture's consequences: International differences in workrelated values. California: Sage Publications.

Hofstede, G. (2001). Culture's consequences: Comparing values, behaviors, institutions, and organizations across nations. California: Sage Publications.

Instituto Nacional de Estadística. (2010). Asistencia escolar. Retrieved from http://www.ine.gob.hn/drupal/node/200

Izumi-Taylor, S., Samuelsson, I. P., \& Rogers, C. S. (2010). Perspectives of play in three nations: A comparative study in Japan, the United States, and Sweden. Early Childhood Research and Practice, 12(1).

Johnson, B., \& Christensen, L. (2008). Educational research: Quantitative, qualitative, and mixed approaches (3rd.ed.). California: Sage Publications.

Karnes, F., \& Stephens, K. (1999). Lead the way to leadership education. Education Digest, 64(8), 62-65.

Lambert, L. (2002). A framework for shared leadership. Educational Leadership, 59(8), 37-40.

Lee, S. Y., Recchia, S. L., \& Shin, M. S. (2005). "Not the same kind of leaders": Four young children's unique ways of influencing others. Journal of Research in Early Childhood Education, 20(2), 132-148.

Lim, C. (2010). Understanding Singaporean preschool teachers' beliefs about literacy development: Four different perspectives. Teaching and Teacher Education, 26(2), 215-224. 
Luft, J., \& Roehrig, G. (2007). Capturing science teachers' epistemological beliefs: The development of the teacher beliefs interview. Electronic Journal of Science Education, 11(2), 38-63.

Mawson, B. (2009). Dictators and directors: Leadership roles in children's collaborative play. New Zealand Research in Early Childhood Education, 12, 11-21.

Mawson, B. (2010). Gender and leadership styles in children's play. Australasian Journal of Early Childhood, 35(3), 115-123.

McMullen, M., Elicker, J., Wang, J., Erdiller, Z., Lee, S. M., Lin, C. H., \& Sun, P. Y. (2005). Comparing beliefs about appropriate practice among early childhood education and care professionals from the U.S., China, Taiwan, Korea and Turkey. Early Childhood Research Quarterly, 20(4), 451-464.

Merriam, S. B. (1988). Qualitative research and case study applications in education (1st ed.). San Francisco: Jossey-Bass Publishers.

Merriam, S. B. (1998). Qualitative research and case study applications in education (2nd ed.). San Francisco: Jossey-Bass Publishers.

Mullarkey, L. S., Recchia, S. L., Lee, S. Y., Shin, M. S., \& Lee, Y. J. (2005). Manipulative managers and devilish dictators: Teachers' perspectives on the dilemmas and challenges of classroom leadership. Journal of Early Childhood Teacher Education, 25(2), 123-129.

New Zealand Ministry of Education. (1996). Te Whāriki: He whāriki matauranga mō ngā mokopuna o Aotearoa: Early childhood curriculum. Wellington, New Zealand: Learning Media.

New Zealand Ministry of Education. (2009). Kei tua o te pae. Retrieved from www.educate.ece.govt.nz/learning/curriculumAndLearning/Assesmentforl earning/KeiTuaotePae.aspx

New Zealand Ministry of Education. (2012a). Moving on to school. Retrieved from

http://www.minedu.govt.nz/Parents/EarlyYears/MovingOnToSchool.aspx

New Zealand Ministry of Education. (2012b). Pathways to the future: English plans and translations. Retrieved from http://www.minedu.govt.nz/NZEducation/EducationPolicies/EarlyChildho od/ECEStrategicPlan/PathwaysToTheFutureEnglishPlanAndTranslations aspx 
New Zealand Ministry of Education. (2012c). Teacher-led services. Retrieved from

http://www.minedu.govt.nz/Parents/EarlyYears/HowECEWorks/TypesOf ECEService/TeacherLedService.aspx

New Zealand Ministry of Social Development. (2010). Economic standard of living. Retrieved from

http://www.socialreport.msd.govt.nz/documents/economic-standard-ofliving-social-report-2010.pdf

Nivala, V., \& Hujala, E. (Eds.). (2002). Leadership in early childhood education: Cross-cultural perspectives. Oulu, Finland: Oulu University Press.

Nuttall, J. (2005). Pathway to the future? Doing childcare in the era of New Zealand's early childhood strategic plan. Wellington, New Zealand: Victoria University of Wellington, Institute for Early Childhood Studies.

Owen, H. (2007). Creating leaders in the classroom: How teachers can develop a new generation of leaders. London: Routledge.

Pajares, M. F. (1992). Teachers' beliefs and educational research: Cleaning up a messy construct. Review of Educational Research, 62(3), 307-332.

Parten, M. B. (1933). Leadership among preschool children. Journal of Abnormal and Social Psychology, 27, 430-440.

Patton, M. (2002). Qualitative research and evaluation methods (3rd ed.). California: Sage Publications.

Ragin, C. (1987). The comparative method: Moving beyond qualitative and quantitative strategies. California: University of California Press.

Richardson, V. (1996). The role of attitudes and beliefs in learning to teach. In J. Sikula (Ed.). Handbook of research on teacher education (2nd ed., pp.102-119). New York: Macmillan Library.

Scheer, S., \& Safrit, R. (2001). Nurturing future leadership skills in five to eight year-old children through self-awareness activities. Journal of Leadership \& Organizational Studies, 8(2), 105-111.

Schommer-Aikins, M., Bird, M., \& Bakken, L. (2010). Manifestations of an epistemological belief system in preschool to grade twelve classrooms. In L. D. Bendixen \& F. C. Feucht (Eds.), Personal epistemology in the classroom: Theory, research, and implications for practice (pp. 31-54). Cambridge: Cambridge University Press. 
Schwandt, T. (2007). The sage dictionary of qualitative inquiry. Los Angeles: Sage Publications.

Schwartz, S. H. (1999). A theory of cultural values and some implementations for work. Applied Psychology: An International Review, 48(1), 23-47.

Schweinhart, L., \& Weikart, D. (1988). Education for young children living in poverty: Child-initiated learning or teacher-directed instruction? The Elementary School Journal, 89(2), 212-225.

Schweisfurth, M. (2001). Gleaning meaning from case studies in international comparison: Teachers' experiences of reform in Russia and South Africa. In K. Watson (Ed.), Doing comparative education research: Issues and problems (pp. 211-223). Oxford, United Kingdom: Symposium Books.

Secretaría de Educación de Honduras. (2001). Currículo nacional de educación prebásica. Tegucigalpa, Honduras.

Secretaría de Educación de Honduras. (2002). Diseño curricular nacional para la educación prebásica. Tegucigalpa, Honduras.

Secretaría de Educación de Honduras. (2003). Currículo nacional básico. Retrieved from http://www.se.gob.hn/content_htm/pdfs/cnb/cnb.pdf

Secretaría de Educación de Honduras. (2011). Anteproyecto de ley general de educación versión revisada Abril 2011. Tegucigalpa, Honduras.

Shin, M. S., Recchia, S. L., Lee, S. Y., Lee, Y. J., \& Mullarkey, L. S. (2004). Understanding early childhood leadership: Emerging competencies in the context of relationships. Journal of Early Childhood Research, 2(3), 301306.

Statistics New Zealand. (2010). New Zealand childcare survey 2009. Retrieved from

http://www.stats.govt.nz/browse for stats/people and communities/chil dren/childcaresurvey hotp2009revised.aspx

Statistics New Zealand. (2011). New Zealand in Profile 2011. Retrieved from http://www.stats.govt.nz/browse for stats/snapshots-of-nz/nz-in-profile2011.aspx

Tamati, A., Hond-Flavell, E., Korewha, H., \& the whānau of Te Kōpae Piripino. (2008). Centre of innovation research report of Te Kōpae Piripino. Retrieved from http://www.educationcounts.govt.nz/publications/ece/22551/34825/34830 
Te Kōpae Piripino. (2006). Ngā takohanga e wha - The four responsibilities. Retrieved from

http://www.educate.ece.govt.nz/Programmes/Centresoflnnovation/Docu mentsandResources/ServiceSpecific/NgaTakohangaeWha.aspx

Trawick-Smith, J. (1988). "Let's say you're the baby, ok?": Play leadership and following behavior of young children. Young Children, 43(5), 51-59.

United Nations. (2011). Rural poverty in Honduras. Retrieved from http://www.ruralpovertyportal.org/web/guest/country/home/tags/honduras USAID. (2012). Gender equality and women's empowerment. Retrieved from http://www.usaid.gov/our_work/crosscutting_programs/wid/ed/powertolead.html

Vartulli, S. (2005). Beliefs: The heart of teaching. Young Children, 60(5), 76-86. Wang, J., Elicker, J., McMullen, M., \& Mao, S. (2008). Chinese and American preschool teachers' beliefs about early childhood curriculum. Early Childhood Development and Care, 178(3), 227-249.

Wellington Kindergartens. (n.d.). Te Manawa: Criteria for curriculum implementation. Wellington, New Zealand.

Wiger, N. P. (2010). Adolescent girl's leadership in Honduras: CARE's girl's leadership index survey (Unpublished master's thesis University Of Minnesota, United States). Retrieved from http://conservancy.umn.edu/bitstream/93300/1/Pellowski\%20Wiger_Nan cy_May\%202010.pdf

Yin, R. (2003). Case study research: Design and methods (3rd ed.). London: Sage Publications. 


\title{
Appendices
}

\section{Appendix A - Information sheet for head teachers/supervisors}

\author{
VICTORIA UNIVERSITY OF WELLINGTON \\ Te Whare Wananga o te Upoko o te Ika a Maui
}

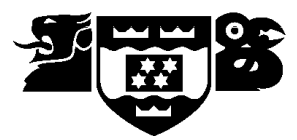 \\ FACULTY OF EDUCATION}

Research project: Teachers' beliefs and practices regarding young children's leadership: a comparison between New Zealand and Honduras

Researcher: Maria Auxiliadora Cerrato Corrales, School of Education Policy and Implementation

Dear Sir/Madam:

I am a student studying for my Master of Education thesis at Victoria University of Wellington. The main aim of my research is to explore how teachers in Honduras and New Zealand translate their beliefs regarding young children's leadership into practice. Understanding teacher beliefs about children's leadership can help us understand how these inform teaching practice.

As part of my degree I am undertaking a research project leading to a thesis. I am seeking your permission to interview two of your early childhood teachers and also observe them in their classrooms. I am interested in working with teachers of children from age four to five. I would appreciate if you could send this information sheet to teachers of children of this age, and ask who wants to volunteer as a participant of this project. From the volunteering teachers, I will liaise with you and the teachers to invite two of them to participate in the study. The study involves two early childhood centres in Wellington, the capital city of New Zealand; and two early childhood centres in Tegucigalpa, the capital city of Honduras. 
The methods of data collection include an interview and two classroom observations for each participant teacher.

The purpose of the interview is to explore teachers' beliefs regarding young children's leadership. The interview questions will be given to the teachers a few days before the interview, to give them time to start reflecting on their responses. The interview will last about one hour, and will take place at a time and site designated by the teacher. The interview will also be audio recorded and transcribed. After transcribing the data, findings will be reported back to the teachers to make sure the information is accurate and give them the chance to make any changes they wish. When necessary, after the observations, the researcher will contact participant teachers to further clarify any queries that arouse with the observations.

There are three main things which are going to be observed in each classroom. The first are teachers' practices regarding young children's leadership. Each participant teacher will be observed on two different days - for a period of two to three hours. The exact days and time of the observations will be negotiated with each teacher. The time arranged with each teacher will be the same for the two days of the observations. Second, when observing the teachers, the researcher will also look at their interaction with the children in order to observe children's responses to teachers' practices. The teachers will explain the children my role as a researcher in the setting as an observer of the teacher. Third, the researcher will observe pedagogical documentation - for example, portfolios of the children and documentation displayed in bulletin boards - and also pedagogical teaching resources in each setting. If needed and if you agree, photographs will be taken in order to record pedagogical documentation observed. Teachers and children will not be included in the captions. The photographs will only be used for data analysis and will not be included in the final report.

The participation in the research is voluntary. The participants can withdraw from the study without question at any time up to the final point of data collection, without giving a reason. Written consents will be obtained from 
principals, participating teachers, parents or guardians of the children involved in the study.

Data collected will form the basis of my study. Any information provided by the participants will not be attributed to any individual. The names of the early childhood centres, teachers and children will not be able to be identified in any way. All data will be kept confidential, in a locked file or password-protected folder. Only my supervisors and I will have the access to the research records. All data collected will be destroyed five years after the conclusion of the project. Data will be analysed and findings will be shared with participants who request it. The thesis will be deposited in the Victoria University of Wellington Library. Research findings may be presented in journal articles or in educational conferences.

This research has been assessed and approved by Victoria University Faculty of Education Ethics Committee. I hope that you will be able to allow teachers and children in your early childhood centre to be part of this study. If you have any questions, please feel free to contact me or my supervisors for further information. Contact details are given below.

If you agree for your centre to be part of the study, please complete the consent form attached, sign and return it to me by [date].

Thank you,

Maria Cerrato

Email: Maria.Corrales@vuw.ac.nz

Telephone: +64-4-463 5233 (extension 9401)

Dr. Kate Thornton (Supervisor)

Email: kate.thornton@vuw.ac.nz

Telephone: +64-4-4639776
Maggie Haggerty (Supervisor)

Email Maggie.haggerty@vuw.ac.nz

Telephone: +64-4-463 9624 


\title{
Appendix B - Consent form for head teachers/supervisors
}

\author{
VICTORIA UNIVERSITY OF WELLINGTON \\ Te Whare Wananga o te Upoko o te Ika a Maui
}

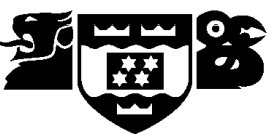

\section{FACULTY OF EDUCATION}

Research project: Teachers' beliefs and practices regarding young children's leadership: a comparison between New Zealand and Honduras

[Please mark each box with a tick to indicate agreement, then sign and date this form]

I have been given and have understood an explanation relating to the nature and purpose of this research project. I have had the opportunity to ask questions and have them answered to my satisfaction.

I give permission for Maria Cerrato to conduct her research project in this early childhood centre.

I understand that the research project involves an interview with each participant teacher and two classroom observations by the researcher.

I give permission for the researcher to take photographs on pedagogical documentation on the understandings that these will form part of the research data only and will not be used in the final report.

I understand that the names of the early childhood centre, children and teachers will remain confidential to the researcher. Pseudonyms will be used.

I understand that the data collected will be kept secure and only the researcher and her two supervisors will have access to that data. I also understand that all the data collected will be destroyed five years after the conclusion of the study. 
I understand that research findings will be deposited in the University library as a student thesis, and may be presented in academic or professional journals or at educational conferences.

I understand that participants can withdraw from the study without giving a reason up to the final point of data collection.

Name:

Principal's Signature: Date:

I would like to receive a summary of the results of this research when it is completed and therefore I will provide my mailing or email address. YES/ NO

Early Childhood Centre

Mailing/Email address 


\title{
Appendix C - Information sheet for teachers
}

\author{
VICTORIA UNIVERSITY OF WELLINGTON \\ Te Whare Wananga o te Upoko o te Ika a Maui
}

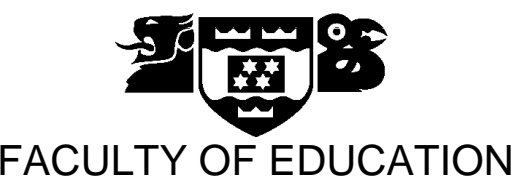

Research project: Teachers' beliefs and practices regarding young children's leadership: a comparison between New Zealand and Honduras

Researcher: Maria Auxiliadora Cerrato Corrales, School of Education Policy and Implementation

\section{Dear Sir/Madam:}

I am a student studying for my Master of Education thesis at Victoria University of Wellington. The main aim of my research is to explore how teachers in Honduras and New Zealand translate their beliefs regarding young children's leadership into practice. Understanding teacher beliefs about children's leadership can help us understand how these inform teaching practice.

As part of my degree I am undertaking a research project leading to a thesis. I would like to invite you to be a participant in my study. I am also seeking your consent to be interviewed and observed as part of my research project.

The study involves two early childhood centres in Wellington, the capital city of New Zealand; and two early childhood centres in Tegucigalpa, the capital city of Honduras.

In order to collect data for my study, I would like to explore your beliefs regarding young children's leadership, and also observe your natural day-to-day teaching practice. For this, I will begin with an interview about your beliefs regarding young children's leadership. I will provide you with the interview questions a few days before the interview, in order to give you time to start reflecting on your responses. Each interview will last about one hour, and will 
take place at a time and site designated by you. The interviews will also be audio recorded and transcribed. You will receive a copy of the transcribed interview so you can check for accuracy and make changes if you wish. When necessary, after the observations, I will contact you to further clarify any queries that arouse with the observations.

Then, there are three main things which are going to be observed in your setting. The first is your natural teaching practice. I will observe you on two different days - for a period of two to three hours. The exact days and time of the observations will be negotiated with you. The time arranged will be the same for the two days of the observations. Second, when observing your teaching practice, I will also look at your interaction with the children in order to observe children's responses. You will explain the children my role as a researcher in the setting as an observer of the teacher. Third, I will observe pedagogical documentation - for example, portfolios of the children and documentation displayed in bulletin boards - and also pedagogical teaching resources in your setting. If needed and if you agree, photographs will be taken in order to record pedagogical documentation observed. Teachers and children will not be included in the captions. The photographs will only be used for data analysis and will not be included in the final report.

The participation in the research is voluntary. You can withdraw from the study without question at any time up to the final point of data collection, without giving a reason. Written consents will be obtained from the principal, participating teachers, and parents or guardians of the children involved in the study.

Data collected will form the basis of my study. Any information provided by the participants will not be attributed to any individual. Your name, the names of the children and of the early childhood centre will not be able to be identified in any way. All data will be kept confidential, in a locked file or password-protected folder. Only my supervisors and I will have the access to the research records. All data collected will be destroyed five years after the conclusion of the project. 
Data will be analysed and findings will be shared with participants who desire it. The thesis will be deposited in the Victoria University of Wellington Library. Research findings may be presented in journal articles or in educational conferences.

This research has been assessed and approved by Victoria University Faculty of Education Ethics Committee. I hope that you will be able to assist me in this project. If you have any questions, please feel free to contact me or my supervisors for further information. Contact details are given below.

If you agree to participate in the study, please complete the consent form attached, sign and return it to me by [date].

Thank you,

Maria Cerrato

Email: Maria.Corrales@vuw.ac.nz

Telephone: +64-4-463 5233 (extension 9401)

Dr. Kate Thornton (Supervisor)

Email: kate.thornton@vuw.ac.nz

Telephone: +64-4-463 9776
Maggie Haggerty (Supervisor)

Email Maggie.haggerty@vuw.ac.nz

Telephone: +64-4-463 9624 


\title{
Appendix D - Consent form for teachers
}

\author{
VICTORIA UNIVERSITY OF WELLINGTON \\ Te Whare Wananga o te Upoko o te Ika a Maui
}

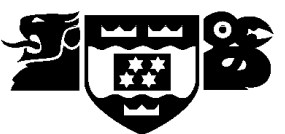

\section{FACULTY OF EDUCATION}

Research project: Teachers' beliefs and practices regarding young children's leadership: a comparison between New Zealand and Honduras

[Please mark each box with a tick to indicate agreement, then sign and date this form]

I have been given and have understood an explanation relating to the nature and purpose of this research project. I have had the opportunity to ask questions and have them answered to my satisfaction.

I agree to be interviewed by Maria Cerrato for the purposes of this research and I consent to the use of my beliefs in this research providing they will not be attributed to me. I also understand that the interviews will be audio recorded and transcribed. I will have the opportunity to check the transcript for accuracy and make changes if I wish.

I agree to be observed by the researcher for two days day in my setting. I understand that the time and days of the observations will be negotiated with me.

I give permission for the researcher to take photographs on pedagogical documentation on the understandings that these will form part of the research data only and will not be used in the final report.

I understand that the names of the early childhood centre, teachers and students, will remain confidential to the researcher. Pseudonyms will be used. 
I understand that the data collected will be kept secure and only the researcher and her two supervisors will have access to that data. I also understand that all the data collected will be destroyed five years after the conclusion of the study.

I understand that research findings will be deposited in the University library as a student thesis, and may be presented in academic or professional journals or at educational conferences.

I understand I can withdraw from the study without giving a reason up to the final point of data collection.

Name:

Teacher's Signature:

Date:

I would like to receive a summary of the results of this research when it is completed and therefore I will provide my mailing or email address. YES/ NO

Early Childhood Centre

Mailing/Email address 


\section{Appendix E - Interview of teachers' beliefs}

Background Information

- What is your early childhood education degree qualification?

- How many years of experience do you have as a pre-school teacher?

1. Leadership is a difficult concept to define as it could mean different things to different people. There are different ideas about what constitutes leadership in young children. What comes into your mind when you think of young children's leadership?

2. Could you give some examples of children's leadership?

3. What are some indicators that a child demonstrates leadership?

4. Some literature suggests everybody can be a leader, and so all children can have leadership potential. What is your opinion about this view?

5. There is a debate in the literature of whether leadership should be encouraged in all students? What do you think are the advantages of encouraging leadership in all children? Do you think there are any disadvantages?

6. In what ways do you think the early childhood curriculum encourages children's leadership?

7. In what ways do you encourage leadership in your classroom?

8. In what ways do you think the early childhood centre supports you in fostering leadership in your students?

9. What do you think are some barriers for developing a child's leadership? 


\section{Appendix F - Example of New Zealand observation field notes}

\section{Early Childhood Centre: Centre 1 \\ $1^{\text {st }}$ day of Observation}

\section{Teacher: Erica}

Date: Tuesday, June $28^{\text {th }} 2011$

Time: 10:20-10:50

Activity: Playtime

Environment: The children continued playing after they finished their morning tea. There were two teachers inside, and two outside. Erica was inside with another teacher. She was in charge of teachers' morning tea today. The head teacher and another teacher were outside.

\section{Description:}

Erica was sitting at one of the tables at art centre. A girl approaches Erica and she answers:

Erica: Yeah, I was just cutting this paper to put into the collage.

Girl: Can I have some please?

Erica: Which paper?

Girl: This one.

Erica: Sure. You want some flowers? It has another colour if you turn it around.

(The girl takes the paper).

Erica: Oh, there are from my house. I cut them and I put them in the collage.

I then observed the rest of the children and some of them were still eating at the mat, others were outside playing, others at the centres inside. Erica stood up from the art centre, and the girl stayed playing. 
Time: 11:05-11:20

\section{Description:}

I suddenly observed that two girls were fighting for two feathers, in one of the tables close to the art centre. It was one purple, and one pink feather. Erica comes close to them and says:

Erica: Excuse me, what do we do?

Okay I have a purple feather and a pink one. What do we do?

Erica: Sharing, right?

Erica: Which one do you want?

Girl: Purple

(Erica asks the other girl)

Erica: Which one do you want?

Girl: Pink and purple

Erica: If she wants purple, which one can you have?

Girl: Pink

(The girls take one feather each and start playing together again. Erica leaves the centre and the girls stayed playing. Moments after, one of the girls came to Erica).

Girl: Excuse me, we swap because she wanted that one.

Erica: Well done, that is a pretty good idea there.

The girls kept playing in the centre with some shapes, and each one had one of the feathers in their hand.

There was another girl playing at the computer close to the reading centre. Then Erica asks the girl:

Erica: Hey, what are you doing there?

Girl: It's a story.

Erica: Oh very cool (Erica takes a picture of the girl making a story).

Erica: What is your story about?

Girl: It's about mermaids.

Erica: Are you okay if we see it at mat time?

Girl: Yes

Erica: Ok, go put it over there. Monica will show you where.

I noticed that the girl went and put the book close to the place where mat time was given in the morning. 


\title{
Appendix G - Example of Honduran observation field notes
}

\author{
Centro Pre-escolar: Centre 3
}

Primer día de observación

Maestra: Blanca

Fecha: 23 de Mayo de 2011.

Hora: 8:15-8:30

Actividad: Área de Relación con el entorno. Tema: Las Plantas

Ambiente: Después del acto cívico, el cual se llevó a cabo en el pasillo al frente de las aulas de Kínder, todos los niños regresaron junto con sus maestras a sus respectivas aulas. Ana pidió a sus alumnos que se trasladaran al aula de Blanca. Los niños de Ana se sientan en el suelo en el aula de Blanca. Los alumnos de Blanca están sentados en sus mesas. Blanca está parada al frente del aula cerca de la pizarra. Cuando todos los niños están sentados ella comienza a dar la clase a sus alumnos y a los de Ana. El tema de la semana es "Las Plantas".

\section{Descripción:}

Blanca: A ver repasemos. Las platas son seres vivos. ¿Por qué son seres vivos? Porque nacen, crecen, se reproducen y luego se...

Niños: ¡Mueren!

Blanca: Y luego se mueren. A ver, ¿Cuáles son las partes de la planta?

(Blanca comienza a preguntar cada una de las partes de la planta y los niños responden. Una niña pregunta)

Niña: ¿Qué hacemos con las plantas?

Blanca: Las plantas son muy importantes porque las comemos, nos dan alimento. Las regamos para qué...

Niños: Crezcan.

Blanca: Vamos a repetir el nombre de las plantas medicinales.

En la pizarra está pegada una lámina con las partes de la planta. Blanca comienza a señalar con una regla las partes de la planta y los niños repiten. 
Un niño dice: raíz

Blanca: Muy bien un aplauso para él (Todos los niños aplauden). Otra vez repetimos.

(De repente una niña dice)

Niña: Mi mamá no le echa agua a las plantas.

Blanca: Entonces tiene que decirle que si no se riegan se...

Niños: ¡Mueren!

Blanca: Se mueren

(Otro niño le dice algo a Blanca en voz baja. Luego ella les dice a todos los niños)

Blanca: La mamá de él le echa agua a las plantas.

Niño: Ella le habló a las plantas y nació una flor, una flor pequeña y creció una más grande.

Otro niño dice: Mi papá le echa agua a las plantas.

\section{Hora: 8:55-9:15}

Actividad: Área de Personal y Social: Sentido del Olfato

Ambiente: Blanca está parada en frente de la pizarra para dar la clase. Había una lámina de los sentidos del olfato pegado en la pizarra.

\section{Descripción:}

Blanca: Vamos a ver, vamos a hablar ahorita del sentido del olfato. El sentido del olfato es la nariz, ¿Para qué nos sirve?

Niños: Para oler.

Blanca: Para oler. ¿Qué podemos oler?

Una niña responde: Las plantas.

Blanca: Muy bien las plantas.

Otro niño dice: Las flores.

Luego observé que Blanca se va al otro lado del aula y les dice a los niños:

Blanca: Vamos a ver, vamos a hablar un poquito de los colores. ¿Qué color vimos ahorita?

Niños: Blanco

Blanca: ¿Qué cosas han visto de color blanco?

(Los niños comienzan a levantar la mano para contestar las preguntas). 


\title{
Appendix $\mathrm{H}$ - Information sheet for parents and guardians
}

\author{
VICTORIA UNIVERSITY OF WELLINGTON
}

Te Whare Wananga o te Upoko o te Ika a Maui

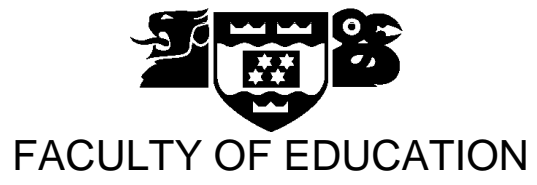

Research project: Teachers' beliefs and practices regarding young children's leadership: a comparison between New Zealand and Honduras

Researcher: Maria Auxiliadora Cerrato Corrales, School of Education Policy and Implementation

Dear Sir/Madam:

I am a student studying for my Master of Education thesis at Victoria University of Wellington. As part of my degree I am undertaking a research project leading to a thesis. The main aim of my research is to explore how teachers in Honduras and New Zealand translate their beliefs regarding young children's leadership into practice. The study involves two early childhood centres in Wellington, the capital city of New Zealand; and two early childhood centres in Tegucigalpa, the capital city of Honduras.

As part of my research project, I am seeking your consent to allow your child to be observed in his/her early childhood classroom. The purpose of the observation is to observe teachers' day-to-day teaching practice. Therefore the observations involve looking at the teachers' interaction with the children and observing how children respond to teachers' practices. Each participant teacher will be observed on two different days - for a period of two to three hours. The exact days and time of the observations will be negotiated with each teacher. The observations also involve looking at pedagogical documentation - for example, portfolios of the children and documentation displayed in bulletin boards - and also pedagogical teaching resources in each setting. All the information recorded will be kept confidential and the names of the teachers and children will not be identified in the study report. 
The participation in the research is voluntary. I have obtained permission from the principal to include teachers and children from this centre. You may withdraw your child from the study without question at any time up to the final point of data collection, without giving a reason.

All data will be kept confidential, in a locked file or password-protected folder. Only my supervisors and I will have the access to the research records. All data collected will be destroyed five years after the conclusion of the project. Data will be analysed and findings will be shared with the early childhood centre. The thesis will be deposited in the Victoria University of Wellington Library. Research findings may be presented in journal articles or in educational conferences. It is hoped that the research can identify and inform teaching practices that could support children's leadership. A summary of the research findings will be given to the early childhood centre.

This research has been assessed and approved by Victoria University Faculty of Education Ethics Committee. I hope that you agree for your child to be observed as part of this study. If you have any questions, please feel free to contact me or my supervisors for further information. Contact details are given below.

If you agree to let your child be observed in the study, please complete and signed the attached consent form.

Thank you,

Maria Cerrato

Email: Maria.Corrales@vuw.ac.nz

Telephone: +64-4-463 5233 (extension 9401)

Dr. Kate Thornton (Supervisor)

Email: kate.thornton@vuw.ac.nz

Telephone: +64-4-463 9776
Maggie Haggerty (Supervisor) Email Maggie.haggerty@vuw.ac.nz Telephone: +64-4-463 9624 


\title{
Appendix I - Consent form for parents and guardians
}

\author{
VICTORIA UNIVERSITY OF WELLINGTON
}

Te Whare Wananga o te Upoko o te Ika a Maui

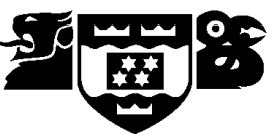

\section{FACULTY OF EDUCATION}

Research project: Teachers' beliefs and practices regarding young children's leadership: a comparison between New Zealand and Honduras

[Please mark each box with a tick to indicate agreement, then sign and date this form]

I understand that permission has been sought from the principal for this research.

I have been given and have understood an explanation relating to the nature and purpose of this research project. I have had the opportunity to ask questions about it.

I agree for the researcher to observe my child in his/her classroom. Any interaction between the teacher and children will form part of the data in the study.

I agree for the researcher to observe my child's portfolio.

I understand that the name of my child will remain confidential to the researcher and will not be identified in the study report. Pseudonyms will be used.

I understand that the data collected will be kept secure and only the researcher and her supervisors will have access to that data. I also understand that all the data collected will be destroyed five years after the conclusion of the study.

I understand that research findings will be deposited in the University library as a student thesis, and may be presented in academic or professional journals or at educational conferences.

I can withdraw my child from the study without giving a reason up to the final point of data collection. 
Parent's Name:

Signature:

Date: 